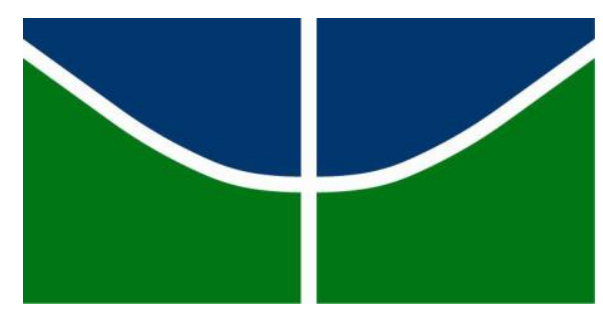

Universidade de Brasília

Instituto de Ciências Biológicas

Programa de Pós-Graduação em Ecologia

\title{
HISTÓRIA NATURAL E EFEITO DAS MUDANÇAS CLIMÁTICAS NO TAMANHO DA NINHADA DE Pyrocephalus rubinus (AVES, TYRANNIDAE)
}

Nicole Meireles Dubois

BRASÍLIA

30 de março de 2016 


\title{
HISTÓRIA NATURAL E EFEITO DAS MUDANÇAS CLIMÁTICAS NO TAMANHO DA NINHADA DE Pyrocephalus rubinus (AVES, TYRANNIDAE)
}

\begin{abstract}
Dissertação apresentada ao Programa de PósGraduação em Ecologia, do Instituto de Ciências Biológicas da Universidade de Brasília, como requisito parcial para a obtenção do título de Mestre em Ecologia.
\end{abstract}

Orientador: Prof. Dr. Miguel Ângelo Marini

BRASÍLIA

30 de março de 2016 


\author{
Universidade de Brasília \\ Instituto de Ciências Biológicas \\ Programa de Pós-Graduação em Ecologia
}

Dissertação de Mestrado

\title{
HISTÓRIA NATURAL E EFEITO DAS MUDANÇAS CLIMÁTICAS NO \\ TAMANHO DA NINHADA DE Pyrocephalus rubinus \\ (AVES, TYRANNIDAE)
}

Nicole Meireles Dubois

Banca Examinadora:

\footnotetext{
Prof. Dr. Miguel Ângelo Marini

Orientador - UnB
}
Profa. Dra. Regina Helena Ferraz Macedo
Membro Titular - UnB
Profa. Dra. Carla Suertegaray Fontana Membro Titular - PUCRS
Prof. Dr. Ricardo Bomfim Machado
Suplente - UnB


À Ananélia, ao Gaëtan, ao Lucas, à Maria Emília que sempre foram meu porto seguro. E, em especial, ao Jean Clément Laurent que me ensinou que basta ser loucamente apaixonado pela vida para ter sucesso e para fazer desse mundo um lugar excepcional. E todos, a quem dedico esse trabalho, ensinaram-me que é imperioso ter amor para ser feliz. 


\section{AGRADECIMENTOS}

Montaigne, filósofo francês, alegava que o desenvolvimento intelectual (acadêmico) predispõe o indivíduo à possibilidade de se tornar arrogante, autoritário quanto à sua visão de mundo. A melhor solução para evitar esse fim é ampliar os horizontes e compreender a limitação dos próprios conhecimentos e dos conhecimentos alheios. A sabedoria, um tipo de inteligência, é adquirida por meio da modéstia, da humildade e da aceitação das próprias limitações intelectuais e físicas, de acordo com o filósofo. Um ser humano dotado de sabedoria seria mais feliz que um ser humano dotado apenas da inteligência dita acadêmica.

A partir dessa reflexão, da minha experiência e das minhas limitações, compreendi que o meu sucesso é o resultado do meu trabalho em conjunto com o trabalho de todos envolvidos direta ou indiretamente nesse processo. Por isso, agradeço o apoio e a estrutura emocionais ofertados pela minha família e pelos meus amigos. Sou grata ao meu orientador, Miguel Ângelo Marini, pela paciência frente ao meu processo de aprendizado e ao meu coorientador extraoficial, Neander Marcel Heming, pela colaboração nas análises estatísticas. Em especial, agradeço à minha mãe, Ananélia Meireles Dubois, e ao meu pai, Gaëtan Serge Jean Dubois, pela dedicação do tempo e da energia para a conclusão de mais uma etapa. Agradeço igualmente à atenção e à recepção dos curadores das coleções europeias, sul e norte americanas por receberem a nossa equipe em suas instituições.

Adicionalmente, agradeço às instituições de fomento Conselho Nacional de Desenvolvimento Científico e Tecnológico (CNPq), Coordenação de Aperfeiçoaento de Pessoal e Nível Superior (CAPES) pelas bolsas de mestrado concedidas e à Fundação de Apoio à Pesquisa do Distrito Federal (FAPDF) pelo apoio financeiro fornecido para realizar visitas técnicas. Agradeço também ao bom serviço prestado pela secretaria e pela coordenação da Pós-Graduação em Ecologia e pelos servidores da limpeza que sempre mantiveram o ambiente limpo e organizado para o devido funcionamento do Laboratório de Ecologia e Conservação de Aves e do Departamento de Zoologia do Instituto de Ciências Biológicas (Universidade de Brasília). 
"Quando um viajante pediu à empregada de Wordsworth que lhe mostrasse o gabinete de estudos do patrão, ela respondeu: 'Esta é a sua biblioteca, mas o seu gabinete está lá fora'."

Thoreau, H. D. 


\section{SUMÁRIO}

RESUMO

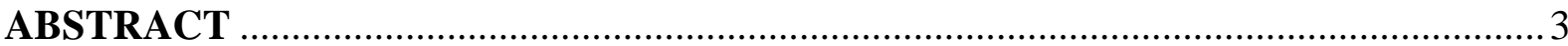

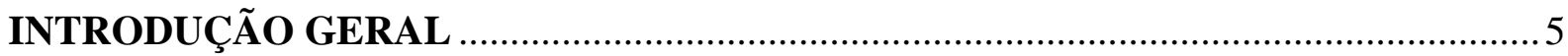

CAPÍTULO 1 - História natural de Pyrocephalus rubinus (Aves, Tyrannidae) ..................... 6

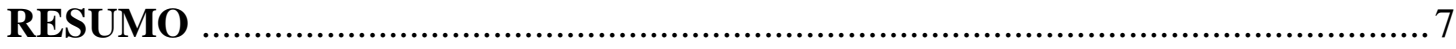

1. INTRODUÇÃ

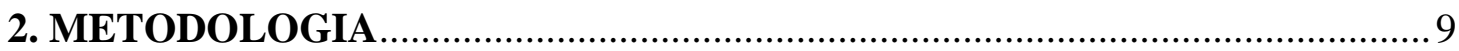

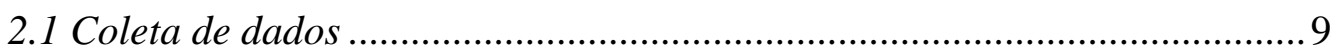

2.2 Construção de mapas de distribuição .................................................... 11

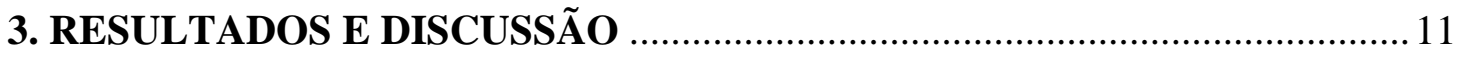

3.1 Análise quantitativa dos dados .............................................................. 11

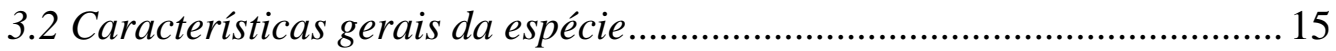

3.3 Período reprodutivo, tamanho de ninhada, migração ............................... 19

3.4 Distribuição geográfica da espécie ............................................................. 20

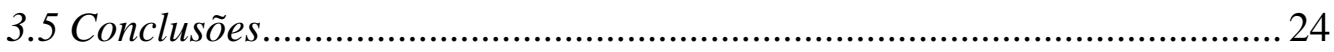

CAPÍTULO 2 - Efeitos das mudanças climáticas no tamanho de ninhada de Pyrocephalus

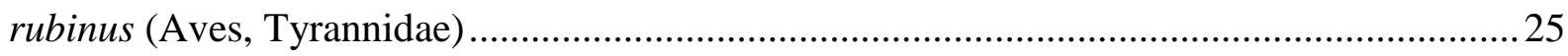

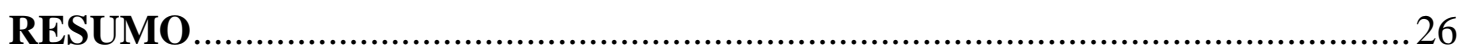

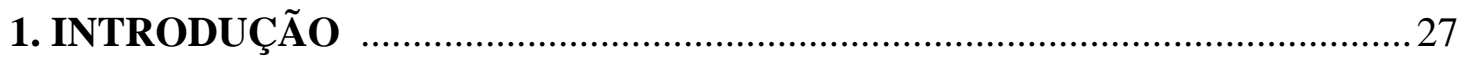

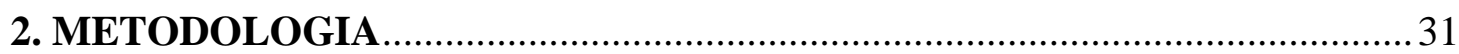

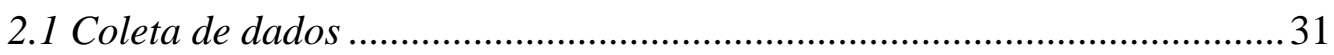

2.2 Extração de variáveis bioclimáticas ........................................................ 31

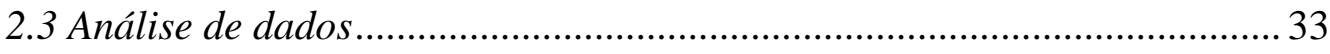

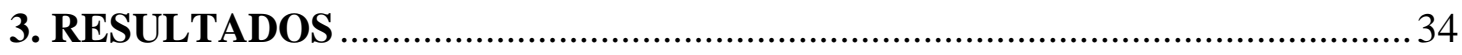

3.1 Variação geográfica do tamanho de ninhada ............................................ 35

3.2 Variação temporal do tamanho de ninhada ............................................. 37 


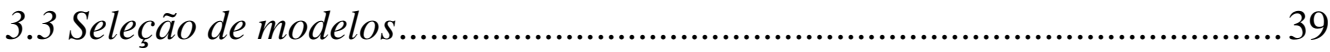

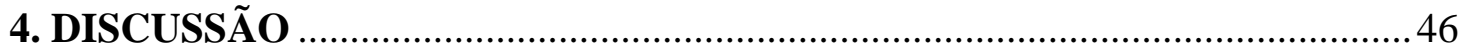

4.1 Variação geográfica do tamanho de ninhada ............................................46

4.2 Variação temporal do tamanho de ninhada ............................................. 48

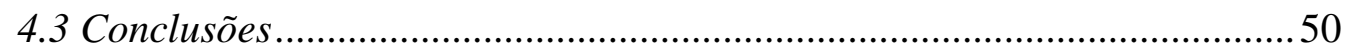

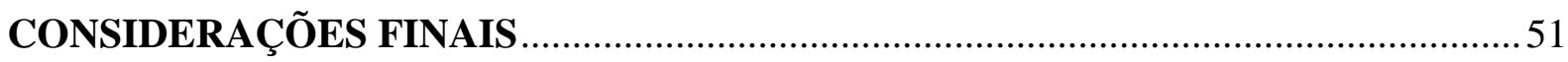

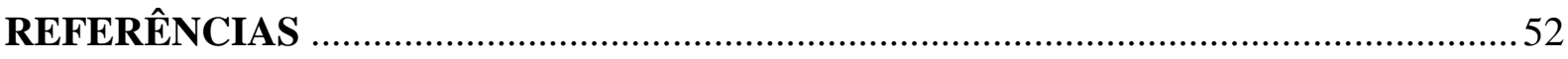

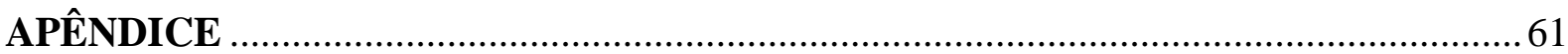




\section{ÍNDICE DE FIGURAS}

CAPÍTULO 1 - História Natural de Pyrocephalus rubinus (Aves, Tyrannidae)

Figura 1. Macho de Pyrocephalus rubinus. a) Vista dorsal, b) vista lateral e c) vista ventral. Pele oriunda da Coleção Ornitológica Marcelo Bagno, Universidade de Brasília. 16

Figura 2. Fêmea de Pyrocephalus rubinus. a) Vista dorsal e b) vista ventral. Pele oriunda da Coleção Ornitológica do Museu de Zoologia da Universidade de São Paulo. 17

Figura 3. Jovem macho de Pyrocephalus rubinus. a) Vista dorsal, b) vista lateral e c) vista ventral. Pele oriunda da Coleção Ornitológica Marcelo Bagno, Universidade de Brasília. 17 Figura 4. Ovos de Pyrocephalus rubinus com ninhadas das subespécies P.r. rubinus (a), P. r. cocachacrae (b), P. r. mexicanus (c), P. r. flammeus (d). As ninhadas e os registros coletados são oriundos do Museo Argentino de Ciencias Naturales e do Museu Western Foundation of Vertebrate Zoology, EUA.

Figura 5. Mapa de distribuição geográfica de Pyrocephalus rubinus. Os pontos em vermelho são referentes aos registros reprodutivos (ninhos, ninhadas, registro visual de cuidado parental). Registros não reprodutivos como peles, tecidos, fluídos, ossos, vídeos, mudas e registros sonoros e de ocorrência que estivessem datados dentro do período reprodutivo da espécie foram utilizados como fonte de dados para a construção de mapas de distribuição geográfica da região reprodutiva da espécie. Os pontos pretos são referentes aos registros não reprodutivos (peles, tecidos, fluídos, ossos, vídeos, mudas e registros sonoros e de ocorrência) fora do período reprodutivo.

21

CAPÍTULO 2 - Efeito das mudanças climáticas no tamanho de ninhada de Pyrocephalus rubinus (Aves, Tyrannidae)

Figura 1. Variação temporal e geográfica do tamanho de ninhada de Pyrocephalus rubinus da região norte de sua distribuição geográfica. A variação temporal do tamanho de ninhada ao longo dos anos (a), a variação do tamanho de ninhada entre localidades com distintas médias históricas de isotermalidade (LTM.yr.Tisot) na região norte (b) e a variação anual da variação do tamanho de ninhada em resposta à anomalia da precipitação do mês mais seco (Anom.yr.Pmin, c).

Figura 2. Variação temporal e geográfica do tamanho de ninhada de Pyrocephalus rubinus na região sul de sua distribuição geográfica. A variação temporal do tamanho de ninhada ao longo dos anos (a), a variação do tamanho de ninhada entre localidades com distintas médias históricas do mês mais quente do ano (LTM.yr.Tmax) na região sul (b) e a variação 
anual da variação do tamanho de ninhada em resposta à anomalia da precipitação mensal total (Anom.month.yr.Ptot, c).

Figura 1. Mapa de distribuição geográfica de Pyrocephalus rubinus flammeus no sul dos EUA e no norte e no centro do México. Os pontos em vermelho são referentes aos registros reprodutivos (ninhos, ninhadas, registro visual de cuidado parental). Registros não reprodutivos como peles, tecidos, fluídos, ossos, vídeos, mudas e registros sonoros e de ocorrência que estivessem datados dentro do período reprodutivo da subespécie foram utilizados como fonte de dados para a construção de mapas de distribuição geográfica da região reprodutiva da subespécie. Os pontos pretos são referentes aos registros não reprodutivos (peles, tecidos, fluídos, ossos, vídeos, mudas e registros sonoros e de ocorrência) fora do período reprodutivo.

Figura 2. Mapa de distribuição geográfica de Pyrocephalus rubinus mexicanus no sul dos EUA e no México. Os pontos em vermelho são referentes aos registros reprodutivos (ninhos, ninhadas, registro visual de cuidado parental). Registros não reprodutivos como peles, tecidos, fluídos, ossos, vídeos, mudas e registros sonoros e de ocorrência que estivessem datados dentro do período reprodutivo da subespécie foram utilizados como fonte de dados para a construção de mapas de distribuição geográfica da região reprodutiva da subespécie. Os pontos pretos são referentes aos registros não reprodutivos (peles, tecidos, fluídos, ossos, vídeos, mudas e registros sonoros e de ocorrência) fora do período reprodutivo.

Figura 3. Mapa de distribuição geográfica de Pyrocephalus rubinus blatteus no sul e no centro do México. Os pontos pretos são referentes a registros como peles, tecidos, fluídos, ossos, vídeos, mudas e registros sonoros e de ocorrência.

Figura 4. Mapa de distribuição geográfica de Pyrocephalus rubinus pinicola na Nicarágua, América Central. Os pontos pretos são referentes a registros como peles, tecidos, fluídos, ossos, vídeos, mudas e registros sonoros e de ocorrência.

Figura 5. Mapa de distribuição goegráfica de Pyrocephalus rubinus saturatus no oeste da Colômbia, no norte da Venezuela e do Brasil. Os pontos pretos são referentes a registros como peles, tecidos, fluídos, ossos, vídeos, mudas e registros sonoros e de ocorrência..... 64 Figura 6. Mapa de distribuição geográfica de Pyrocephalus rubinus piurae no centro e no sul da Colômbia, no oeste e no centro do Equador e noroeste do Peru. Os pontos em vermelho são referentes aos registros reprodutivos (ninhos, ninhadas, registro visual de cuidado parental). Os pontos pretos são referentes aos registros não reprodutivos (peles, 
tecidos, fluídos, ossos, vídeos, mudas e registros sonoros e de ocorrência) fora do período reprodutivo.

Figura 7. Mapa de distribuição geográfica de Pyrocephalus rubinus ardens no noroeste do Peru. Os pontos em vermelho são referentes aos registros reprodutivos (ninhos, ninhadas, registro visual de cuidado parental). Os pontos pretos são referentes aos registros não reprodutivos (peles, tecidos, fluídos, ossos, vídeos, mudas e registros sonoros e de ocorrência) fora do período reprodutivo. 66

Figura 8. Mapa de distribuição geográfica de Pyrocephalus rubinus obscurus no oeste da Colômbia, do Equador e do Peru. Os pontos em vermelho são referentes aos registros reprodutivos (ninhos, ninhadas, registro visual de cuidado parental). Os pontos pretos são referentes aos registros não reprodutivos (peles, tecidos, fluídos, ossos, vídeos, mudas e registros sonoros e de ocorrência) fora do período reprodutivo.

Figura 9. Mapa de distribuição geográfica de Pyrocephalus rubinus cocachacrae no sudoeste do Peru. Os pontos em vermelho são referentes aos registros reprodutivos (ninhos, ninhadas, registro visual de cuidado parental). Os pontos pretos são referentes aos registros não reprodutivos (peles, tecidos, fluídos, ossos, vídeos, mudas e registros sonoros e de ocorrência) fora do período reprodutivo. 68

Figura 10. Mapa de distribuição geográfica de Pyrocephalus rubinus rubinus. Os pontos em vermelho são referentes aos registros reprodutivos (ninhos, ninhadas, registro visual de cuidado parental). Registros não reprodutivos como peles, tecidos, fluídos, ossos, vídeos, mudas e registros sonoros e de ocorrência que estivessem datados dentro do período reprodutivo da subespécie foram utilzados como fonte de dados para a construção de mapas de distribuição geográfica da região reprodutiva da subespécie. Os pontos pretos são referentes aos registros não reprodutivos (peles, tecidos, fluídos, ossos, vídeos, mudas e registros sonoros e de ocorrência) fora do período reprodutivo.

Figura 11. Sazonalidade de temperatura para as Américas do Norte, Central e do Sul. Mapa construído a partir do raster extraído da base de dados WorldClim Bioclimatic Database. 70 Figura 12. Log da sazonalidade da precipitação nas Américas do Norte, Central e do Sul. Mapa construído a partir do raster extraído da base de dados WorldClim Bioclimatic Database 


\section{ÍNDICE DE TABELAS}

CAPÍTULO 1 - História Natural de Pyrocephalus rubinus (Aves, Tyrannidae)

Tabela 1. Distribuição dos registros de tamanho da ninhada $(\mathrm{n}=547)$ e ninhadas $(\mathrm{n}=922)$ de Pyrocephalus rubinus nas regiões norte, central e sul de sua distribuição geográfica, caracterizadas pelo clima temperado norte, tropical e temperado sul, respectivamente. Registros oriundos de museus provêm de informações de cada ninhada da coleção, enquanto que aqueles procedentes de revisão de literatura são resultados da média do tamanho das ninhadas descritas em cada artigo revisado.

Tabela 2. Número de registros reprodutivos e não reprodutivos das 12 subespécies de Pyrocephalus rubinus. Os registros reprodutivos possuem informação sobre o tamanho de ninhada e o mês da coleta do registro reprodutivo. Registros não reprodutivos são provenientes de peles, tecidos, fluídos, ossos, vídeos, mudas e registros sonoros e de ocorrência, todos coletados em bases de museus e alguns registros reprodutivos foram coletados por meio de revisão bibliográfica.

Tabela 3. Distribuição geográfica, status migratório e territórios de reprodução e de invernada das subespécies de Pyrocephalus rubinus. M (migratório); R (residente); SI (sem informação). 23

CAPÍTULO 2 - Efeito das mudanças climáticas no tamanho de ninhada de Pyrocephalus rubinus (Aves, Tyrannidae) 25

Tabela 1. Ranqueamento dos 13 modelos utilizados para selecionar a variável bioclimática de maior importância para a variação geográfica no tamanho de ninhada de Pyrocephalus rubinus para a região norte de sua distribuição geográfica. Número de parâmetros estimados (K), valores do critério de correção de enviesamento de segunda ordem (AICc), valores da diferença de segunda ordem $(\triangle \mathrm{AICc})$, peso dos $\mathrm{AICc}\left(w_{i}\right)$ e a probabilidade logarítmica (LL) de cada modelo foram calculados. As variáveis explanatórias utilizadas foram as médias históricas da isotermalidade da temperatura (LTM.yr.Tisot), da sazonalidade da temperatura (LTM.yr.Tseas) e da precipitação (LTM.yr.Pseas), do mês mais quente (LTM.yr.Tmax) e mais chuvoso (LTM.yr.Pmax), do mês mais frio (LTM.yr.Tmin) e mais seco (LTM.yr.Pmin), da temperatura média mensal (LTM.month.Tavg), da variação anual da temperatura, da precipitação total anual (LTM.yr.Ptot) e total mensal (LTM.month.yr.Ptot). 
Tabela 2. Ranqueamento dos 13 modelos utilizados para selecionar a variável bioclimática de maior importância para a variação geográfica no tamanho de ninhada de Pyrocephalus rubinus para a região sul de sua distribuição geográfica. Número de parâmetros estimados $(\mathrm{K})$, valores do critério de correção de enviesamento de segunda ordem (AICc), valores da diferença de segunda ordem ( $\triangle \mathrm{AICc})$, peso dos AICc $\left(w_{i}\right)$ e a probabilidade logarítmica (LL) de cada modelo foram calculados. As variáveis explanatórias utilizadas foram as médias históricas da isotermalidade da temperatura (LTM.yr.Tisot), da sazonalidade da temperatura (LTM.yr.Tseas) e da precipitação (LTM.yr.Pseas), do mês mais quente (LTM.yr.Tmax) e mais chuvoso (LTM.yr.Pmax), do mês mais frio (LTM.yr.Tmin) e mais seco (LTM.yr.Pmin), da temperatura média mensal (LTM.month.Tavg), da variação anual da temperatura, da precipitação total anual (LTM.yr.Ptot) e total mensal (LTM.month.yr.Ptot).

Tabela 3. Ranqueamento dos 13 modelos utilizados para selecionar a variável bioclimática de maior importância para a variação temporal no tamanho de ninhada de Pyrocephalus rubinus para a região norte de sua distribuição geográfica. Número de parâmetros estimados (K), valores do critério de correção de enviesamento de segunda ordem (AICc), valores da diferença de segunda ordem $(\triangle \mathrm{AICc})$, peso dos $\mathrm{AICc}\left(w_{i}\right)$ e a probabilidade logarítmica (LL) de cada modelo foram calculados. As variáveis explanatórias utilizadas foram as anomalias da isotermalidade da temperatura (Anom.yr.Tisot), da sazonalidade da temperatura (Anom.yr.Tseas) e da precipitação (Anom.yr.Pseas), do mês mais quente (Anom.yr.Tmax) e mais chuvoso (Anom.yr.Pmax) do ano, do mês mais frio (Anom.yr.Tmin) e mais seco (Anom.yr.Pmin) do ano, da temperatura média mensal (Anom.month.Tavg), da variação anual da temperatura, da precipitação total anual (Anom.yr.Ptot) e total mensal (Anom.month.yr.Ptot).

Tabela 4. Ranqueamento dos 13 modelos utilizados para selecionar a variável bioclimática de maior importância para a variação temporal no tamanho de ninhada de Pyrocephalus rubinus para a região sul de sua distribuição geográfica. Número de parâmetros estimados $(\mathrm{K})$, valores do critério de correção de enviesamento de segunda ordem (AICc), valores da diferença de segunda ordem $(\triangle \mathrm{AICc})$, peso dos $\mathrm{AICc}\left(\mathrm{w}_{\mathrm{i}}\right)$ e a probabilidade logarítmica (LL) de cada modelo foram calculados. As variáveis explanatórias utilizadas foram as anomalias da isotermalidade da temperatura (Anom.yr.Tisot), da sazonalidade da temperatura (Anom.yr.Tseas) e da precipitação (Anom.yr.Pseas), do mês mais quente (Anom.yr.Tmax) e mais chuvoso (Anom.yr.Pmax) do ano, do mês mais frio (Anom.yr.Tmin) e mais seco (Anom.yr.Pmin) do ano, da temperatura média mensal 
(Anom.month.Tavg), da variação anual da temperatura, da precipitação total anual (Anom.yr.Ptot) e total mensal (Anom.month.yr.Ptot).

Tabela 5. Ranqueamento dos modelos candidatos utilizados para testar os efeitos das variáveis bioclimáticas para a variação temporal no tamanho de ninhada de Pyrocephalus rubinus na região norte da distribuição geográfica dessa espécie. Número de parâmetros estimados (K), valores do critério de correção de enviesamento de segunda ordem (AICc), valores da diferença de segunda ordem $(\triangle \mathrm{AICc})$, peso dos $\mathrm{AICc}\left(w_{i}\right)$ e a probabilidade logarítmica (LL) de cada modelo foram calculados. A variável explanatória utilizada foi a anomalia da precipitação total mensal (Anom.month.yr.Ptot). A média histórica da temperatura do mês mais quente (LTM.yr.Tmax) e o ano foram inseridos como variáveis controle para variação geográfica e variação temporal, respectivamente.

Tabela 6. Média de modelos para a região norte da distribuição goegráfica de Pyrocephalus rubinus. Coeficientes, erros padrão não condicionais (SE), intervalo de confiança de $95 \%$ de probabilidade $(\mathrm{CI})$, a importância (W) de cada variável nos modelos gerados pela modelagem de quadrados mínimos generalizado (Generalized Least Squares Model - GLSM) e a quantidade de modelos em que cada variável foi inserida. A variável explanatória de maior interesse foi a precipitação do mês da reprodução da espécie (Anom.month.yr.Ptot) e as demais, ano (year) e média histórica da temperatura do mês mais quente (LTM.yr.Tmax), foram inseridas na modelagem como variáveis para controle da tendência da variação temporal e da variação geográfica da ninhada, respectivamente 41 Tabela 7. Ranqueamento dos modelos candidatos utilizados para testar os efeitos das variáveis bioclimáticas para a variação temporal no tamanho de ninhada de Pyrocephalus rubinus na região sul da distribuição geográfica dessa espécie. Número de parâmetros estimados (K), valores do critério de correção de enviesamento de segunda ordem (AICc), valores da diferença de segunda ordem $(\triangle \mathrm{AICc})$, peso dos $\mathrm{AICc}\left(\mathrm{w}_{\mathrm{i}}\right)$ e a probabilidade logarítmica (LL) de cada modelo foram calculados. A variável explanatória utilizada foi a anomalia da precipitação mês menos chuvoso (Anom.yr.Pmin). A média histórica da isotermalidade (LTM.yr.Tisot) e o ano foram inseridos como variáveis controle para variação geográfica e variação temporal, respectivamente.

Tabela 8. Média de modelos para a região sul da distribuição geográfica de Pyrocephalus rubinus. Coeficientes, erros padrão não condicionais (SE), intervalo de confiança de $95 \%$ de probabilidade (CI), a importância de cada variável nos modelos gerados pela modelagem de quadrados mínimos generalizado (Generalized Least Squares Model GLSM) para testar o efeito de cada variável na variação do tamanho de ninhada de 
Pyrocephalus rubinus e a quantidade de modelos em que cada variável foi inserida. A variável explanatória de maior interesse foi a precipitação do mês mais seco do ano (Anom.yr.Pmin) e as demais, ano (year) e média histórica de isotermalidade (LTM.yr.Tisot), foram inseridas na modelagem como variáveis para controle da tendência da variação temporal e da variação geográfica do tamanho de ninhada, respectivamente.. 44

Tabela 1. Número de registros reprodutivos coletados por meio de revisão da literatura e coleções de museus. 


\section{RESUMO}

A história natural engloba um conjunto de disciplinas que abordam as características intrínsecas dos organismos e sua relação com o ambiente que habitam, sendo fonte substancial para a construção do conhecimento biológico e serve como base para a compreensão dos efeitos das mudanças climáticas sobre os organimos. A distribuição geográfica, a biologia reprodutiva e história de vida das espécies estão entre os focos de estudo dessa área de conhecimento. A história de vida é definida por uma série de eventos durante a vida de um organismo, nos quais ele deve distribuir tempo e energia e a história de vida das aves foi um dos aspectos da história natural muito estudado nesse último século, fundamental para a compreensão das respostas das aves às mudanças climáticas. O tamanho dos ovos, parâmetro de história de vida, sofrem alteração (aumento ou diminuição) como resposta adaptativa às mudanças de temperatura e de precipitação. Esse trabalho objetivou estudar a distribuição geográfica de Pyrocephalus rubinus (Tyrannidae) e de suas 12 subespécies, as regiões climáticas de sua distribuição geográfica e o tamanho de ninhada e o período reprodutivo de cada subespécie. Assim, foi possível analisar a resposta da espécie $P$. rubinus às variações climáticas nos últimos 100 anos com relação a um parâmetro reprodutivo - tamanho de ninhada. A hipótese testada foi se P. rubinus alterou o tamanho da ninhada em resposta às mudanças de temperatura e de precipitação ao longo dos anos. Foi analizado se existe variação latitudinal do tamanho de ninhada da espécie. Os dados são oriundos de registros coletados de museus da Europa, das Américas do Norte e do Sul e por revisão de literatura. Os dados foram organizados em três regiões (norte, central e sul) relativas à distribuição das subespécies $P$. rubinus e às condições climáticas de cada região. Os mapas das regiões climáticas foram construídos a partir dos rasteres de sazonalidade da precipitação e da temperatura extraídos da base de dados WorldClim Bioclimatic Database. Para a análise da variação espacial e temporal do tamanho de ninhada, foram utilizados registros com mês e ano da reprodução e com localidade georeferenciada. As variáveis bioclimáticas são oriundas de rasteres extraídos da base WordClim Bioclimatic Database, Berkeley Earth e Global Precipitation Climatology Center (GPCC). Utilizou-se o método de análise quadrados mínimos generalizado (Generalized Least Squares - GLS) para a modelagem dos dados. A região norte da distribuição geográfica da espécie possuiu maior amostragem $(\mathrm{n}=330)$, seguida pela região sul $(\mathrm{n}=167)$ para o total de registros reprodutivos $(\mathrm{n}=547)$ coletados e oriundos das ninhadas das coleções dos museus. A região central detém uma pequena quantidade de registros que são mal distribuídos temporalmente $(\mathrm{n}=50)$. A distribuição de $P$. 
rubinus se estende desde o sul dos EUA até a Nicarágua e se torna novamente presente no oeste da Colômbia. Na América do Sul, ela se estende da Colômbia até o norte e centro da Argentina. As subespécies migratórias da região temperada norte invernam nos trópicos e a subespécie migratória da região temperada sul inverna no centro e nas regiões tropicais da América do Sul. O tamanho médio de ninhada para a região norte e sul da distribuição geográfica é similar com 3,0 e 2,8 ovos por ninho, respectivamente. O tamanho médio de ninhada para a região central foi de 2,6 ovos por ninhada. Esses valores já apontam variação geográfica desse parâmetro reprodutivo entre as regiões norte, central e sul da distribuição geográfica da espécie $P$. rubinus. A análise estatística demonstrou que o tamanho da ninhada diminuiu em resposta à variação espacial da isotermalidade e da temperatura mais quente do ano na região norte e sul, respectivamente. Quanto à resposta dessa espécie às variações climáticas anuais, o tamanho de ninhada diminuiu em ambas as regiões em resposta ao aumento da precipitação.

Palavras-chave: distribuição geográfica, biologia reprodutiva, migração, história de vida. 


\begin{abstract}
Natural history is a study area that focus, mainly, at species traits, their ecological relations, geographic distribution, breeding biology and life history. It is a substantial information source for biology knowledge construction and serves as a basis for understanding climate change effects on organisms. Life history is defined by a series of events during the life of an organism, in which it must distribute time and energy. Birds' life history, an aspect well studied and discussed during the last century, turned into an essencial foundation to understand bird responses to temperature and rainfall changes. Clutch size, a life history parameter, can change, increase or decrease, as an adaptive response to climate variations. This work aimed to study geographic distribution of Vermilion Flycatcher (Pyrocephalus rubinus), Tyrannidae, and of the species and its 12 sub-species, climate regions of its geographic distribution, as well as clutch size and breeding period of the subspecies. Thus, it was possible to analyze $P$. rubinus response to climate change during the past century, using as study object its clutch size variation. The hypothesis tested was whether Vermilion Flycatcher changed its clutch size in response to temperature and rainfall variation over the years. It was also tested if exist any latitudinal variation in this species' clutch size. The data came from collected records of North American and European museums and from a literature review. Data was organized into three regions (north, central and south) related to sub-species geographical distributions and climate characteristics of each region. Climate region map was built from temperature and precipitation seasonality rasters extracted from WorldClim Bioclimatic Database. Data with egg laying month, year and geographical location was used to run statistical analyses of geographic and temporal variation of clutch size. Bioclimatic variables were extracted from WorldClim, Berkeley Earth and Global Precipitation Climatology Center (GPCC) database. It was used generalized least squares analysis (Generalized Least Squares - GLS) for modeling data. From 547 breeding records (nests, clutches and parental care records), northern region obtained more records $(n=330)$, followed by southern region $(\mathrm{n}=167)$. The central region had the smallest amount of records and poorly distributed temporally $(\mathrm{n}=50)$. P. rubinus geographic distribution ranges from southern United States of America until Nicaragua and from east Colombia until north and central Argentina. Northern migratory sub-species winter at tropical regions, while southern migratory sub-species winter at north and central South America. Species average clutch size of north, central and south regions are 3.0, 2.6 and 2.8 eggs, respectively. Clutch size decreased in response to geographic variation of isothermarlity in the north and of hottest
\end{abstract}


month of the year at the south region. Annual climate variation affected this species, as it diminished its clutch size in response to precipitation variation at both regions.

Key words: geographic distribution, breeding biology, migration, life history. 


\section{INTRODUÇÃO GERAL}

A história natural engloba um conjunto de disciplinas que abordam as características intrínsecas dos organismos e sua relação com o ambiente que habitam. Os trabalhos dessa área de conhecimento focam nos diversos níveis organizacionais (de indivíduos à ecossistema), em distribuição geográfica e abundância das espécies e em história de vida (Herman 2002). Ela é fonte substancial para a construção do conhecimento biológico. Serve também como base para a compreensão de processos ecológicos, evolutivos e para mitigação de problemas relacionados à conservação (Greene 1986) e às mudanças climáticas (Wormworth \& Şekercioğlu 2011). O conhecimento de história natural permite ao pesquisador a construção de novas e precisas hipóteses (Bartholomew 1986; Futuyma 1998).

A história de vida das aves, um dos objetos de estudo de história natural, começou a ser explorada em 1940, com maior ênfase na década de 1960 (Ricklefs 2000a). O processo de levantamento e de comprovação de hipóteses relacionadas aos parâmetros de história de vida forneceu base para a discussão a respeito da variação geográfica do tamanho de ninhada (Ashmole 1963; Lack 1967; Skutch 1949,1950), assim como os mecanismos pelos quais os organismos respondem às mudanças climáticas (Wormworth \& Şekercioğlu 2011). As aves, organismos sensíveis ao aquecimento global, podem adiantar ou atrasar seu período reprodutivo e diminuir ou aumentar seu tamanho de ninhada em resposta às mudanças de temperatura e precipitação (Visser et al. 2004; Senapathi et al. 2011; Wormworth \& Şekercioğlu 2011).

Objetivei, por meio desse trabalho, estudar a distribuição geográfica e a biologia reprodutiva da espécie Pyrocephalus rubinus (Príncipe, Fluvicolinae) para melhor entender os efeitos das mudanças climáticas sobre o tamanho de ninhada dessa espécie. No primeiro capítulo dessa dissertação, abordo a distribuição geográfica da espécie e de suas 12 subespécies, a região climática de sua distribuição geográfica e o tamanho de ninhada e o período reprodutivo de cada subespécie. No segundo capítulo, analiso a resposta da espécie $P$. rubinus às variações climáticas nos últimos 100 anos no que se refere ao tamanho de ninhada. Testei a hipótese que $P$. rubinus alterou o tamanho da ninhada em resposta às mudanças de temperatura e precipitação ao longo dos anos. Adicionalmente, analisei se existe variação latitudinal do tamanho de ninhada da espécie. 


\section{CAPÍTULO 1}

\section{BIOLOGIA REPRODUTIVA E DISTRIBUIÇÃO GEOGRÁFICA DE Pyrocephalus rubinus (AVES, TYRANNIDAE)}




\section{RESUMO}

Trabalhos sobre história natural podem ser uma fonte de informações importante para estudos relacionados à conservação, mudanças climáticas, dinâmica e demografia populacional. A espécie Pyrocephalus rubinus, Tyrannidae, é amplamente distribuída no sul da América do Norte, na América Central e na América do Sul e possui 12 subespécies. O comportamento migratório, a biologia reprodutiva e a distribuição geográfica dessa espécie já foram descritos, todavia receberam pouco detalhamento no que diz respeito às subespécies. $\mathrm{O}$ objetivo dessa pesquisa é, então, descrever a distribuição geográfica da espécies e de suas 12 subespécies, as regiões climáticas de sua distribuição geográfica e o tamanho de ninhada e o período reprodutivo de cada subespécie por meio da coleta de dados oriundos de museus da Europa, das Américas do Norte e do Sul e por revisão de literatura. Os registros reprodutivos foram organizados em três regiões (norte, central e sul) relativas à distribuição das subespécies $P$. rubinus e às condições climáticas de cada região. Os mapas das regiões climáticas foram construídos a partir dos de rasteres de sazonalidade da precipitação e da temperatura extraídos da base de dados WorldClim Bioclimatic Database. A região norte da distribuição geográfica da espécie possui maior amostragem de registros reprodutivos $(\mathrm{n}=$ $330)$, seguida pela região sul $(n=167)$. A região central detém uma pequena quantidade de registros que são mal distribuídos ao longo dos anos do estudo $(n=50)$. Essa espécie ocorre desde o sudoeste dos Estados Unidos da América do Norte (EUA) até a Nicarágua e se torna novamente presente no oeste da Colômbia. Na América do Sul, ela se estende da Colômbia até o norte e o centro da Argentina. As subespécies migratórias do norte da distribuição geográfica da espécie invernam nos trópicos e a subespécie migratória da região sul inverna no centro e nas regiões tropicais da América do Sul. É comumente encontrada em áreas semiabertas com vegetação constituída por arbustos e árvores esparsamente distribuídas e locais modificados em cultivo e em áreas urbanizadas. O macho dessa espécie insetívora possui plumagem vermelha e preta, a fêmea e o jovem, plumagem marrom escuro e claro. A cor da plumagem varia entre subespécies. Os ovos da espécie possuem cor creme com manchas em disposição de guirlanda. A cor e disposição das manchas dos ovos e o formato dos ovos variam entre subespécies, entre indivíduos e entre ovos da mesma ninhada. O ninho é aberto em formato de taça, construído em forquilha. O tamanho médio de ninhada para a região temperada norte e sul são similares com 3,0 e 2,8 ovos por ninho, respectivamente. $\mathrm{O}$ tamanho médio de ninhada para a região tropical é de 2,6 ovos por ninhada. 


\section{INTRODUÇÃO}

Estudos de história natural trazem consigo diversas funções. Ao estudar as exigências ambientais de uma espécie é possível compreender a sua distribuição geográfica (Newton 1998), assim como a população é limitada pela disposição de recursos e pelas interações biológicas (predação, competição; Lack 1968). Essas informações podem subsidiar estudos relacionados à conservação, mudanças climáticas, dinâmica e demografia populacional (Newton 1998; Blumstein 2006; Wormworth \& Şekercioğlu 2011).

Existe uma grande quantidade de informações biológicas sobre a família Tyrannidae (Heming et al. 2013). Essa família possui um total de 429 espécies, amplamente distribuídas, desde o hemisfério sul e norte das Américas (Fitzpatrick 2004). Pyrocephalus rubinus, Príncipe, pertence a essa família e é amplamente distribuída, abrangendo o sul da América do Norte, a América Central e América do Sul e possui 12 subespécies (Farnsworth \& Lebbin 2004). As populações da espécie presentes no norte e sul da sua distribuição geográfica possuem comportamento migratório já descrito na literatura, reproduzindo nessas respectivas regiões e invernando nos trópicos (Ridgely \& Tudor 1946; Joseph 1997). As posturas mais frequentes da espécie variam entre dois e três ovos por ninho, todavia podem haver ninhadas com quatro ovos (Bent 1942; Marchant 1960; Borrero 1972; Fraga 1977; Munhoz 2014) e o período reprodutivo pode variar (Marchant 1959; Taylor \& Hanson 1970; Borrero 1972; Ramo \& Busto 1984; Mezquida 2002; Zuria \& Hernández 2010), dependendo da região ocupada e da subespécie.

O comportamento migratório, a biologia reprodutiva e a distribuição geográfica dessa espécie já foram descritos, todavia receberam pouco detalhamento no que diz respeito às subespécies. A ausência de trabalhos mais aprofundados se explica por diversos fatores. Devido a razões históricas e culturais, mais estudos são realizados na Europa e na América do Norte, apesar da menor riqueza de espécies encontrada nesses dois continentes (Stutchbury \& Morton 2001; Vuilleumier 2003). Além disso, a quantidade de pesquisas feitas em um país ou em uma região está relacionada ao índice de desenvolvimento humano (IDH), em especial na América do Sul e Central (James 1987; Heming et al. 2013).

Considerando a importância de estudos relativos à biologia reprodutiva, à distribuição geográfica e a baixa quantidade de trabalhos a respeito de $P$. rubinus, o objetivo dessa pesquisa é descrever a distribuição geográfica da espécie e de suas subespécies, a região climática na qual as subespécies ocorrem e a biologia reprodutiva da espécie ao longo de sua 
distribuição geográfica por meio da coleta de dados oriundos de museus e revisão bibliográfica.

\section{MATERIAL E MÉTODOS}

\subsection{Coleta de dados}

Construí a base de dados com registro de material proveniente de coleções de museus da Europa e das Américas do Norte e do Sul e por revisão de literatura. Extraí registros oriundos de museus do sítio da base de dados portal VertNet. Dos museus, coletei dados das localidades ou de reprodução e se referem peles, tecidos, fluídos, ossos, vídeos, mudas e registros reprodutivos (ninhadas, ninhos), sonoros e de ocorrência. Extraí dos registros reprodutivos dados sobre o tamanho da ninhada, data (dia, mês e ano) da coleta do material (ninho ou ninhada), e estágio do período reprodutivo (construção de ninho e desenvolvimento dos ovos). Além desses dados, coletei informações reprodutivas na literatura e segui a mesma metodologia aplicada por Heming e colaboradores (2013) para a revisão de literatura, mas só para a espécie Pyrocephalus rubinus.

Extraí a localidade (cidade, município, estado e país), ou latitude e longitude para cada registro, informação necessária para georefereciar os dados pelo World Geodetic System 1984 (WGS 84) datum. Para assegurar a precisão na geolocalização, utilizei como apoio os dicionários geográficos ornitológicos da América do Sul (Paynter 1982, 1988, 1993, 1994, 1995, 1997, Stephens \& Traylor 1983, Paynter \& Traylor 1991a, 1991b). Excluí qualquer dado que possuísse localização incerta ou estivesse mal geolocalizada, tanto por nós, quanto pela fonte original dos dados. Considerei todos os dados reprodutivos - ninhada, ninho e vídeos - que possuíssem data (mês e ano) e país para determinar o período reprodutivo da espécie. Para calcular o tamanho médio de ninhada, utilizei todos os registros que possuíam tal informação, independente da precisão da data e da localidade. Entretanto, utilizei apenas os dados precisamente georeferenciados para a geração de mapas de ocorrência da espécie.

A nomenclatura e classificação das subespécies de $P$. rubinus seguiu a mesma adotada por Farnsworth e Lebbin (2004). A divisão da espécie em subespécie passou por discussões sobre a sua aplicabilidade e conveniência e a controvérsia entre a existência ou não da divisão da espécie entre subespécies foi em decorrência dos níveis de diferenças morfológicas, comportamentais e genéticas entre as populações (Mayr 1982). Em decorrência desse impasse e da ausência de informações genéticas a respeito da diferença entre as subespécies de $P$. 
rubinus, a divisão entre subespécies será de ordem didática para diferenciar as populações entre si.

Organizei os registros reprodutivos em três regiões relativas à distribuição das subespécies $P$. rubinus e às condições climáticas de cada região. Agrupei os registros, localizados em regiões onde a temperatura e a precipitação apresentam maior variação na região temperada do hemisfério norte das Américas. Nessa região, encontram-se as subespécies $P . r$. blatteus, $P . r$. flammeus e $P . r$. mexicanus. A região norte está entre as latitudes norte $40^{\circ} 14^{\prime}$ e $16^{\circ} 13^{\prime}$. Incluí os registros reprodutivos que estivessem próximos a linha do Equador e estivessem em regiões nas quais as variações climáticas são mais suaves ao longo do ano na região central da distribuição da espécie, na qual encontram-se as subespécies $P$. r. piurae, P. r. cocachacrae, P. r. dubius, P. r. nanus, P. r. pinicola, P. $r$. saturatus, $P$. r. ardens e $P$. r. obscurus. A região central é delimitada pela latitude norte $16^{\circ}$ $13^{\prime}$ e pela latitude sul $-22^{\circ} 0^{\prime}$. No sul do hemisfério sul das Américas, a subespécie $P$. $r$. rubinus foi inserida na região temperada e sul da distribuição geográfica da espécie, região com variações de temperatura maiores que na região tropical, todavia menores que na temperada norte. Essa região está localizada entre as latitudes sul $-22^{\circ} 0^{\prime}$ e $-40^{\circ} 48^{\prime}$.

\subsection{Construção dos mapas de distribuição}

Mapas das regiões climáticas e de distribuição geográfica foram construídos com o intuito de compreender melhor a biologia reprodutiva e a distribuição das subespécies de $P$. rubinus. Os mapas da sazonalidade da precipitação e da sazonalidade da temperatura foram construídos a partir dos rasteres referentes às médias históricas (Long Term Mean - LTM) dessas duas variáveis bioclimáticas. As variáveis ambientais são oriundas de rasteres extraídos da base de dados WorldClim Bioclimatic Database. A sazonalidade da temperatura e da precipitação foram calculadas por meio do desvio padrão da temperatura e precipitação média, respectivamente (Hijmans et al. 2005).

Foram utilizados registros reprodutivos e não reprodutivos para construir os mapas de distribuição geográfica. Os registros reprodutivos considerados foram ninhos, ninhadas e registro visual de cuidado parental. Registros não reprodutivos como peles, tecidos, fluídos, ossos, vídeos, mudas e registros sonoros e de ocorrência que estivessem datados dentro do período reprodutivo da subespécie foram utilizados como fonte de dados para a construção de mapas de distribuição geográfica da região reprodutiva da subespécie. 


\section{RESULTADOS E DISCUSSÃO}

\subsection{Análise quantitativa dos dados}

Dos 738 registros reprodutivos coletados de Pyrocephalus rubinus, 547 registros com informação sobre o tamanho de ninhada foram devidamente georeferenciados, totalizando 922 ninhadas. A região norte da distribuição geográfica de $P$. rubinus possui maior amostragem e é melhor distribuída entre 1866 e 1968 ( $n=330$ registros), seguida pela região sul de sua distribuição geográfica com dados bem amostrados e distribuídos entre 1932 e 2004 ( $\mathrm{n}=167)$. A região central de sua distribuição geográfica detém uma pequena quantidade de registros e mal distribuída temporalmente $(n=50$; Tabela 1$)$. 
Tabela 1. Distribuição dos registros de tamanho da ninhada $(n=547)$ e ninhadas $(n=922)$ de Pyrocephalus rubinus nas regiões norte, central e sul de sua distribuição geográfica, caracterizadas pelo clima temperado norte, tropical e temperado sul, respectivamente. Registros oriundos de museus forneceram informações de cada ninhada da coleção, enquanto que aqueles procedentes de revisão de literatura são resultados da média do tamanho das ninhadas descritas em cada artigo revisado.

\begin{tabular}{|c|c|c|c|c|c|c|}
\hline \multirow{2}{*}{ Década } & \multicolumn{2}{|c|}{ Norte } & \multicolumn{2}{|c|}{ Central } & \multicolumn{2}{|c|}{ Sul } \\
\hline & Registros & Ninhadas & Registros & Ninhadas & Registros & Ninhada \\
\hline 1850 & 0 & 0 & 0 & 0 & 1 & 1 \\
\hline 1860 & 1 & 1 & 0 & 0 & 2 & 2 \\
\hline 1870 & 21 & 21 & 0 & 0 & 2 & 3 \\
\hline 1880 & 16 & 16 & 0 & 0 & 11 & 11 \\
\hline 1890 & 63 & 63 & 1 & 1 & 4 & 4 \\
\hline 1900 & 52 & 52 & 10 & 10 & 9 & 9 \\
\hline 1910 & 24 & 24 & 0 & 0 & 3 & 3 \\
\hline 1920 & 46 & 75 & 0 & 0 & 5 & 5 \\
\hline 1930 & 44 & 45 & 5 & 5 & 41 & 41 \\
\hline 1940 & 11 & 14 & 10 & 10 & 1 & 1 \\
\hline 1950 & 34 & 37 & 14 & 154 & 0 & 0 \\
\hline 1960 & 12 & 12 & 1 & 1 & 3 & 3 \\
\hline 1970 & 0 & 0 & 2 & 2 & 18 & 35 \\
\hline 1980 & 1 & 1 & 3 & 3 & 31 & 34 \\
\hline 1990 & 1 & 14 & 1 & 1 & 30 & 35 \\
\hline 2000 & 4 & 122 & 3 & 13 & 5 & 10 \\
\hline 2010 & 0 & 0 & 0 & 0 & 1 & 28 \\
\hline Total & 330 & 497 & 50 & 200 & 167 & 225 \\
\hline
\end{tabular}

Dos 5921 registros não reprodutivos, 5214 foram precisamente georeferenciados e 4472 especificaram a subespécie. Dos 738 registros reprodutivos coletados, 438 registros com tamanho de ninhada especificaram a qual subespécie pertencia o registro. As subespécies com mais de 500 registros não reprodutivos foram $P$. r. mexicanus, $P$. r. flammeus, $P$. r. nanus e $P$. r. rubinus e aquelas com menos de 100 registros foram P. r. ardens, $P$. r. cocachacrae e P. $r$. pinicola. As demais subespécies possuem entre 100 e 300 registros. Os registros reprodutivos 
demonstram a deficiência na pesquisa da biologia reprodutiva de nove subespécies. As subespécies $P$. r. flammeus, P. r. mexicanus e P. r. rubinus possuem 110, 144 e 165 registros, respectivamente. $P$. r. pinicola, $P$. r. saturatus e $P$. r. blatteus não tiveram nenhum registro e as demais subespécies detém menos de 10 registros coletados (ver Tabela 2). Pyrocephalus $r$. dubius e $P$. r. nanus não possuíram grande quantidade de registros reprodutivos, mesmo sendo subespécies bem amostradas por meio de registros não reprodutivos (ver Tabela 2). 
Tabela 2. Número de registros reprodutivos e não reprodutivos das 12 subespécies de Pyrocephalus rubinus. Os registros reprodutivos possuem informação sobre o tamanho de ninhada e o mês da coleta do registro reprodutivo. Registros não reprodutivos são provenientes de peles, tecidos, fluídos, ossos, vídeos, mudas e registros sonoros e de ocorrência, todos coletados em bases de museus e alguns registros reprodutivos foram coletados por meio de revisão bibliográfica.

\begin{tabular}{|c|c|c|c|c|c|c|c|}
\hline \multirow[b]{2}{*}{ Região } & \multirow[b]{2}{*}{ Subespécies } & \multicolumn{2}{|c|}{ Registros } & \multicolumn{3}{|c|}{ Tamanho de ninhada } & \multirow{2}{*}{$\begin{array}{c}\text { Mês de } \\
\text { Reprodução }\end{array}$} \\
\hline & & $\begin{array}{c}\text { Não } \\
\text { Reprodutivos } \\
\end{array}$ & Reprodutivos & Dois & Três & Quatro & \\
\hline \multirow{3}{*}{ Norte } & P.r.mexicanus & 797 & 144 & 20 & 103 & 21 & Março a Julho \\
\hline & P. r. flammeus & 1296 & 110 & 7 & 102 & 1 & Março a Agosto \\
\hline & P. r. blatteus & 238 & 0 & 0 & 0 & 0 & Sem informação \\
\hline \multirow{8}{*}{ Central } & P.r. obscurus & 130 & 5 & 0 & 5 & 0 & Março e Abril \\
\hline & P. r. ardens & 24 & 5 & 3 & 2 & 0 & Janeiro, Março e Abril \\
\hline & P. r. cocachacrae & 26 & 4 & 1 & 3 & 0 & Agosto e Novembro \\
\hline & P.r.dubius & 167 & 2 & 2 & 0 & 0 & Março \\
\hline & P.r.nanus & 543 & $1 *$ & 0 & 0 & 0 & Março \\
\hline & P. r. piurae & 273 & 2 & 2 & 0 & 0 & Sem informação** \\
\hline & P. r. pinicola & 37 & 0 & 0 & 0 & 0 & Sem informação \\
\hline & P.r. saturatus & 190 & 0 & 0 & 0 & 0 & Sem informação \\
\hline Sul & P. r. rubinus & 751 & 165 & 41 & 115 & 9 & Agosto a Janeiro \\
\hline
\end{tabular}

*O registro reprodutivo de $P$. r. nanus refere-se a um ovo coletado no mês de março. Não foi contabilizado por não apresentar o tamanho de ninhada esperado para a espécie (Marchant 1960, Borrero 1972, Fraga 1977, Munhoz 2014).

**Há registro com dado sobre tamanho de ninhada, mas não há informação sobre o período em que os ovos foram postos. 
Esses resultados confirmam os padrões já observados na pesquisa ornitológica (Stutchbury \& Morton 2001). As regiões com maior quantidade de dados reprodutivos para a espécie são a região norte da distribuição geográfica da espécie, representada principalmente por Estados Unidos da América e México e a região sul, representada por Brasil, Argentina e Uruguai. Por razões históricas e econômicas, os Estados Unidos investem mais em pesquisa e possuem grande interesse em pesquisa ornitológica (James 1987; Birkhead \& Chamantier 2009). A Argentina, por sua vez, investe em pesquisa ornitológica, devido também ao interesse cultural pelo estudo das aves (Vuilleumier 2003; Heming et al. 2013). Outro fator preponderante para a diferença da quantidade de dados reprodutivos entre essas duas regiões (sul e norte) e a região central é a disponibilidade financeira ao investimento na pesquisa científica (James 1987). Países com menor índice de desenvolvimento humano tendem a investir menos em pesquisa (Heming et al. 2013). A má distribuição dos registros reprodutivos e não reprodutivos das subespécies reflete o mesmo padrão, já que $P$. r. piurae, P. r. cocachacrae, $P$. r. pinicola, $P$. r. saturatus, $P$. $r$. ardens, $P$. $r$. dubius, $P$. $r$. nanus e $P$. $r$. obscurus ocupam a região central da distribuição geográfica da espécie, $P$. r. flammeus, $P$. $r$. blatteus e P. r. mexicanus ocupa o norte da distribuição e $P$. r. rubinus ocupa a região sul.

Apesar das Ilhas de Galápagos estarem inseridas em uma região de pouca amostragem, de pouco investimento em desenvolvimento humano e pouca tradição em pesquisa ornitológica (James 1987; Heming et al 2013), as subspécies presentes nas ilhas ( $P$. $r$. dubius e $P$. r. nanus), possuem grande quantidade de registros não reprodutivos. Esse fator pode ser explicado pelo grande interesse no estudo das espécies insulares devido ao alto índice de endemismo e à fragilidade das espécies à extinção (Johnson \& Stattersfield 1990). Contudo, essas subespécies ainda carecem de mais trabalhos referentes à sua biologia reprodutiva.

\subsection{Características gerais da espécie}

Pyrocephalus rubinus possui um tamanho corporal entre 13 e $14 \mathrm{~cm}$ e a plumagem da espécie varia entre os indivíduos de diferente sexo e idade e entre subespécies (Farnsworth \& Lebbin, 2004). O macho possui uma plumagem chamativa. A plumagem na coroa da cabeça, na garganta, no peito e na barriga é vermelha (Figura 1). As penas do dorso, da asa e da cauda são marrom escuro, facilmente confundível com preto. As bárbulas distais das barbas próximas à porção final da raque possuem a cor branca, formando uma fina listra branca ao 
final das penas das asas (Figura 1). As penas auriculares, do supercílio e de uma parte da nuca possuem também uma cor marrom escura, formando uma máscara (Figura 1b).

a)

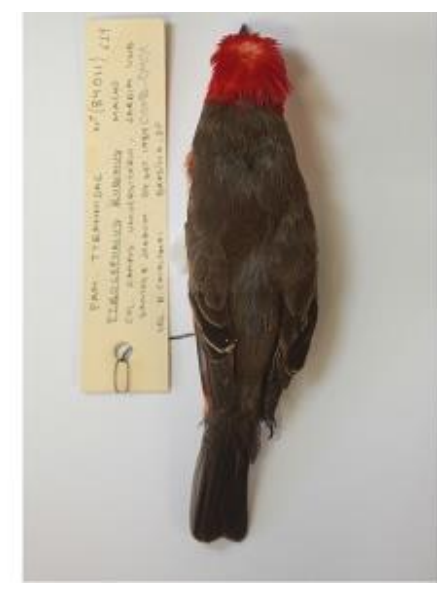

b)

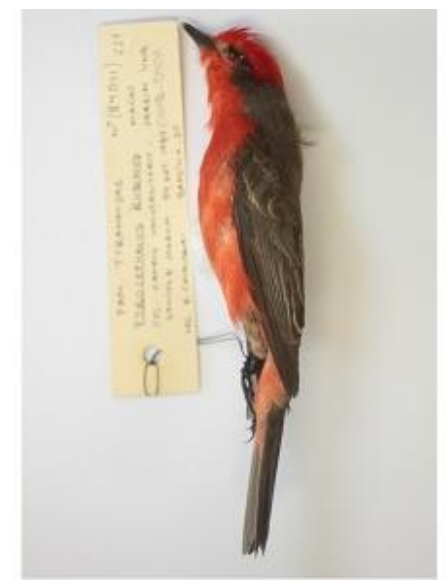

c)

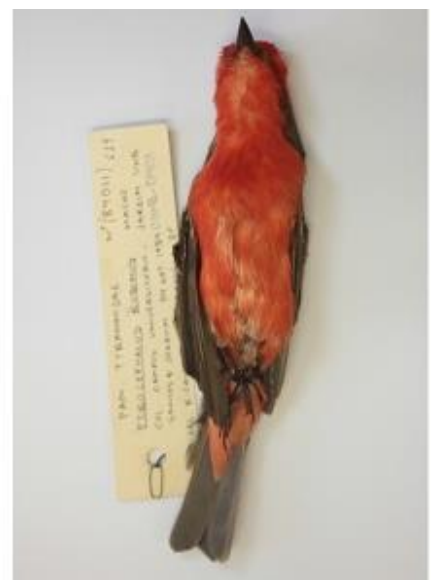

Figura 1. Macho de Pyrocephalus rubinus rubinus. a) Vista dorsal, b) vista lateral e c) vista ventral. Pele oriunda da Coleção Ornitológica Marcelo Bagno, Universidade de Brasília.

As fêmeas possuem uma plumagem inconspícua. Sua plumagem em todo o dorso e nas asas é caracterizada por uma cor marrom mais clara que a plumagem dos machos. Todavia, a cor marrom das penas do dorso e das asas das fêmeas é mais escura do que a cor marrom das penas da região da nuca, da região auricular e da coroa da cabeça (Figura 2a). As penas dos supercílios são cinza-claro (Farnsworth \& Lebbin 2004). As bárbulas distais das barbas próximas à porção final da raque também são brancas, formando uma fina listra branca no final das penas das asas (Figura 2a). As penas da garganta são brancas acinzentadas e as penas do peito produzem um efeito intenso de rajado branco acinzentado e marrom. Esse efeito rajado torna-se mais suave na barriga até ser preenchida por penas brancas acinzentadas. Próximo à cauda, as penas da barriga podem adquirir um tom mais amarelado (Figura 2b). Os jovens machos se assemelham às fêmeas, contudo apresentam penas avermelhadas próximas a cauda, espalhadas na barriga e na coroa da cabeça (Figura 3). As cores dos machos, fêmeas e jovens podem variar entre subespécies, principalmente na tonalidade das cores (ver Farnsworth \& Lebbin 2004). 
a)

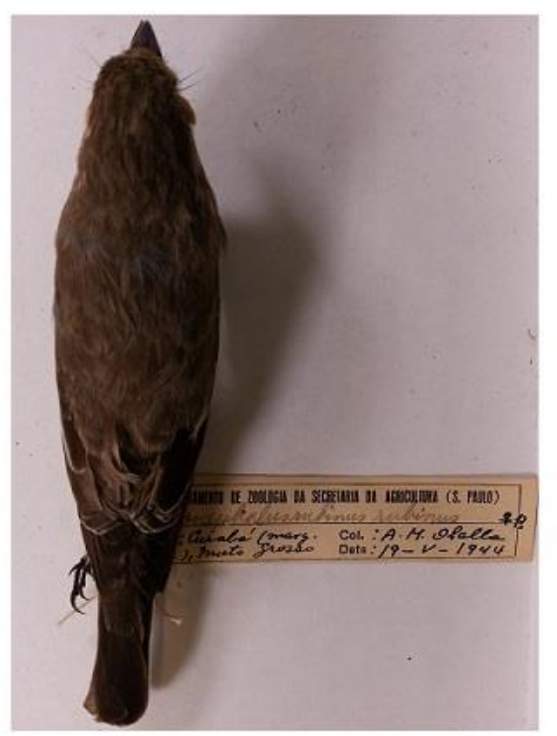

b)

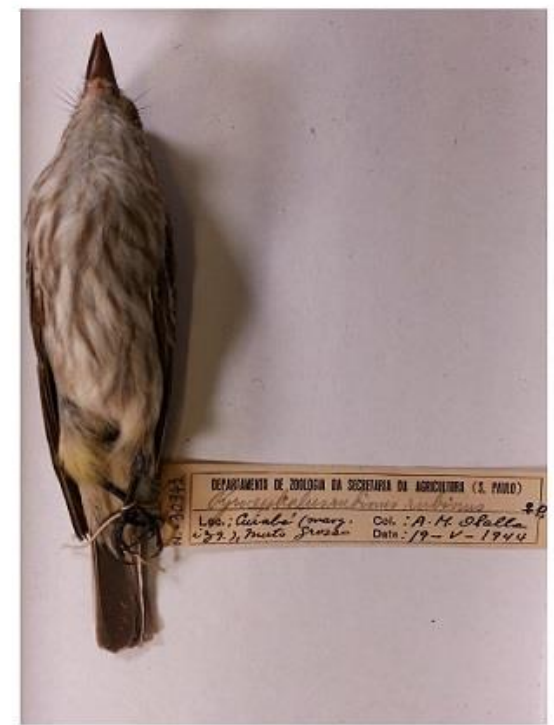

Figura 2. Fêmea de Pyrocephalus rubinus rubinus. a) Vista dorsal e b) vista ventral. Pele oriunda da coleção ornitológica do Museu de Zoologia da Universidade de São Paulo.

a)

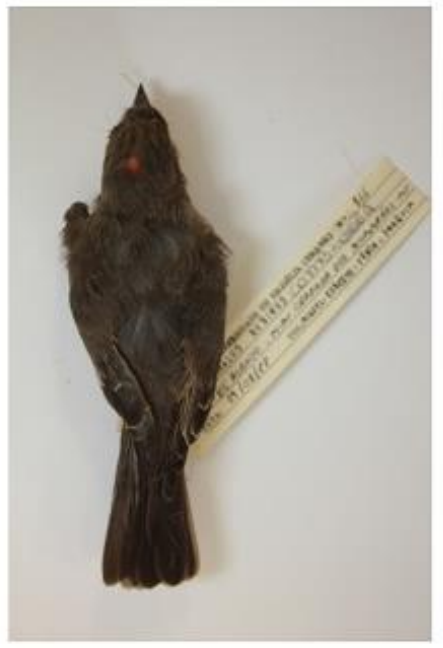

b)

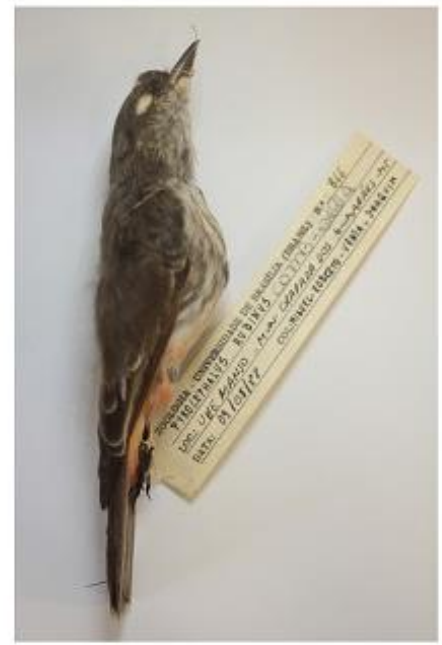

c)

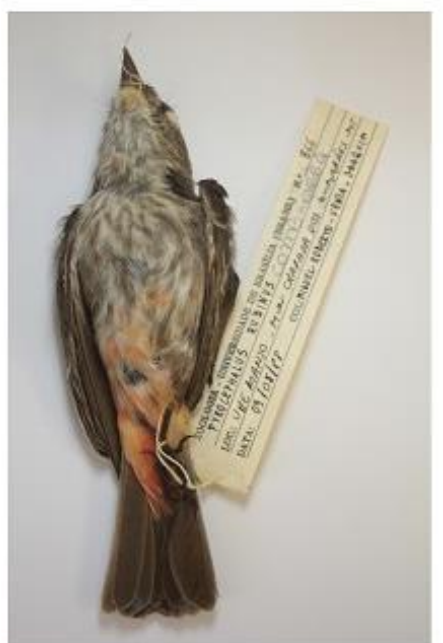

Figura 3. Jovem macho de Pyrocephalus rubinus rubinus. a) Vista dorsal, b) vistal lateral e c) vista ventral. Pele oriunda da Coleção Ornitológica Marcelo Bagno, Universidade de Brasília.

Os ninhos, aberto e em formato de cesto raso, são construídos pelos casais entre o nó de dois galhos durante período de 5 a 7 dias (Munhoz 2014). O casal faz uso de fibras de vegetais, pelos de animais, raízes e palha na construção da parte interna do ninho. Líquens e teia de aranha na borda servem de sustentação para o ninho. Outros materiais são depositados na cama do ninho durante a incubação, como paina, penas e pelos (ver descrição completa do ninho em Munhoz 2014). Os ovos da espécie são ovais, com manchas ao redor da parte mais 
larga do ovo, formando uma guirlanda (Winkler 2004, ver Figura 4). Algumas manchas possuem uma cor marrom ameraledo, outras manchas possuem cor cinza claro. A cor do ovo é creme. A cor e formato dos ovos, disposição e cor das manchas podem variar entre os indivíduos da espécie P. rubinus, entre subespécies e entre ovos da mesma ninhada (Figura $4)$.

a)

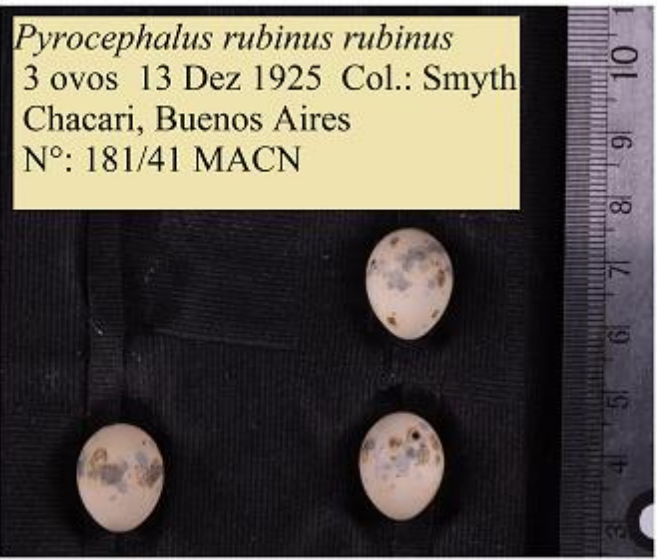

c)

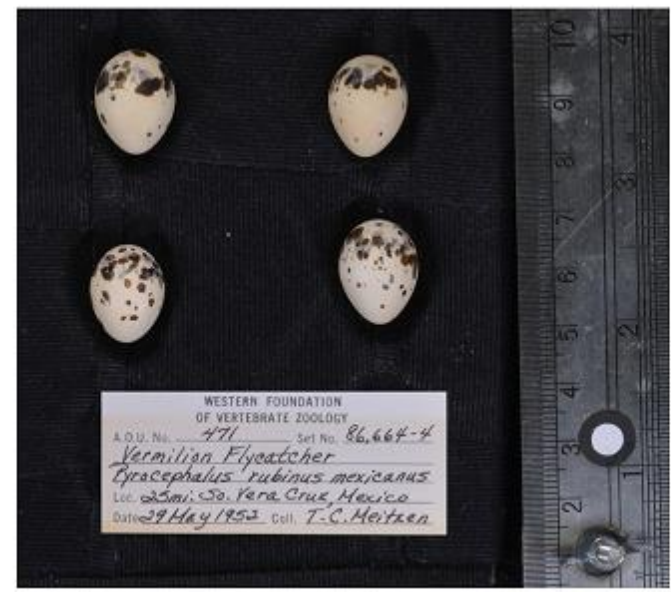

b)

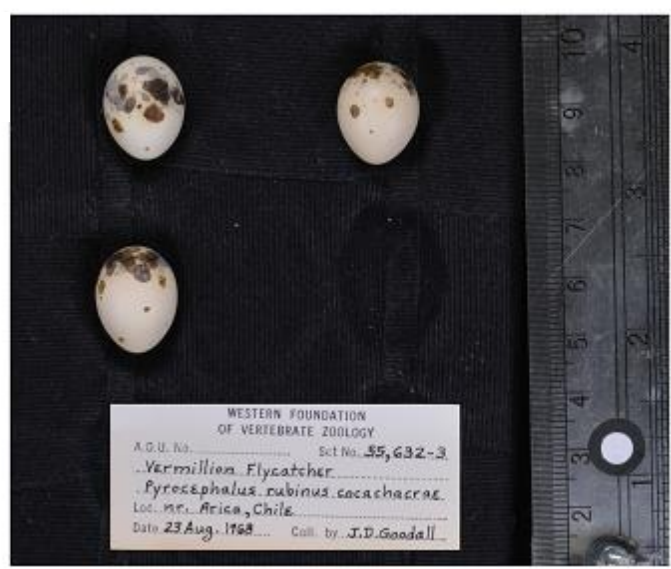

d)

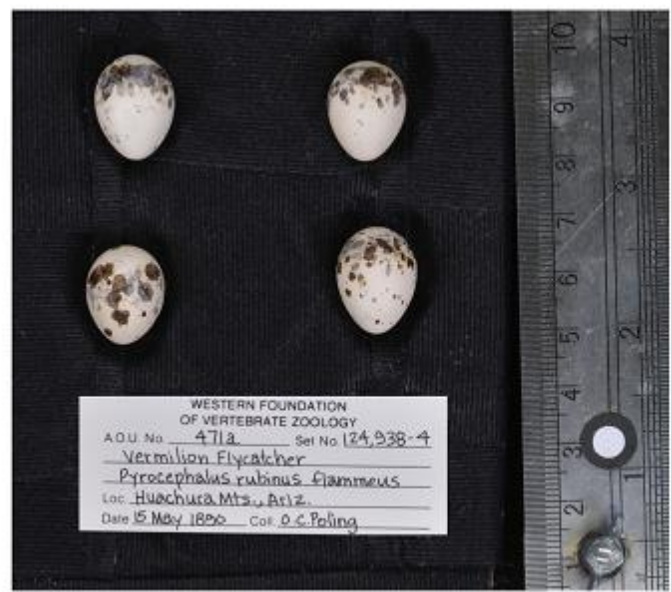

Figura 4. Ovos de Pyrocephalus rubinus com ninhadas das subespécies P.r. rubinus (a), P. r. cocachacrae (b), P. r. mexicanus (c), P. r. flammeus (d). As ninhadas e os registros coletados são oriundos do Museo Argentino de Ciencias Naturales e do Museu Western Foundation of Vertebrate Zoology, EUA.

Pyrocephalus rubinus é insetívora e forrageia próximo ao chão, em superfícies aquáticas e em habitats com vegetações de baixa estatura (Fitzpatrick 1980). Alimenta-se de espécies pertencentes às ordens Odonata, Coleoptera, Hemiptera e Diptera (Ordano et al. 1999). 


\subsection{Período reprodutivo, tamanho de ninhada, migração}

Na América do Norte, as subespécies $P$. r. flammeus e $P$. r. mexicanus produzem ninhadas entre dois e quatro ovos, sendo mais comum ninhadas com três ovos (Tabela 2; Bancroft 1930; Bent 1942). O tamanho médio das subespécies presentes nessa região é de 3,0 ovos. Essa espécie não põe cada ovo, obrigatoriamente, em dias consecutivos (Taylor \& Hanson 1970). A espécie realiza novas tentativas de reprodução na mesma estação reprodutiva (Ellison 2008).

Na América do Sul, P. rubinus produz com maior frequência tamanhos de ninhadas de 2 a 3 ovos (Tabela 2), postos em dias consecutivos, e podem produzir duas ou mais ninhadas em uma mesma estação reprodutiva (Marchant 1960; Borrero 1972; Fraga 1977; Munhoz 2014). Na região central, o tamanho de ninhada da espécie condiz com o tamanho de ninhada reportado pela literatura, com tamanho médio de 2,6 ovos por ninhada. Contudo, a subespécie $P$. r. rubinus pode produzir ninhadas de quatro ovos (Tabela 2). A média do tamanho de ninhada foi de 2,8 ovos por ninho na região sul da distribuição geográfica da espécie.

O período reprodutivo, por sua vez, varia muito entre as regiões e, provavelmente, entre as subespécies estudadas. Na América do Norte, o período reprodutivo inicia entre março e maio e finaliza entre junho e agosto (Tabela 2; Bancroft 1930; Bent 1942; Taylor \& Hanson 1970; Zuria \& Hernández 2010). Pyrocephalus r. mexicanus, P. r. flammeus e P. r. blatteus estão presentes nessa região, fator que pode explicar a pequena variação do período reprodutivo apresentada pela literatura. $\mathrm{O}$ período de reprodução da subespécie $P . r$. mexicanus ocorre entre março e julho e da P. r. flammeus ocorre entre março e agosto. Não foram encontrados dados reprodutivos da subespécie P. r. blatteus (Tabela2).

No Equador, a subespécie P. r. obscurus se reproduz de janeiro a maio (Marchant 1959, 1960), período corroborado pelos meses dos registros reprodutivos da subespécie (Tabela 2). Em contraponto, P. rubinus se reproduz em vários meses ao longo do ano na Venezuela (Ramo \& Busto 1984) e na Colômbia (Borrero 1972). Contudo, deve-se observar que na Colômbia, por exemplo, estão distribuídas três subespécies - P. r. piurae, $P$. r. rubinus e P. r. saturatus - (Borrero 1972). Como não há uma distinção dos registros reprodutivos e não há informação sobre o período reprodutivo de cada subespécie, ou seja, o período reprodutivo reportado é para toda a espécie e não para uma subespécie específica, o período reprodutivo pode ser extenso, devido à possibilidade de uma sobreposição do período reprodutivo de cada subespécie (Tabela 2; Borrero 1972). As outras subespécies de P. rubinus 
variaram quanto ao mês da reprodução reportado pelos registros. Pyrocephalus $r$. ardens reproduzem em janeiro, março e abril, $P$. $r$. cocachacrae em agosto e novembro e as subespécies endêmicas das Ilhas de Galápagos ( $P$. r. dubius e $P$. r. nanus) reproduzem em março. Não foram encontrados dados reprodutivos das subespécies $P$. r. piurae, $P$. r. pinicola, P. r. saturatus (Tabela 2). Observou-se que a subespécie $P$. r. rubinus inicia a reprodução em agosto e pode finalizar entre dezembro e fevereiro na Argentina e no sul do Brasil (ver Tabela 2; Fraga 1977; Mezquida 2002; Munhoz 2014).

Pyrocephalus rubinus é considerada uma espécie parcialmente migratória e de longa distância (Ridgely \& Tudor 1946; Farnsworth \& Lebbin, 2004). As subespécies que se reproduzem na América do Norte, passam a invernada na América Central e na Amazônia em agosto, retornando aos territórios reprodutivos em março (Joseph 1997; Fitzpatrick 2004). A subespécie $P$. r. rubinus migra do sul da América do Sul durante o inverno para a Amazônia, sudeste da Colômbia, sudeste do Equador (Ridgely \& Tudor 1946). No Brasil, essa subespécie pode migrar para a região pantaneira (Pivatto et al. 2008) e para a região central do Brasil (Negret 1988), além de estabelecer territórios na região amazônica durante a invernada (Joseph 1997; Fitzpatrick 2004; ver Figura 10 do Apêndice). A migração inicia entre os meses de abril e junho e o retorno ao território reprodutivo ocorre entre agosto e setembro (Fitzpatrick 2004).

\subsection{Distribuição geográfica da espécie}

A distribuição geográfica de Pyrocephalus rubinus se estende, igualmente, ao longo das Américas do Norte, Central e do Sul, porém não é contínua e seus registros de ocorrência estão em regiões específicas (Bent 1942). Essa espécie ocorre desde o sudoeste dos Estados Unidos da América do Norte (EUA) até a Nicarágua e se torna novamente presente no oeste da Colômbia (Ridgely \& Tudor 1946). Não foi, ainda, registrada nenhuma ocorrência dessa espécie nas ilhas do Caribe (Figura 5, Tabela 3). Da Colômbia, ela se estende pela Venezuela, Guiana, oeste do Equador, Ilhas de Galápagos, oeste do Peru, leste da Bolívia, Paraguai, norte do Chile, Uruguai, norte e centro da Argentina (Ridgely \& Tudor 1946). Essa espécie também está presente no norte, no centro e no sul do Brasil (Ridgely \& Tudor 1946; Negret 1988;

Pivatto et al. 2008; ver Figura 5). É comumente encontrada em áreas semiabertas com vegetação constituída por arbustos e árvores esparsamente distribuídas (Borrero 1972; Munhoz 2014). Todavia, pode habitar locais modificados em cultivo, assim como regiões urbanizadas (Borrero 1972; Zuria \& Réndon-Hernández 2010). 


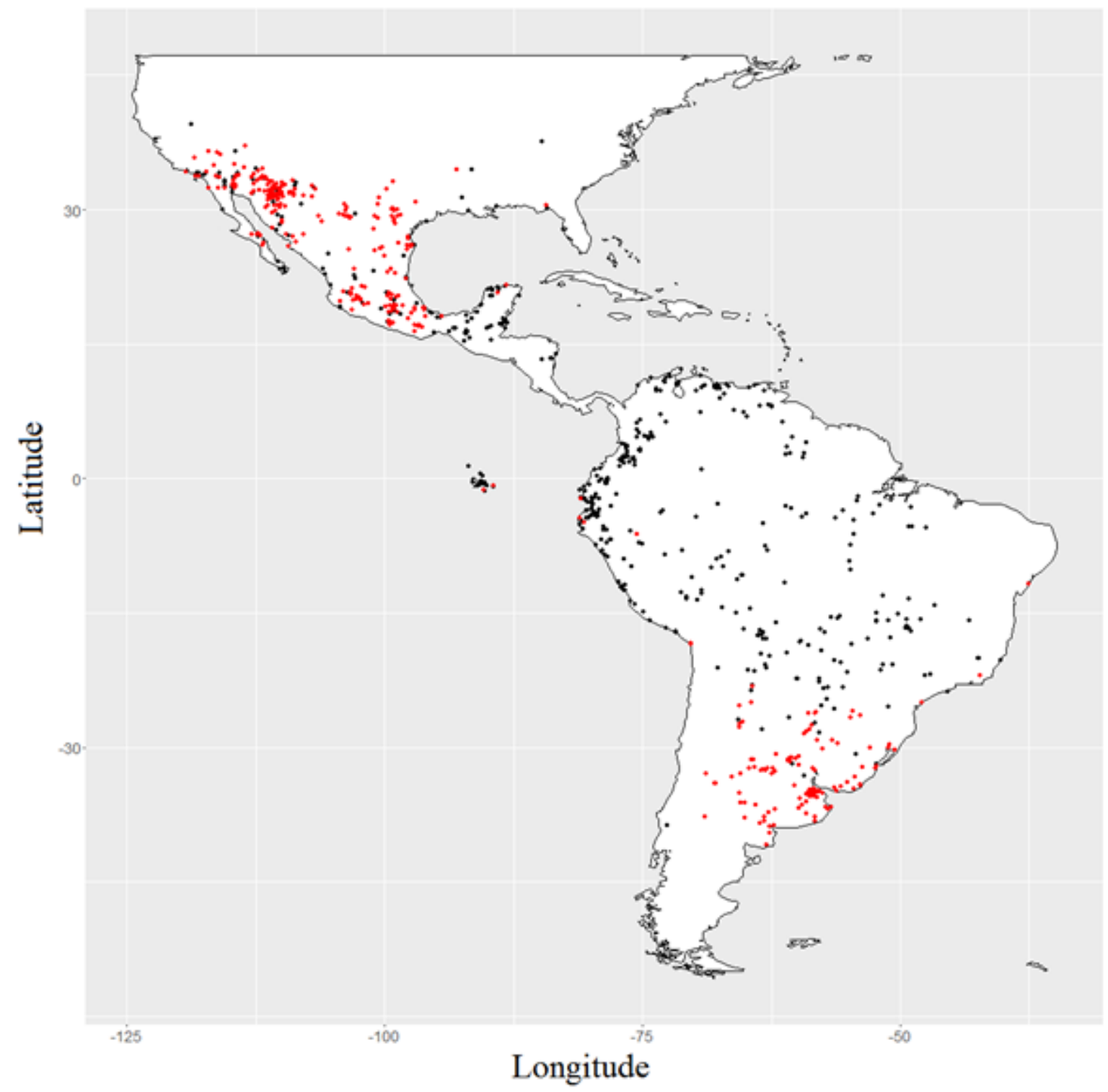

Figura 5. Mapa de distribuição geográfica de Pyrocephalus rubinus. Os pontos em vermelho são referentes aos registros reprodutivos (ninhos, ninhadas, registro visual de cuidado parental). Registros não reprodutivos como peles, tecidos, fluídos, ossos, vídeos, mudas e registros sonoros e de ocorrência que estivessem datados dentro do período reprodutivo da espécie foram utilzados como fonte de dados para a construção de mapas de distribuição geográfica da região reprodutiva da espécie. Os pontos pretos são referentes aos registros não reprodutivos (peles, tecidos, fluídos, ossos, vídeos, mudas e registros sonoros e de ocorrência) fora do período reprodutivo. 
Tabela 3. Distribuição geográfica, status migratório e territórios de reprodução e de invernada das subespécies de Pyrocephalus rubinus. M (migratório); R (residente); SI (sem informação).

\begin{tabular}{|c|c|c|c|c|c|c|}
\hline \multirow{2}{*}{ Região } & \multirow{2}{*}{ Subespécie } & \multirow{2}{*}{ Ocorrência } & \multirow{2}{*}{$\begin{array}{c}\text { Status } \\
\text { Migratório }\end{array}$} & \multicolumn{2}{|c|}{ Território de } & \multirow{2}{*}{ Citação } \\
\hline & & & & Reprodução & Invernada & \\
\hline \multirow{3}{*}{ Norte } & P. r. flammeus & $\begin{array}{l}\text { Sul dos EUA, centro e } \\
\text { norte do México }\end{array}$ & M & EUA, México & Bioma Amazônico & $\begin{array}{l}\text { Joseph } 1997 \text {; Farnsworth \& } \\
\text { Lebbin } 2004\end{array}$ \\
\hline & P. r. blatteus & $\begin{array}{l}\text { Sul e centro do México, } \\
\text { Guatemala, Belize e } \\
\text { Honduras }\end{array}$ & M & SI & SI & $\begin{array}{l}\text { Howell 1965; Joseph } 1997 \text {; } \\
\text { Farnsworth \& Lebbin } 2004\end{array}$ \\
\hline & P. r. mexicanus & $\begin{array}{l}\text { Sul dos EUA e sul, } \\
\text { noroeste e centro do } \\
\text { México }\end{array}$ & M & EUA, México & Bioma Amazônico & $\begin{array}{l}\text { Joseph 1997; Farnsworth \& } \\
\text { Lebbin } 2004\end{array}$ \\
\hline \multirow{8}{*}{ Central } & P. r. pinicola & $\begin{array}{l}\text { Noroeste da Nicarágua, } \\
\text { leste de Honduras }\end{array}$ & SI & SI & SI & Howell 1965 \\
\hline & P.r. nanus & Ilhas de Galápagos & $\mathrm{R}$ & Ilhas de Galápagos & Ilhas de Galápagos & Harris 1973 \\
\hline & P.r.dubius & Ilhas de Galápagos & $\mathrm{R}$ & Ilhas de Galápagos & Ilhas de Galápagos & Harris 1973 \\
\hline & P. r. saturatus & $\begin{array}{l}\text { Nordeste da Colômbia, } \\
\text { oeste e norte da Venezuela, } \\
\text { Guiana e norte do Brasil }\end{array}$ & SI & SI & SI & Farnsworth \& Lebbin 2004 \\
\hline & P.r.piurae & $\begin{array}{l}\text { Centro e sul da Colômbia, } \\
\text { centro e oeste do Equador, } \\
\text { noroeste do Peru }\end{array}$ & SI & SI & SI & Bond 1947; Borrero 1972 \\
\hline & P.r. ardens & Peru e Colômbia & SI & SI & SI & Bond 1947; Borrero 1972 \\
\hline & P.r. obscurus & $\begin{array}{l}\text { Costa do Peru e do } \\
\text { Equador, sul da Colômbia, } \\
\text { norte da Venezuela e do } \\
\text { Brasil }\end{array}$ & SI & SI & SI & Bond 1947; Marchant 1960 \\
\hline & P. r. cocachacrae & $\begin{array}{l}\text { Regiões costeiras do Peru e } \\
\text { norte do Chile }\end{array}$ & SI & SI & SI & Zimmer 1941 \\
\hline Sul & P. r. rubinus & $\begin{array}{l}\text { Bem distribuído ao longo } \\
\text { da América do Sul }\end{array}$ & M & $\begin{array}{l}\text { Sul da América do } \\
\text { Sul }\end{array}$ & $\begin{array}{l}\text { Norte e Centro da } \\
\text { América do Sul }\end{array}$ & $\begin{array}{l}\text { Negret 1988; Farnsworth \& } \\
\text { Lebbin } 2004\end{array}$ \\
\hline
\end{tabular}


Essa espécie é constituída por 12 subespécies, cada qual com uma distribuição geográfica distinta (Tabela 3). As subespécies que se reproduzem nos EUA e no México, passam a invernada em regiões da América Central e do bioma amazônico em agosto, retornando aos territórios reprodutivos em março (Joseph 1997; Fitzpatrick 2004). Nessa região, as subespécies $P$. $r$. flammeus, $P$. $r$. mexicanus e $P$. $r$. blatteus estão presentes em um ambiente de alta sazonalidade. Pyrocephalus r. flammeus e P. r. mexicanus se reproduzem em regiões com alta sazonalidade de precipitação e de temperatura e em regiões com menor sazonalidade de temperatura e alta sazonalidade de precipitação (ver Figuras 1, 2, 11 e 12 do Apêndice). Pyrocephalus $r$. blatteus ocorre em um ambiente com alta sazonalidade de precipitação, entretanto baixa sazonalidade de temperatura (ver Figuras 3, 11 e 12 do 11 Apêndice).

As espécies da região central da distribuição geográfica da espécie possuem pouco detalhamento quanto ao status migratório, não havendo trabalhos a respeito do comportamento migratório ou residente dessas subespécies. Apenas as subespécies insulares P. r. nanus e P. r. dubius foram classificadas como espécies residentes (Tabela 3). As populações dessa espécie presente na região central ocorrem em um ambiente de baixa sazonalidade de temperatura, ou seja, a temperatura se mantém constante ao longo do ano. A sazonalidade nesse ambiente é marcada principalmente pela sazonalidade de precipitação (Foster 1974). As subespécies P. r. piurae, P. r. saturatus e P. r. obscurus possuem registros de ocorrência tanto em regiões de alta sazonalidade de precipitação, como em regiões de menor sazonalidade de precipitação (ver Figuras 5, 6, 8, 11 e 12 do Apêndice). As demais subespécies dessa região - P. r. ardens, $P$. $r$. nanus, $P$. $r$. dubius e $P$. $r$. cocachacrae - são encontradas em ambientes caracterizados por alta sazonalidade de precipitação (ver Figura 5 e Figuras 7, 911 e 12 do Apêndice).

A subespécie com maior abrangência geográfica é Pyrocephalus $r$. rubinus que se 13 reproduz no sudeste da Bolívia, no Paraguai, no sul do Brasil, na Argentina e no Uruguai 14 (Farnsworth \& Lebbin 2004; Tabela 3). Durante a invernada, encontra-se no leste dos Andes, 15 do norte ao leste do Equador, no sudeste da Colômbia, na Amazônia e no sul e na região 16 central do Brasil (Negret 1988; Farnsworth \& Lebbin 2004; Tabela 3). P. r. rubinus só não 17 possui registros de ocorrência na Venezuela, Guiana, Suriname e Guiana Francesa (ver Figura 1810 do Apêndice). No Brasil, essa subespécie pode migrar e estabelecer territórios na região 19 pantaneira (Pivatto et al. 2008) na região central do Brasil (Negret 1988), na região amazônica 20 (Joseph 1997; Fitzpatrick 2004) e na região sul do nordeste do país (ver Figura 10 do 21 Apêndice). As características climáticas da região na qual ocorre a reprodução da subespécie 
1 - sul e sudeste da América do Sul - e da região na qual a subespécie migra para passar o

2 período de invernada são distintas. No sul e sudeste da América do Sul, P. r. rubinus está 3 presente em regiões caracterizadas por maior sazonalidade de temperatura (Figura 11 do 4 Apêndice) quando comparada às regiões ocupadas pelas subespécies da região central da 5 distribuição geográfica da espécie, porém mais amenas à sazonalidade de temperatura dos 6 territórios reprodutivos das subespécies P. r. flammeus, P. r. blatteus e P. r. mexicanus.

7 Quanto à sazonalidade da precipitação, a subespécie se reproduz em regiões de alta e baixa 8 sazonalidade de precipitação (Figuras 12 do Apêndice). Na região de invernada, a subespécie 9 encontra-se em regiões com baixa sazonalidade de temperatura e em regiões de alta e baixa 10 sazonalidade de precipitação (Figuras 11 e 12 do Apêndice).

\subsection{Conclusões}

13

A revisão da bibliografia e de registros coletados em campo são fundamentais para o 15 estudo da história natural de uma espécie. Por meio desse trabalho, demonstrei que a espécie 16 Pyrocephalus rubinus ainda não foi descrita de maneira a detalhar as diferenças existentes 17 entre suas subespécies quanto à distribuição geográfica e à biologia reprodutiva. Em razão da 18 pouca informação a respeito das diferentes populações dessa espécie, sugiro futuros estudos 19 que tratem sobre as diferenças morfológicas, comportamentais e genéticas de tal maneira que 20 a espécie seja reanalisada quanto à subdivisão em subespécies.

21 Adicionalmente, esse estudo foi capaz de demonstrar as lacunas a serem preenchidas 22 por mais pesquisas e pelo compartilhamento de dados oriundos de instituições de ensino e 23 museus. Faz-se necessário maior investimento em pesquisa e estudos no bioma amazônico 24 (Figura 5) e na biologia reprodutiva das espécies e de suas respectivas subespécies para 25 auxiliar futuros trabalhos em outras áreas de conhecimento, além da história natural. 


\section{CAPÍTULO 2}

\section{EFEITO DAS VARIAÇÕES CLIMÁTICAS NO TAMANHO DE NINHADA DE Pyrocephalus rubinus (AVES, TYRANNIDAE)}




\section{RESUMO}

Os ecossistemas, as comunidades, a dinâmica de populações e a fenologia dos organismos estão sendo alterados em decorrência do aquecimento global. As aves são tidas como grupo indicador das mudanças climáticas, devido à alta reatividade às mudanças do clima. Dentre as diversas respostas das aves ao aquecimento global, há mudanças em alguns parâmetros da história de vida. O presente trabalho tem por objetivo geral analisar a resposta da espécie Pyrocephalus rubinus, Tyrannidae, às variações climáticas nos últimos 100 anos no que se refere ao tamanho de ninhada. A hipótese testada foi que P. rubinus alterou o tamanho da ninhada em resposta às mudanças de temperatura e precipitação ao longo dos anos. Adicionalmente, foi analisado se existe variação latitudinal do tamanho de ninhada da espécie. Os dados para tamanho de ninhada foram obtidos de coleções de museus da Europa e das Américas do Norte e do Sul e por revisão de literatura. Foram utilizados registros com mês e ano da reprodução, localidade georeferenciada para realizar as análises estatísticas. As variáveis bioclimáticas são oriundas de rasteres extraídos da base WordClim Bioclimatic Database, Berkeley Earth e Global Precipitation Climatology Center (GPCC). Utilizou-se o método de análise quadrados mínimos generalizado (Generalized Least Squares - GLS) para a modelagem dos dados. O tamanho de ninhada em $P$. rubinus aumentou na região norte de sua distribuição geográfica em resposta à variação climática que vem sendo registrada no último século, todavia diminuiu o tamanho de ninhada quando relacionado à variação anual da precipitação do mês mais seco do ano e à variação geográfica da isotermalidade. Na região sul de sua distribuição, o tamanho da ninhada diminuiu ao longo dos anos e em relação à variação anual da precipitação do mês referente à data de reprodução e à variação geográfica da temperatura mais quente do ano. A resposta da espécie às mudanças climáticas pode não ser suficiente para acompanhar o rápido aumento de temperatura e de precipitação previstos para os próximos 100 anos. Contudo, ao considerar as respostas de P. rubinus à variação geográfica de temperatura e a variação anual de precipitação, os indivíduos podem diminuir o tamanho de ninhada em decorrência ao aumento da temperatura e da precipitação previstas para o próximo século o que pode afetar a reprodução da espécie. 


\section{INTRODUÇÃO}

O clima variou naturalmente em curtas e amplas escalas de tempo (Jones \& Mann 2004) ao longo da história da Terra (Sowers \& Bender 1995). Contudo, houve um aumento significativo na temperatura de $0,85{ }^{\circ} \mathrm{C}$ que ocorreu entre 1880 e 2012 (Hartmann et al. 2013). Durante o século XX, o aquecimento global ocorreu devido ao aumento da concentração de gases de efeito estufa, à variação na concentração de aerossóis atmosféricos, à irradiação solar, a erupções vulcânicas, à desertificação e ao deflorestamento (Hansen \& Lacis 1990). É importante frisar que a precipitação é fator influenciado pela variação da temperatura (Maden \& Williams 1978; Barros \& Silvestri 2002). Foi previsto para os próximos anos que regiões tropicais, com o aquecimento global, serão mais úmidas, enquanto regiões subtropicais ficarão mais áridas (Emori \& Brown 2005; Seager et al. 2007). As estações anuais também serão afetadas pelo aumento da temperatura. Estações úmidas terão maior taxa de precipitação e a umidade diminuirá em estações secas (Chou et al. 2007).

Essas mudanças climáticas afetam os ecossistemas, as comunidades, a dinâmica de populações e a fenologia dos organismos (Stenseth \& Mysterud 2002; Walther et al. 2002). A distribuição das populações está sendo alterada em resposta às mudanças de temperatura, e por fim, resultará na reorganização das comunidades (Root et al. 2003). Essa reformulação representará um alto impacto nas interações das espécies, nos níveis tróficos e influencia no funcionamento dos ecossistemas. Os organismos podem entrar em extinção em decorrência das mudanças climáticas (Pounds et al.1999), ou então, mudam a sua distribuição geográfica em resposta às variações de temperatura e precipitação (Parmesan \& Yohe 2003; Root et al. 2003). Aqueles organismos que permanecem em suas distribuições geográficas respondem às variações climáticas com a mudança da fenologia que pode desregular as relações ecológicas entre espécies (Walther 2010). O ciclo reprodutivo dos indivíduos está relacionado com a fenologia e com as relações de uma rede trófica. Logo, as variações na fenologia dos organismos e nas interações ecológicas podem gerar descompasso do ciclo reprodutivo dos organismos (Visser et al. 2004).

As aves são tidas como grupo indicador das mudanças climáticas por possuírem características tais como ampla distribuição, alta mobilidade, expectativa de vida que possibilitam estudos de curto e longo prazo e reatividade a mudanças no clima (Studds \& Marra 2007; Wormworth \& Şekercioğlu 2011). Dentre as diversas respostas das aves ao aquecimento global, há mudanças na fenologia, ciclos de eventos biológicos que ocorrem ao 
longo do ano (Bradley et al. 1999), e em algumas características da história de vida (Dunn 2004).

A história de vida é definida por uma série de eventos durante a vida de um organismo, nos quais ele deve distribuir tempo e energia (Cody 1966). A história de vida das aves caracteriza-se por determinados parâmetros como data de postura, tamanho de ninhada, tamanho corporal, tamanho de ovo, período de incubação, taxa de desenvolvimento dos ninhegos, idade, maturidade, longevidade e sobrevivência, que estão relacionados com as particularidades ambientais onde as espécies estão inseridas (Ricklefs 2000b). Algumas hipóteses foram cunhadas com o intuito de explicar a variação de tamanho de ninhada, principalmente entre os trópicos e as regiões temperadas (Ricklefs 2000a). Lack (1967) postulou que o tamanho de ninhada seria definido pela quantidade de alimento que os pais poderiam coletar e entregar aos seus filhotes, considerando o tempo (duração do dia) disponível para tais atividades. Ashmole (1963), por sua vez, propôs a hipótese na qual o tamanho de ninhada seria definido pela sazonalidade de recursos e pela mortalidade proveniente da instabilidade ambiental. Ou seja, em um ambiente no qual a sazonalidade quanto à quantidade de recursos é alta, as populações possuem alta taxa de mortalidade, não alcançando a capacidade suporte desse ambiente. Durante o inverno, as populações passam por altas taxas de mortalidade e enfrentam período de pouca oferta de recurso. Em contraponto, durante o período reprodutivo, a disponibilidade de recursos é alta e as populações são pequenas, o que permite aos indivíduos a elevada produção de descendentes. As populações que ocupam um ambiente de menor sazonalidade quanto à quantidade de recursos estão próximas do limite da capacidade suporte do ambiente, consequentemente investem em sobrevivência, maior tempo de maturação, habilidades competitivas e produzem menos descendentes. Alguns estudos apoiaram ambas as hipóteses (Ricklefs 1980; Griebeler \& Gaese-Böhning 2004). A predação foi outro aspecto levantado por Skutch (1949, 1950, 1985) como responsável pela diferença dos tamanhos de ninhada entre as latitudes. Alegou que a alta taxa de predação, a alta taxa de competição inter e intraespecífica promovem a baixa taxa de entrega e a baixa disponibilidade de alimentos aos filhotes nos trópicos. Dessa forma, as espécies tropicais adaptam o tamanho de ninhada a tais circunstâncias para aumentar a sobrevivência dos adultos e filhotes. Martin e colaboradores (2000) contestam a hipótese de Skutch, demonstrando que a predação é um fator importante para a determinação do tamanho da ninhada, mas que não explica as diferenças latitudinais encontradas entre Hemisfério Norte e Sul. Outros aspectos podem ser, no entanto, determinantes para as diferenças latitudinais do tamanho de ninhada, como a interação entre a taxa de mortalidade 
dos adultos e dos jovens, taxa de entrega de alimento aos filhotes e o processo de desenvolvimento corpóreo dos ninhegos (Martin, 2015).

As variações latitudinais dos parâmetros reprodutivos vêm sendo estudadas desde a década de 1940 (Ricklefs 2000a) e os conhecimentos desenvolvidos acerca do assunto tem contribuído para os estudos realizados sobre os efeitos das mudanças climáticas nos parâmetros reprodutivos das aves. Os indivíduos de uma espécie podem se adaptar às condições ambientais características daquele ano (clima e abundância de alimentos), já que as espécies respondem às condições ambientais vigentes, sem prever a ocorrência de anos bons ou ruins para produção de descendentes (Roff 1992; Senapathi et al. 2011). A capacidade dos organismos de alterarem a sua expressão genotípica para se adaptar a situações ambientais inusitadas é denominada plasticidade fenotípica (Senapathi et al. 2011).

Estudos sobre as respostas das aves às mudanças climáticas analisam quais são as variações nos parâmetros reprodutivos que vêm ocorrendo ao longo dos anos associada às novas condições de temperatura, precipitação e à assincronia da abundância de recursos. A data de postura de algumas espécies, por exemplo, vem sendo adiantada em resposta às variações climáticas, possível resultado da plasticidade fenotípica, e o tamanho de ninhada varia em resposta à mudança da data de postura (Charmantier \& Gienapp 2014). A espécie Ficedula hypoleuca, típica de região temperada, presente na região central da Holanda, adianta em oito dias a data de postura, diminui o tempo de intervalo entre uma postura e outra e aumenta o tamanho da ninhada em resposta a primaveras mais quentes e à variação do período de abundância alimentar (Both \& Visser 2005). As aves de regiões temperadas são fortemente influenciadas pela temperatura, enquanto os eventos reprodutivos de espécies tropicais podem ser controlados pelo fotoperíodo e pela precipitação (Dunn 2004; Senapathi et al. 2011). Essas respostas divergentes entre as espécies podem ser explicadas pelas diferenças ecológicas e de histórias de vida (Dunn 2004).

As espécies reagem de maneira diferente à variação de temperatura ao longo do tempo no que diz respeito ao tamanho de ninhada. Em um estudo com 30 anos de duração, a média do tamanho de ninhada de Tachycineta bicolor, espécie bem distribuída na América do Norte, não foi alterada consideravelmente, apesar de realizar posturas adiantadas (Winkler et al. 2002). Esse resultado difere do encontrado para Ficedula hypoleuca frente às variações do clima (Both \& Visser 2005). Diferentemente das espécies de regiões temperadas, as espécies tropicais tendem a atrasar sua atividade reprodutiva em resposta às mudanças climáticas, com ênfase na variação da precipitação (Gibbs et al. 2011; Senapathi et al. 2011), e a diminuir o tamanho de ninhada (Senapathi et al. 2011). Esses e outros trabalhos demonstram haver uma 
relação não linear entre os tamanhos de ninhada e as condições climáticas. Essa relação é explicada por uma série de razões que não só a temperatura, porém podem ser afetadas pela variação dos parâmetros da história de vida e das respostas das aves por meio de seu comportamento de forrageio (Stenseth \& Mysterud 2002).

Pyrocephalus rubinus, Príncipe, é uma espécie pertencente à subfamília Fluvicolinae, da família Tyrannidae, bem distribuída ao longo do América do Norte, Central e América do Sul (Fitzpatrick 2004). Essa subfamília possui variações no tamanho de ninhada em decorrência de variáveis intrínsecas (comportamento migratório ou residente, formato do ninho) e em resposta a variações ambientais, da sazonalidade de recursos e da duração do dia e (Heming 2012). Constatou-se que a sazonalidade recursos e a duração do dia podem influenciar a produção de maiores ninhadas no Hemisfério Norte e menores no Hemisfério Sul e que as diferenças no tamanho de ninhada são explicadas também pelas características intrínsecas às espécies dessa subfamília, como a presença ou ausência do comportamento migratório (Heming 2012). Nas Américas, as espécies migratórias do Hemisfério Sul produzem tamanhos de ninhada próximos das aves residentes (Yom-Tov et al. 1994). Porém, as espécies migratórias do Hemisfério Norte produzem ninhadas menores comparadas às ninhadas dos residentes (material suplementar em Heming \& Marini 2015). O tamanho dos ovos é outro parâmetro reprodutivo dessa subfamília influenciado diretamente por variáveis extrínsecas e intrínsecas (Heming \& Marini 2015). Esses autores demonstraram que o tamanho dos ovos diminui em regiões com temperaturas mais quentes, ao passo que os ovos aumentam em volume em regiões com temperaturas mais frias. As aves, contudo, não responderam somente a variáveis ambientais, mas também a variáveis ecológicas, sendo a migração a variável de maior impacto (Heming \& Marini 2015).

Considerando que a subfamília Fluvicolinae varia seus parâmetros reprodutivos espacialmente em resposta à temperatura (Heming \& Marini 2015), o presente trabalho tem por objetivo geral analisar variações em um parâmetro reprodutivo - tamanho de ninhada dessa espécie, ocorridas nos últimos 100 anos em resposta a variações climáticas. A hipótese a ser testada é de que $P$. rubinus altera o tamanho da ninhada em resposta às mudanças de temperatura e precipitação. Analisaremos também se há variação latitudinal do tamanho de ninhada da espécie. A predição para a hipótese de variação geográfica do tamanho de ninhada é que os indivíduos localizados em ambientes com climas estáveis produzem menores tamanhos de ninhada que em regiões com instabilidade climática. A importância desse trabalho deve-se à análise de um parâmetro reprodutivo importante - tamanho de ninhada - de uma espécie amplamente distribuída, contribuindo para a explicação da 
variação geográfica do tamanho de ninhada. Adicionalmente, esse trabalho contribui para a compreensão da imprevisibilidade das respostas das espécies às variações climáticas.

\section{METODOLOGIA}

\subsection{Coleta de dados}

A base de dados para tamanho de ninhada foi construída com registro de material proveniente de coleções de museus da Europa e das Américas do Norte e do Sul (ver Apêndice, Tabela 1) e por revisão de literatura (ver Capítulo 1). O georeferenciamento dos dados seguiu a mesma metodologia empregada no Capítulo 1. Utilizou-se o mês e o ano da reprodução, a localidade georeferenciada (latitude e longitude) e o tamanho de ninhada de cada registro para realizar as análises estatísticas. Excluímos dados que não possuíam alguma das informações citadas. A região central, correspondente ao clima tropical, não foi considerada na análise, tendo em vista seu pequeno tamanho amostral ao longo dos anos estudados e por haver registros geograficamente mal distribuídos (ver Tabela 1, Capítulo 1). Adicionalmente, as subespécies presentes nessa região possuem biologia distinta das subespécies migratórias das regiões sul e norte da distribuição da espécie (ver Capítulo 1).

\subsection{Extração das variáveis bioclimáticas}

Os rasteres referentes à média histórica (Long Term Mean - LTM) foram extraídos da base WordClim Bioclimatic Database e os rasteres anuais e mensais de temperatura e precipitação foram extraídos de Berkeley Earth e Global Precipitation Climatology Centre (GPCC). A anomalia das variáveis bioclimáticas é resultado da diferença das médias históricas das variáveis bioclimáticas com os registros anuais de temperatura e precipitação.

As médias históricas das variáveis bioclimáticas se referem à média de cada variável ao longo do período do estudo e serão utilizadas para analisar a variação geográfica do tamanho de ninhada de $P$. rubinus. A anomalia é a variação da variável bioclimática de um ano ou mês para a média histórica daquela variável. Por exemplo, o valor médio da temperatura máxima ao longo dos 100 anos foi $30^{\circ} \mathrm{C}$ em uma determinada região. No ano de 1915 , a temperatura máxima nessa região foi $28^{\circ} \mathrm{C}$. Ou seja, a anamolia é a variação de $2^{\circ} \mathrm{C}$ daquele ano em relação à sua média histórica. A anomalia, então, é a variável que será utilizada para explicar a variação entre anos do tamanho de ninhada. 
As variáveis bioclimáticas como temperatura do mês mais quente (yr.Tmax - BIO 5, ${ }^{\circ} \mathrm{C}$ ) e mais frio (yr.Tmin - BIO $6,{ }^{\circ} \mathrm{C}$ ) do ano, precipitação do mês mais chuvoso (yr.Pmax BIO 13, mm ) e mais seco (yr.Pmin - BIO 14, mm) do ano, precipitação total mensal (month.yr.Ptot, $\mathrm{mm}$ ) e anual (yr.Ptot - BIO 12, mm) foram extraídas diretamente das bases de dados climáticos para todos os anos (1866 - 2004). As variáveis bioclimáticas calculadas foram isotermalidade (Tisot - BIO 3), sazonalidade da temperatura (Tseas - BIO 4) e da precipitação (Pseas - BIO 15), média da variação da temperatura mensal (month.Tavg - BIO $2,{ }^{\circ} \mathrm{C}$ ) e variação da temperatura anual (yr.Trange - BIO $7,{ }^{\circ} \mathrm{C}$ ). $\mathrm{O}$ cálculo dessas variáveis bioclimáticas com base nos registros mensais de temperatura e precipitação seguiram Hijmans et al. (2005):

\section{BIO2 - Média da variação (range) mensal de temperatura}

- O valor calculado refere-se a quanto foi a variação de temperatura durante um determinado mês;

Variação mensal = média $($ Temperatura máxima mensal - Temperatura mínima mensal $)$

\section{BIO 3 - Isotermalidade}

- A isotermalidade trata sobre o quão estável é a temperatura ao longo do ano, ou seja, quanto maior a isotermalidade, maior a estabilidade e menor a variação térmica daquela região ao longo do tempo;

Isotermalidade $=(\mathrm{BIO} 2 / \mathrm{BIO} 7) \times 100$

\section{BIO 4 - Sazonalidade da temperatura}

- Essa variável bioclimática resulta na variação sazonal de temperatura ao longo do ano; Sazonalidade $=($ desvio padrão $) \times 100$

\section{BIO7 - Variação anual de temperatura}

- O valor calculado refere-se a quanto foi a variação de temperatura durante um determinado ano;

Variação anual $=$ Temperatura do mês mais quente do ano - Temperatura do mês mais frio do ano

\section{BIO 15 - Sazonalidade da precipitação}

- Essa variável bioclimática resulta na variação sazonal de precipitação ao longo do ano; Sazonalidade $=($ desvio padrão $) \times 100$

As extrações e os cálculos das variáveis bioclimáticas foram realizadas por meio dos pacotes "raster" (Hijmans 2015), “ncdf” (Ripley 2015) e "rgdal” (Bivand et al. 2015) no programa R (R Development Core Team). 
O GPCC detém uma base de dados de precipitação de 1901 a 2010. Os registros presentes na nossa base de dados e incluídos nas análises estatísticas começam em 1866. Assumiu-se que não houve mudança temporal significativa de precipitação no período anterior a 1901 (Hartmann et al. 2013). Por essa razão e para solucionar a falta de dados paras os anos anteriores ao século XX, realizou-se uma média dos valores de precipitação de 1901 a 1906 para assumi-la como valor de precipitação para todos os anos anteriores a 1901.

\subsection{Análises Estatísticas}

Os parâmetros reprodutivos das aves podem ser diretamente influenciados por variações geográficas de temperatura e precipitação (Jetz et al. 2008). Espera-se que exista, também, um efeito da variação temporal dessas variáveis sobre a quantidade de ovos postos por ninho. As médias históricas (LTM) das variáveis bioclimáticas representam as variáveis geográficas e as anomalias das variáveis bioclimáticas representam a variação temporal das variáveis ambientais. Realizou-se uma seleção das variáveis geográficas que melhor explicam a variação espacial do tamanho de ninhada. O intuito de tal seleção é controlar a variação geográfica do tamanho de ninhada para possibilitar o cálculo da variação temporal do tamanho de ninhada. Para tanto, modelos foram construídos nos quais foram incluídos a média histórica (LTM) de uma variável bioclimática como variável explanatória e o tamanho de ninhada como variável resposta com objetivo de selecionar a variável que melhor explica a variação geográfica no tamanho de ninhada. Essa metodologia foi igualmente empregada na seleção das anomalias das variáveis bioclimáticas que melhor contribuem para a variação temporal no tamanho de ninhada com a finalidade de evitar a inserção de variáveis que causassem o super ajustamento dos modelos a serem construídos (Anderson 2007).

A seleção de modelos foi constituída por todos os modelos possíveis usando as variáveis geográficas (LTMs) e temporais (anomalias) previamente selecionadas (Anderson 2007) para as regiões norte e sul em separado. Em todos os modelos, o tamanho de ninhada foi inserido como variável resposta, a variável bioclimática LTM como controle para variação geográfica do tamanho de ninhada e as anomalias das variáveis bioclimáticas foram incluídas apenas no modelo mais complexo do conjunto como variável explanatória. $\mathrm{O}$ ano foi inserido nos modelos para controlar a tendência temporal da variação do tamanho de ninhada (Cowpertwait \& Metcalfe 2009).

Tanto para a seleção das variáveis geográficas (LTMs) e temporais (anomalias), como também, para a seleção de modelos, foram calculados os valores do critério de correção de 
enviesamento de segunda ordem (AICc) para todos modelos de um mesmo conjunto. Os melhores modelos foram selecionados pelo ranqueamento da diferença de segunda ordem $(\triangle \mathrm{AICc})$ e pela soma dos pesos das probabilidades de cada modelo $\left(w_{i}\right)$ (Burnham \& Anderson 2002; Anderson 2007). A partir da construção dos modelos, foi calculada a média dos seus coeficientes, a medida da incerteza associada às variáveis, assim como a variância das estimativas das variáveis em cada modelo (Anderson 2007). Dessa forma, é possível realizar melhores inferências, diminuir o efeito de enviesamento e o superajustamento ou o subajustamento dos modelos aos dados (Burnham \& Anderson 2002).

A análise da relação entre as variáveis geográficas e temporais foi avaliada por meio da modelagem dos dados, utilizando o método de análise quadrados mínimos generalizado (Generalized Least Squares - GLS) com o pacote "nlme" (Pinheiro et al. 2015). Esse método analítico foi empregado, já que as variáveis explanatórias são autocorrelacionadas e o emprego de uma modelagem linear simples poderia afetar as inferências oriundas da modelagem adotada (Kuan 2004, Greene 2012), assim como enviesar os parâmetros estimados e superestimar ou subestimar os efeitos das variáveis explanatórias sobre a variável resposta (Freckleton 2002). Os pacotes “AICcmodavg” (Mazerolle 2015) e "MuMIn” (Barton 2015) foram utilizados no processo da seleção das variáveis e dos modelos. O pacote "visreg" (Breheny \& Burchett 2015) foi utilizado para visualizar a relação entre as variáveis explanatórias (variáveis geográficas e temporais) com a variável resposta (tamanho de ninhada) oriunda do melhor modelo selecionado. Toda a análise estatística e visualização dos modelos foi realizada no programa $\mathrm{R}$ ( $\mathrm{R}$ Devopment Core Team).

\section{RESULTADOS}

Dos 738 registros reprodutivos coletados de Pyrocephalus rubinus, 479 possuem tamanho de ninhada, data (mês e ano), localidade georeferenciada e dados climáticos (temperatura e precipitação) disponíveis para análise. Desses registros reprodutivos de Pyrocephalus rubinus, foram utilizados dados relativos à região norte e à região sul da distribuição da espécie que compreendem regiões de clima temperado norte e sul, respectivamente. As subespécies analisadas foram $P$. r. mexicanus, $P$. r. flammeus e $P . r$. blatteus na região norte da distribuição da espécie e $P$. rubinus rubinus na região sul. Para a região norte, 303 registros foram considerados nas análises entre as décadas de 1860 até a década de 1960. Para a região sul, 110 registros após o ano 1930 até a década de 2000 foram considerados, já que antes desse período a amostragem foi pequena. Os 66 registros não 
utilizados nas análises referem-se à região central da distribuição da espécie, região pouco amostrada e mal distribuída temporalmente (ver Capítulo 1).

3.1 Variação geográfica do tamanho de ninhada

A seleção das variáveis bioclimáticas importantes para a variação geográfica do tamanho de ninhada resultou em uma média histórica (LTM) de uma variável bioclimática para a região sul da distribuição geográfica de Pyrocephalus rubinus e uma média histórica (LTM) de uma variável bioclimática para a região norte de sua distribuição. A média histórica da isotermalidade (LTM.yr.Isot) foi a melhor variável explanatória (AICc $=378,04 ; \Delta \mathrm{AICc}=$ 0) para explicar a variação geográfica do número de ovos postos por ninho na região norte em relação às médias históricas das outras variáveis bioclimáticas, com $96 \%$ de peso explicativo (Tabela 1). Em contraponto, a média histórica da temperatura do mês mais quente (LTM.yr.Tmax) foi a variável que melhor explicou a variação geográfica no tamanho de ninhada para $P$. rubinus na região sul com o melhor suporte $(\mathrm{AICc}=133,14 ; \Delta \mathrm{AICc}=0) \mathrm{em}$ comparação com as outras médias históricas, explicando 52\% dessa variação (Tabela 2). A diferença do peso explicativo entre a região norte $(\mathrm{W}=0,96)$ e a região sul $(\mathrm{W}=0,52)$ é explicada pela maior quantidade de dados analisados para a região norte (303 registros) que para a região sul (110 registros; Burnham \& Anderson 2002). 
Tabela 1. Ranqueamento dos 13 modelos utilizados para selecionar a variável bioclimática de maior importância para a variação geográfica no tamanho de ninhada de Pyrocephalus rubinus para a região norte de sua distribuição geográfica. Número de parâmetros estimados (K), valores do critério de correção de enviesamento de segunda ordem (AICc), valores da diferença de segunda ordem $(\triangle \mathrm{AICc})$, peso dos $\mathrm{AICc}\left(w_{i}\right)$ e a probabilidade logarítmica $(\mathrm{LL})$ de cada modelo foram calculados. As variáveis explanatórias utilizadas foram as médias históricas da isotermalidade da temperatura (LTM.yr.Tisot), da sazonalidade da temperatura (LTM.yr.Tseas) e da precipitação (LTM.yr.Pseas), do mês mais quente (LTM.yr.Tmax) e mais chuvoso (LTM.yr.Pmax), do mês mais frio (LTM.yr.Tmin) e mais seco (LTM.yr.Pmin), da temperatura média mensal (LTM.month.Tavg), da variação anual da temperatura, da precipitação total anual (LTM.yr.Ptot) e total mensal (LTM.month.yr.Ptot).

\begin{tabular}{lccccc}
\hline \multicolumn{1}{c}{ Modelos } & $\mathrm{K}$ & $\mathrm{AICc}$ & $\Delta \mathrm{AICc}$ & $\mathrm{AICcWt}$ & $\mathrm{LL}$ \\
\hline LTM.yr.Tisot & 3 & 378,04 & 0,00 & 0,96 & $-185,98$ \\
LTM.yr.Pseas & 3 & 384,42 & 6,38 & 0,04 & $-189,17$ \\
LTM.yr.Pmin & 3 & 393,02 & 14,98 & 0,00 & $-193,47$ \\
LTM.yr.Tseas & 3 & 397,19 & 19,16 & 0,00 & $-195,56$ \\
LTM.yr.Tmax & 3 & 398,63 & 20,59 & 0,00 & $-196,27$ \\
Nulo & 2 & 401,24 & 23,20 & 0,00 & $-198,60$ \\
LTM.yr.Trange & 3 & 402,08 & 24,05 & 0,00 & $-198,00$ \\
LTM.month.Tavg & 3 & 402,18 & 24,15 & 0,00 & $-198,05$ \\
LTM.month.yr.Ptot & 3 & 402,48 & 24,44 & 0,00 & $-198,20$ \\
LTM.yr.Pmax & 3 & 403,16 & 25,12 & 0,00 & $-198,54$ \\
LTM.yr.Tmin & 3 & 403,25 & 25,21 & 0,00 & $-198,58$ \\
LTM.yr.Ptot & 3 & 403,27 & 25,23 & 0,00 & $-198,59$ \\
\hline
\end{tabular}


Tabela 2. Ranqueamento dos 13 modelos utilizados para selecionar a variável bioclimática de maior importância para a variação geográfica no tamanho de ninhada de Pyrocephalus rubinus para a região sul de sua distribuição geográfica. Número de parâmetros estimados (K), valores do critério de correção de enviesamento de segunda ordem (AICc), valores da diferença de segunda ordem $(\triangle \mathrm{AICc})$, peso dos $\mathrm{AICc}\left(w_{i}\right)$ e a probabilidade logarítmica (LL) de cada modelo foram calculados. As variáveis explanatórias utilizadas foram as médias históricas da isotermalidade da temperatura (LTM.yr.Tisot), da sazonalidade da temperatura (LTM.yr.Tseas) e da precipitação (LTM.yr.Pseas), do mês mais quente (LTM.yr.Tmax) e mais chuvoso (LTM.yr.Pmax), do mês mais frio (LTM.yr.Tmin) e mais seco (LTM.yr.Pmin), da temperatura média mensal (LTM.month.Tavg), da variação anual da temperatura, da precipitação total anual (LTM.yr.Ptot) e total mensal (LTM.month.yr.Ptot).

\begin{tabular}{lccccc}
\hline \multicolumn{1}{c}{ Modelos } & $\mathrm{K}$ & $\mathrm{AICc}$ & $\Delta \mathrm{AICc}$ & $w_{i}$ & $\mathrm{LL}$ \\
\hline LTM.yr.Tmax & 3 & 133,14 & 0,00 & 0,52 & $-63,46$ \\
LTM.yr.Pmin & 3 & 135,37 & 2,23 & 0,17 & $-64,57$ \\
LTM.yr.Pmax & 3 & 137,39 & 4,25 & 0,06 & $-65,58$ \\
LTM.yr.Pseas & 3 & 137,49 & 4,36 & 0,06 & $-65,63$ \\
Nulo & 2 & 138,33 & 5,19 & 0,04 & $-67,11$ \\
LTM.yr.Tmin & 3 & 138,42 & 5,28 & 0,04 & $-66,1$ \\
LTM.month.Tavg & 3 & 139,11 & 5,97 & 0,03 & $-66,44$ \\
LTM.month.yr.Ptot & 3 & 139,68 & 6,54 & 0,02 & $-66,73$ \\
LTM.yr.Trange & 3 & 140,27 & 7,13 & 0,01 & $-67,02$ \\
LTM.yr.Ptot & 3 & 140,29 & 7,15 & 0,01 & $-67,03$ \\
LTM.yr.Tseas & 3 & 140,30 & 7,16 & 0,01 & $-67,04$ \\
LTM.yr.Tisot & 3 & 140,42 & 7,28 & 0,01 & $-67,10$ \\
\hline
\end{tabular}

\subsection{Variação temporal do tamanho de ninhada}

A seleção das variáveis bioclimáticas importantes para a variação temporal do tamanho de ninhada resultou em uma anomalia de uma variável bioclimática para a região norte da distribuição geográfica de Pyrocephalus rubinus e uma anomalia de uma variável bioclimática para a região sul de sua distribuição. A melhor variável ambiental para explicar a variação temporal do tamanho de ninhada na região norte foi a precipitação do mês mais seco (Anom.yr.Pmin; $\mathrm{AICc}=362,71 ; \Delta \mathrm{AICc}=0)$, com $100 \%$ do peso explicativo $($ Tabela 3$) . \mathrm{A}$ precipitação total do mês da reprodução (Anom.month.yr.Ptot) foi, no entanto, a melhor variável $(\mathrm{AICc}=131,38 ; \Delta \mathrm{AICc}=0)$ para justificar a variação temporal no tamanho de ninhada na região sul da distribuição da espécie, explicando $83 \%$ dessa variação (Tabela 4). 
Tabela 3. Ranqueamento dos 13 modelos utilizados para selecionar a variável bioclimática de maior importância para a variação temporal no tamanho de ninhada de Pyrocephalus rubinus para a região norte de sua distribuição geográfica. Número de parâmetros estimados (K), valores do critério de correção de enviesamento de segunda ordem (AICc), valores da diferença de segunda ordem $(\triangle \mathrm{AICc})$, peso dos $\mathrm{AICc}\left(w_{i}\right)$ e a probabilidade logarítmica (LL) de cada modelo foram calculados. As variáveis explanatórias utilizadas foram as anomalias da isotermalidade da temperatura (Anom.yr.Tisot), da sazonalidade da temperatura (Anom.yr.Tseas) e da precipitação (Anom.yr.Pseas), do mês mais quente (Anom.yr.Tmax) e mais chuvoso (Anom.yr.Pmax) do ano, do mês mais frio (Anom.yr.Tmin) e mais seco (Anom.yr.Pmin) do ano, da temperatura média mensal (Anom.month.Tavg), da variação anual da temperatura, da precipitação total anual (Anom.yr.Ptot) e total mensal (Anom.month.yr.Ptot).

\begin{tabular}{lccccc}
\hline \multicolumn{1}{c}{ Modelos } & $\mathrm{K}$ & AICc & $\Delta$ AICc & $w_{i}$ & LL \\
\hline Anom.yr.Pmin & 3 & 362.71 & 0.00 & 1 & -178.31 \\
Anom.yr.Tmax & 3 & 400.25 & 37.54 & 0 & -197.08 \\
Anom.yr.Pmax & 3 & 400.33 & 37.62 & 0 & -197.12 \\
Nulo & 2 & 401.24 & 38.53 & 0 & -198.60 \\
Anom.yr.Tmin & 3 & 401.34 & 38.63 & 0 & -197.63 \\
Anom.month.yr.Ptot & 3 & 402.25 & 39.54 & 0 & -198.08 \\
Anom.month.Tavg & 3 & 402.85 & 40.14 & 0 & -198.38 \\
Anom.yr.Tisot & 3 & 403.07 & 40.37 & 0 & -198.50 \\
Anom.yr.Pseas & 3 & 403.15 & 40.44 & 0 & -198.53 \\
Anom.yr.Tseas & 3 & 403.20 & 40.49 & 0 & -198.56 \\
Anom.yr.Ptot & 3 & 403.20 & 40.50 & 0 & -198.56 \\
Anom.yr.Trange & 3 & 403.27 & 40.56 & 0 & -198.60 \\
\hline
\end{tabular}


Tabela 4. Ranqueamento dos 13 modelos utilizados para selecionar a variável bioclimática de maior importância para a variação temporal no tamanho de ninhada de Pyrocephalus rubinus para a região sul de sua distribuição geográfica. Número de parâmetros estimados (K), valores do critério de correção de enviesamento de segunda ordem (AICc), valores da diferença de segunda ordem $(\triangle \mathrm{AICc})$, peso dos $\mathrm{AICc}\left(w_{i}\right)$ e a probabilidade logarítmica (LL) de cada modelo foram calculados. As variáveis explanatórias utilizadas foram as anomalias da isotermalidade da temperatura (Anom.yr.Tisot), da sazonalidade da temperatura (Anom.yr.Tseas) e da precipitação (Anom.yr.Pseas), do mês mais quente (Anom.yr.Tmax) e mais chuvoso (Anom.yr.Pmax) do ano, do mês mais frio (Anom.yr.Tmin) e mais seco (Anom.yr.Pmin) do ano, da temperatura média mensal (Anom.month.Tavg), da variação anual da temperatura, da precipitação total anual (Anom.yr.Ptot) e total mensal (Anom.month.yr.Ptot).

\begin{tabular}{lccccc}
\hline \multicolumn{1}{c}{ Modelos } & $\mathrm{K}$ & $\mathrm{AICc}$ & $\Delta \mathrm{AICc}$ & $w_{i}$ & $\mathrm{LL}$ \\
\hline Anom.month.yr.Ptot & 3 & 131,38 & 0,00 & 0,83 & $-62,58$ \\
Anom.yr.Ptot & 3 & 137,71 & 6,33 & 0,03 & $-65,74$ \\
Nulo & 2 & 138,33 & 6,94 & 0,03 & $-67,11$ \\
Anom.yr.Pmin & 3 & 138,61 & 7,23 & 0,02 & $-66,19$ \\
Anom.yr.Tmax & 3 & 138,63 & 7,25 & 0,02 & $-66,20$ \\
Anom.yr.Pmax & 3 & 139,77 & 8,38 & 0,01 & $-66,77$ \\
Anom.yr.Pseas & 3 & 140,22 & 8,84 & 0,01 & $-67,00$ \\
Anom.yr.Trange & 3 & 140,23 & 8,84 & 0,01 & $-67,00$ \\
Anom.yr.Tmin & 3 & 140,28 & 8,90 & 0,01 & $-67,03$ \\
Anom.month.Tavg & 3 & 140,31 & 8,92 & 0,01 & $-67,04$ \\
Anom.yr.Tisot & 3 & 140,40 & 9,02 & 0,01 & $-67,09$ \\
Anom.yr.Tseas & 3 & 140,43 & 9,05 & 0,01 & $-67,10$ \\
\hline
\end{tabular}

\subsection{Seleção dos modelos}

A partir da seleção das médias históricas e das anomalias das variáveis bioclimáticas que melhor explicam as variações geográfica e temporal, respectivamente, os modelos foram construídos. Em todos os modelos, o tamanho de ninhada foi inserido como variável resposta, a média histórica (LTM) da variável bioclimática selecionada como controle para variação geográfica do tamanho de ninhada, o ano como controle para a tendência da variação temporal, e a anomalia da variável bioclimática selecionada foi incluída apenas no modelo mais complexo do conjunto como variável explanatória. Assim, o conjunto de modelos para cada região, norte e sul da distribuição de P. rubinus, foi formado por cinco modelos (ver Tabelas 5 e 7). 
Para a região norte da distribuição de $P$. rubinus, o modelo que apresentou o melhor suporte $(\mathrm{AICc}=347,22 ; \Delta \mathrm{AICc}=0$, Tabela 5$)$ dos 5 modelos candidatos retém todas as variáveis, com poder explicativo de $100 \%$. Todas as variáveis apresentaram a mesma importância na modelagem ( $W=1,00$; Tabela 6). Todavia, a média histórica da isotermalidade (LTM.yr.Isot) foi a variável que melhor explicou a variação geográfica do tamanho de ninhada, enquanto que a variação temporal da precipitação nos meses mais secos (Anom.yr.Pmin) foi a variável que melhor contribuiu para explicar a variação temporal do tamanho de ninhada, de acordo com seus respectivos coeficientes e erros padrão (Tabela 6, Figura 1).

Em contraponto a região sul da distribuição geográfica da espécie, o tamanho de ninhada aumentou em 0,20 entre 1866 e 1968 de acordo com o melhor modelo para a região norte da distribuição geográfica da espécie (Figura 1a). Pyrocephalus rubinus apresentou também variação do tamanho de ninhada entre localidades e entre anos. Em localidades de menor isotermalidade para localidades de maior isotermalidade, a espécie diminuiu em 0,61 ovos por ninhada (Figura 1b) na região norte. Entre anos, a variação da precipitação do mês mais seco foi importante para a variação do tamanho de ninhada. Entre anos com menor precipitação no mês seco e anos com maior precipitação, o tamanho de ninhada diminuiu em 1,09 ovos (Figura 1c).

Tabela 5. Ranqueamento dos modelos candidatos utilizados para testar os efeitos das variáveis bioclimáticas para a variação temporal no tamanho de ninhada de Pyrocephalus rubinus na região norte da distribuição geográfica dessa espécie. Número de parâmetros estimados $(\mathrm{K})$, valores do critério de correção de enviesamento de segunda ordem (AICc), valores da diferença de segunda ordem $(\triangle \mathrm{AICc})$, peso dos $\mathrm{AICc}\left(w_{i}\right)$ e a probabilidade logarítmica (LL) de cada modelo foram calculados. A variável explanatória utilizada foi a anomalia da precipitação mês menos chuvoso (Anom.yr.Pmin). A média histórica da isotermalidade (LTM.yr.Tisot) e o ano foram inseridos como variáveis controle para variação geográfica e variação temporal, respectivamente.

\begin{tabular}{lccccc}
\hline Modelos & K & AICc & $\Delta$ AICc & wi & LL \\
\hline Ano + LTM.yr.Tisot + Anom.yr.Pmin & 5 & 347,22 & 0,00 & 1,00 & $-168,51$ \\
LTM.yr.Tisot & 3 & 378,04 & 30,81 & 0,00 & $-185,98$ \\
Ano + LTM.yr.Tisot & 4 & 378,55 & 31,33 & 0,00 & $-185,21$ \\
Nulo & 2 & 401,24 & 54,02 & 0,00 & $-198,60$ \\
Ano & 3 & 401,38 & 54,16 & 0,00 & $-197,65$ \\
\hline
\end{tabular}


Tabela 6. Média de modelos para a região norte da distribuição geográfica de Pyrocephalus rubinus. Coeficientes, erros padrão não condicionais (SE), intervalo de confiança de $95 \%$ de probabilidade (CI), a importância de cada variável nos modelos gerados pela modelagem de quadrados mínimos generalizado (Generalized Least Squares Model - GLSM) para testar o efeito de cada variável na variação do tamanho de ninhada de Pyrocephalus rubinus e a quantidade de modelos em que cada variável foi inserida. A variável explanatória de maior interesse foi a precipitação do mês mais seco do ano (Anom.yr.Pmin) e as demais, ano e média histórica de isotermalidade (LTM.yr.Tisot), foram inseridas na modelagem como variáveis para controle da tendência da variação temporal e da variação geográfica do tamanho de ninhada, respectivamente.

\begin{tabular}{lcccccc}
\hline & Coeficiente & SE & Menor CI & Maior CI & W & Modelo \\
\hline Intercepto & $-0,0299$ & 2,1485 & $-4,2578$ & 4,1981 & & \\
Ano & 0,0020 & 0,0012 & $-0,0003$ & 0,0043 & 1,00 & 3 \\
LTM.yr.Tisot & $-0,0196$ & 0,0044 & $-0,0283$ & 0,0109 & 1,00 & 3 \\
Anom.yr.Pmin & $-0,0245$ & 0,0042 & $-0,0327$ & 0,0163 & 1,00 & 1 \\
\hline
\end{tabular}



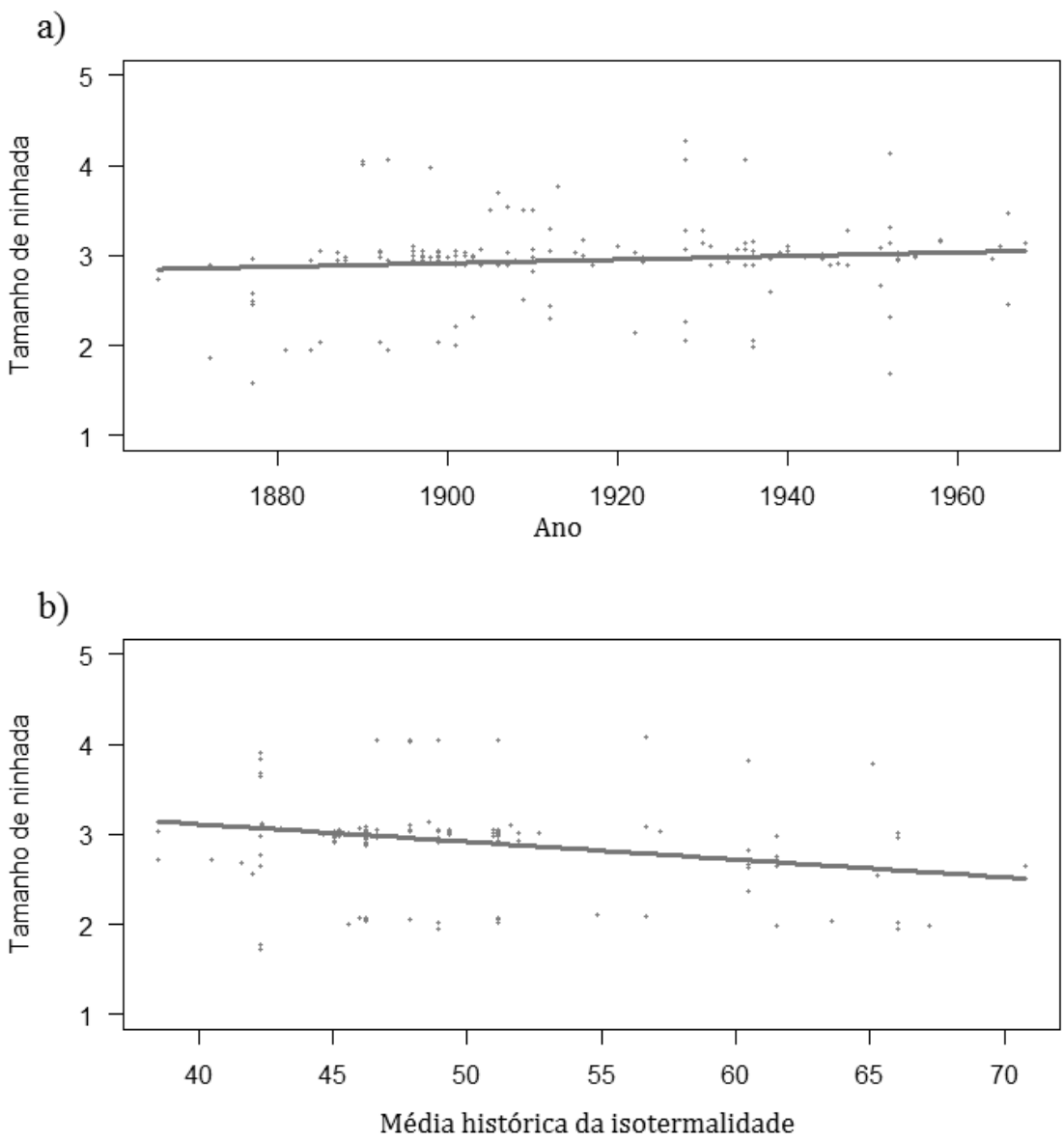

c)

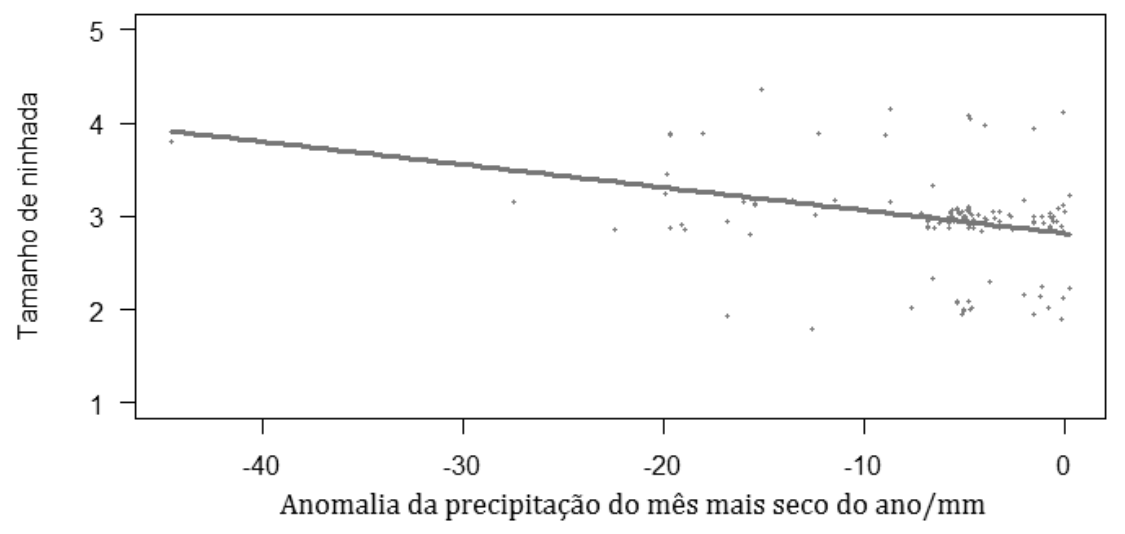

Figura 1. Variação temporal e geográfica do tamanho de ninhada de Pyrocephalus rubinus da região norte de sua distribuição geográfica. A variação temporal do tamanho de ninhada ao longo dos anos (a), a variação do tamanho de ninhada entre localidades com distintas médias históricas de isotermalidade (LTM.yr.Tisot) na região norte (b) e a variação anual da variação do tamanho de ninhada em resposta à anomalia da precipitação do mês mais seco (Anom.yr.Pmin, c). 
Para a região sul, o modelo com melhor suporte $(\mathrm{AICc}=129,24 ; \Delta \mathrm{AICc}=0) \operatorname{dos} 5$ modelos candidatos possui todas as variáveis, com peso de 57\% (Tabela 7). A variável com maior importância foi o ano $(W=0,91)$, seguido pela média histórica da temperatura do mês mais quente $(W=0,83)$ e pela anomalia da precipitação do mês e do ano da reprodução da espécie ( $W=0,57$; Tabela 8$)$. Os coeficientes e os erros padrões das variáveis após o cálculo da média dos modelos indicam que nenhuma variável explanatória teve efeito razoável sobre o tamanho de ninhada (Tabela 8).

De acordo com o melhor modelo, tamanho de ninhada diminuiu em 0,26 entre 1929 e 2004 (Figura 2a). Pyrocephalus rubinus apresentou também variação do tamanho de ninhada entre regiões e entre anos. Em localidades nas quais a temperatura do mês mais quente foi menor $\left(28,19^{\circ} \mathrm{C}\right)$ para localidades com maior temperatura $\left(33,88^{\circ} \mathrm{C}\right)$ na região sul, a espécie diminuiu em 0,21 ovos por ninhada (Figura 2 b). A variação da precipitação do mês da reprodução entre anos foi a variável que mais afetou a variação desse paramêtro reprodutivo com a diminuição de 0,93 do tamanho de ninhada dos anos mais secos para os anos mais chuvosos durante o mês da reprodução (Figura 2c).

Tabela 7. Ranqueamento dos modelos candidatos utilizados para testar os efeitos das variáveis bioclimáticas para a variação temporal no tamanho de ninhada de Pyrocephalus rubinus na região sul da distribuição geográfica dessa espécie. Número de parâmetros estimados $(\mathrm{K})$, valores do critério de correção de enviesamento de segunda ordem (AICc), valores da diferença de segunda ordem $(\triangle \mathrm{AICc})$, peso dos $\mathrm{AICc}\left(w_{i}\right)$ e a probabilidade logarítmica (LL) de cada modelo foram calculados. A variável explanatória utilizada foi a anomalia da precipitação total mensal (Anom.month.yr.Ptot). A média histórica da temperatura do mês mais quente (LTM.yr.Tmax) e o ano foram inseridos como variáveis controle para variação geográfica e variação temporal, respectivamente.

\begin{tabular}{lccccc}
\hline \multicolumn{1}{c}{ Modelos } & $\mathrm{K}$ & $\mathrm{AICc}$ & $\Delta \mathrm{AICc}$ & $w_{i}$ & $\mathrm{LL}$ \\
\hline Ano + LTM.yr.Tmax + Anom.month.yr.Ptot & 5 & 129,24 & 0,00 & 0,57 & $-59,33$ \\
Ano + LTM.yr.Tmax & 4 & 131,59 & 2,34 & 0,18 & $-61,60$ \\
Ano & 3 & 131,74 & 2,50 & 0,16 & $-62,76$ \\
LTM.yr.Tmax & 3 & 133,14 & 3,89 & 0,08 & $-63,46$ \\
Nulo & 2 & 138,33 & 9,08 & 0,01 & $-67,11$ \\
\hline
\end{tabular}


Tabela 7. Média de modelos para a região sul da distribuição geográfica de Pyrocephalus rubinus. Coeficientes, erros padrão não condicionais (SE), intervalo de confiança de $95 \%$ de probabilidade (CI), a importância (W) de cada variável nos modelos gerados pela modelagem de quadrados mínimos generalizado (Generalized Least Squares Model - GLSM) e a quantidade de modelos em que cada variável foi inserida. A variável explanatória de maior interesse foi a precipitação do mês da reprodução da espécie (Anom.month.yr.Ptot) e as demais, ano (year) e média histórica da temperatura do mês mais quente (LTM.yr.Tmax), foram inseridas na modelagem como variáveis para controle da tendência da variação temporal e da variação geográfica da ninhada, respectivamente.

\begin{tabular}{lcccccc}
\hline & Coeficiente & SE & Menor CI & Maior CI & W & Modelo \\
\hline Intercepto & 10,5332 & 4,0813 & 0,9877 & 17,8548 & & \\
Ano & $-0,0034$ & 0,0023 & $-0,0079$ & 0,0001 & 0,91 & 3 \\
LTM.yr.Tmax & $-0,0370$ & 0,0360 & $-0,0030$ & 0,0002 & 0,83 & 3 \\
Anom.month.yr.Ptot & $-0,0008$ & 0,0009 & $-0,1175$ & 0,0168 & 0,57 & 1 \\
\hline
\end{tabular}


a)

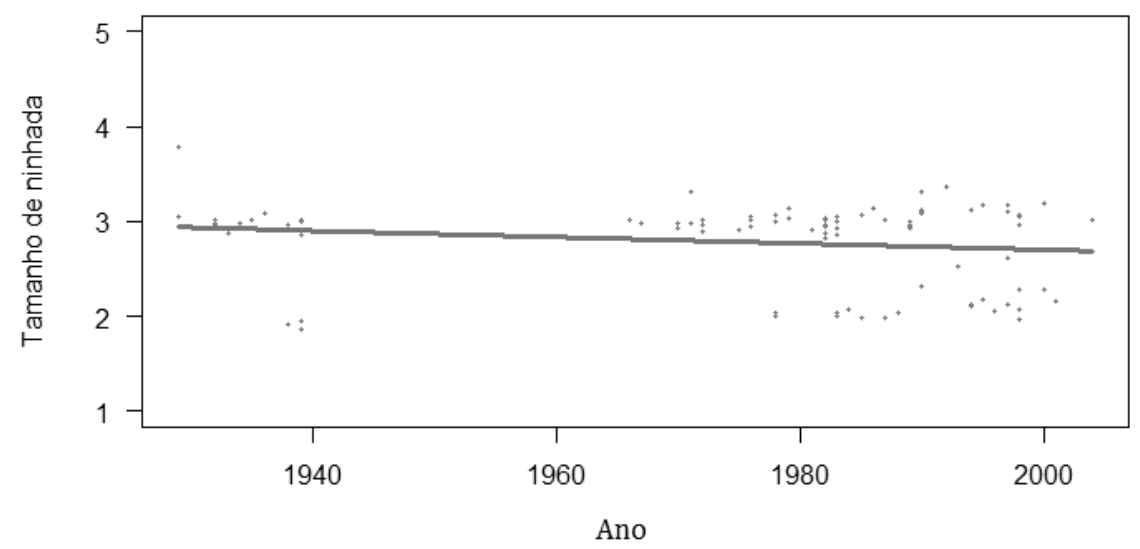

b)

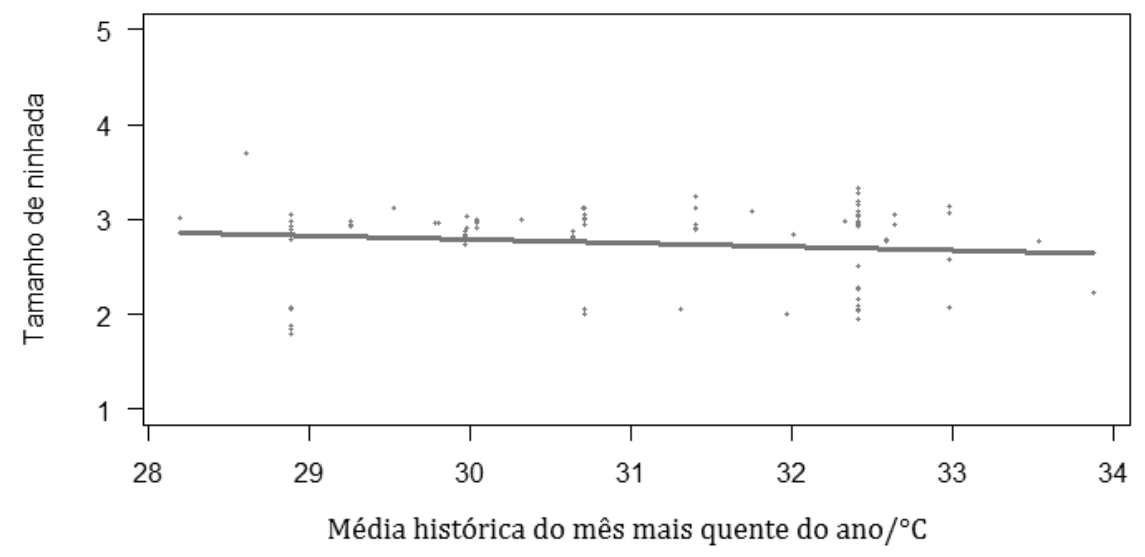

c)

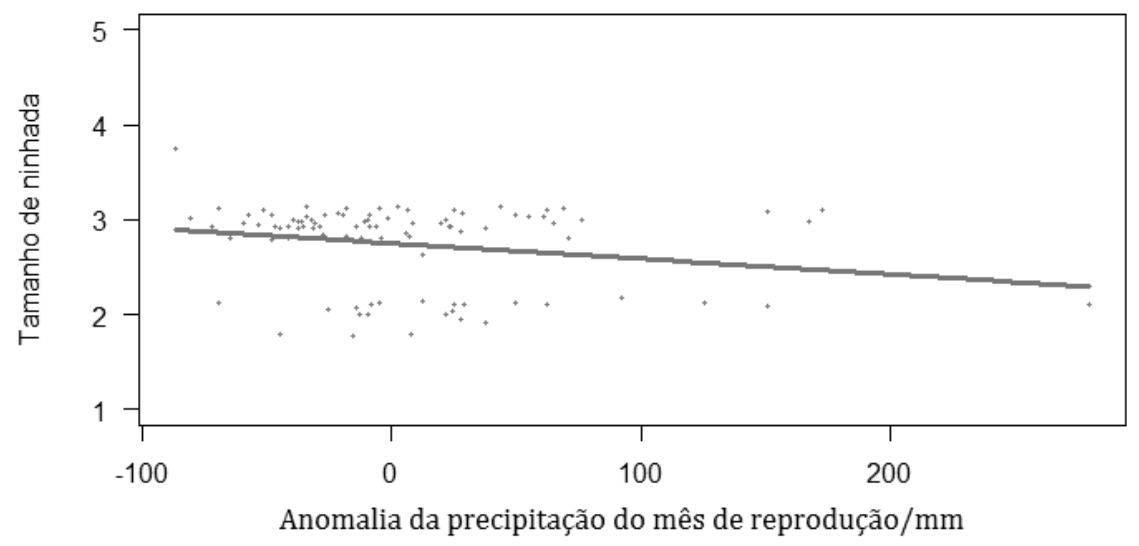

Figura 2. Variação temporal e geográfica do tamanho de ninhada de Pyrocephalus rubinus na região sul de sua distribuição geográfica. A variação temporal do tamanho de ninhada ao longo dos anos (a), a variação do tamanho de ninhada entre localidades com distintas médias históricas do mês mais quente do ano (LTM.yr.Tmax) na região sul (b) e a variação anual da variação do tamanho de ninhada em resposta à anomalia da precipitação mensal total (Anom.month.yr.Ptot, c). 


\section{DISCUSSÃO}

O tamanho da ninhada do Pyrocephalus rubinus variou pouco ao longo dos anos em ambas as regiões. Na região norte de sua distribuição geográfica, o tamanho da ninhada teve um pequeno aumento $(0,20$ ovos/ninhada), enquanto o tamanho de ninhada diminuiu $(0,26$ ovos/ninhada) na região sul ao longo dos anos analisados. A quantidade de ovos por ninhada também varia geograficamente. Em localidades com menor isotermalidade para localidades com maior isotermalidade, houve a diminuição de 0,61 ovos por ninhada na região norte. $\mathrm{E}$ em localidades com menor temperatura máxima para localidades com maior temperatura máxima o tamanho de ninhada diminui 0,21 ovos na região sul da distribuição geográfica da espécie. A precipitação foi uma variável climática importante para a variação da quantidade de ovos postos por ninho entre anos. Em anos com maior taxa de precipitação, a espécie diminuiu 1,09 ovos por ninhada na região norte e 0,93 ovos por ninhada na região sul.

\subsection{Variação geográfica do tamanho de ninhada}

As populações de Pyrocephalus rubinus que nidificam no México e no sul dos EUA são migratórias e passam seu período de invernada nos trópicos, precisamente, na Amazônia (Bullis \& Lincoln 1952; Joseph 1997). No Sul dos EUA e no norte do México, os seus territórios de reprodução localizam-se em uma região com alta variação de temperatura e precipitação e, no centro e sul do México, os seus territórios de reprodução localizam-se em uma região com menor variação de temperatura e alta variação de precipitação (Figuras 11 e 12 do Apêndice, ver Capítulo 1). As populações que nidificam no sul da América do Sul também são migratórias (Farnsworth \& Lebbin 2004) e invernam nos trópicos (Joseph 1997). Seus territórios de reprodução se encontram, no entanto, em regiões que apresentam variações mais amenas de temperatura e precipitação quando comparadas às regiões ocupadas no Hemisfério Norte (Figuras 11 e 12 do Apêndice, ver Capítulo 1).

Em regiões de maior instabilidade ambiental, as aves se deparam com produtividade primária líquida alta durante a primavera nos territórios de reprodução o que provê abundância alimentar durante esse período, porém a produtividade primária líquida é baixa e o clima é rigoroso durante o inverno (Ketterson \& Nolan 1983; Fristoe 2015). As espécies migratórias se deslocam, então, para regiões com climas mais amenos para invernar (Bell 2000). Entretanto, o percurso migratório demanda grande quantidade de energia entre um território de reprodução e um de invernada e vice-versa (Alestram \& Lindström 1990; Jetz et 
al. 2008), resultando em um aumento na mortalidade da população (Skutch 1949; Yom-Tov et al. 1994). Assim, a pequena população, durante o período reprodutivo, e o pico de produção de recursos alimentares durante a primavera permite maior produção de ovos por ninhada, devido à pronta disponibilidade energética aos casais (Ashmole 1963; Griebeler \& GaeseBöhning 2004). Em contrapartida, indivíduos enfrentam maior competição por recursos quando se reproduzem em ambientes com maior estabilidade ambiental e com maior estabilidade na produção de recursos alimentares, já que as populações estão sempre próximas do limite da capacidade suporte (Ashmole 1963; Cody 1966). Assim, alocação de energia referente a outras atividades, além das atividades reprodutivas, promove o menor investimento em produção de ovos por ninhada e maior investimento energético em sobrevivência (Stearns 1992; Martin 1992, 1996).

A isotermalidade pode ser um fator determinante para a variação geográfica do tamanho de ninhada de $P$. rubinus na região norte de sua distribuição geográfica por se reproduzirem em locais com grande variação climática. Sendo assim, a espécie tem menor tamanho de ninhada em regiões de menor estabilidade térmica em comparação com regiões mais instáveis (Figura 2b e Figura 11 do Apêndice). A produção de alimentos é mais estável em regiões com maior isotermalidade, onde a quantidade de recursos alimentares permite que as populações cheguem próximo ao limiar da capacidade suporte (Cody 1966). As espécies migratórias podem competir com as espécies residentes por recursos (Salewski \& Bruderer 2007). Assim, esse ambiente favorece indivíduos que investem menores quantias de energia na reprodução e maiores quantias na sobrevivência e na competição (Ashmole 1963; Both et al. 2000). Em contraponto, indivíduos oriundos de regiões de baixa isotermalidade estão expostos a condições desfavoráveis à sobrevivência em períodos não reprodutivos e suas populações estão em pequeno tamanho durante a estação reprodutiva o que possibilita maiores oportunidades de reprodução (Ashmole 1963) para indivíduos migratórios. Com menor competição por recursos, os organismos realizam maior investimento na produção de ninhadas (Both et al. 2000).

A América do Sul possui menor massa continental com um formato no qual grande parte de seu interior está próximo ao oceano o que promove maior estabilidade climática quando comparado com continentes de maiores massas continentais como a América do Norte (Yom-Tov et al. 1994). Sendo um continente com maior estabilidade climática, a isotermalidade e a sazonalidade da temperatura não foram fatores preponderantes na diferença latitudinal de tamanho de ninhada dentro desse continente (Tabela 1), como foram no Hemisfério Norte. Todavia, a temperatura do mês mais quente foi importante para a diferença 
latitudinal do tamanho da ninhada dessa espécie, já que a produção primária (NPP) aumenta com o aumento de temperatura (Epstein et al. 1997). A alta taxa de produção primária aumenta a capacidade suporte do ambiente, por conseguinte, há maior crescimento populacional e os indivíduos com maior capacidade competitiva são selecionados diante desse cenário (Cody 1966). Porém, a energia alocada nessa habilidade e na sobrevivência diminui a disponibilidade de energia para produção de descendentes (Griebeler \& Gaese 2004) o que pode justificar menores tamanhos de ninhada em regiões que apresentam temperatura mais alta (Figura 1b).

Adicionalmente, a produção de insetos aumenta com o aumento da temperatura, sendo um fator ambiental importante para a determinação da quantidade de ovos por ninhada (Turner 1982). Aves insetívoras aumentam do tamanho de ninhada em decorrência do aumento da temperatura e da produção de insetos (Bryant 1975; Turner 1982). Essa seria outra possível explicação para o maior tamanho de ninhada em localidades com maiores temperaturas que em localidades com menores temperaturas na região sul da distribuição geográfica de $P$. rubinus.

\subsection{Variação temporal do tamanho de ninhada}

O tamanho da ninhada na América do Norte aumentou pouco entre 1866 e 1968 (Figura 2a). Alguns estudos demonstram que algumas espécies aumentaram o seu tamanho de ninhada em consequência da postura adiantada que, por sua vez, é resposta à mudança do período do pico de abundância de recursos alimentares ocasionado pelas mudanças climáticas (Møller 2002; Both \& Visser 2005; Fletcher et al. 2013). A pequena diminuição do tamanho de ninhada entre 1929 e 2004 na região sul da distribuição da espécie segue o mesmo padrão apresentado por espécies na região tropical (Senapathi et al. 2011). As espécies tropicais e temperadas sul atrasam sua atividade reprodutiva e diminuem o tamanho de ninhada de acordo com a variação da intensidade e da frequência da precipitação (Gibbs et al. 2011; Senapathi et al. 2011).

Os indivíduos de uma espécie podem variar o seu tamanho de ninhada entre anos de acordo com os efeitos diretos (clima) e indiretos (disponibilidade de alimento) das condições climáticas vigentes, já que as espécies não preveem a ocorrência de anos bons ou ruins para produção de descendentes (Lack 1967; Roff 1992; Senapathi et al. 2011). Pyrocephalus rubinus diminuiu seu tamanho de ninhada, durante período de 1866 a 1968, com o aumento da precipitação no mês mais seco do ano. Em algumas regiões do norte de sua distribuição, a 
primavera (abril, maio e junho) é o período mais chuvoso, o inverno (janeiro, fevereiro e março) e o verão (julho, agosto e setembro) os períodos mais secos (Box et al. 1967, Hanes 1971, Garza et al. 1985, Harmel et al. 2003). Em outras regiões, o período mais seco se concentra na primavera (maio a junho) e o período mais chuvoso no verão (julho a setembro - Wallmo 1955, Whittaker \& Niering 1965). O aumento da precipitação em regiões áridas aumenta a produção primária (NPP; Begon et al. 2007) e, consequentemente, a quantidade de recursos alimentares disponíveis. Todavia, os padrões dos ciclos anuais de precipitação e a disponibilidade de alimentos são fundamentais para a reprodução das aves. Alterar os ciclos anuais de precipitação afeta a dinâmica populacional de presas e o habitat de forrageamento das espécies (Morrison et al. 2007, Morrison et al. 2009). Ou seja, a precipitação pode aumentar de tal forma que o pico da taxa de crescimento populacional das presas entra em assincronia em relação ao período de reprodução da espécie, além de mudar a distribuição das presas no habitat de forrageamento. Ademais, a precipitação é fator determinante para a produção e abundância de insetos (Wolda 1978), fonte energética dessa espécie (Ordano et al. 1999). Esses fatores podem explicar a diminuição do tamanho de ninhada entre os anos (Morrison et al. 2009).

Outro possível motivo para diminuição do tamanho de ninhada pode se dar pela qualidade do território de invernada. Isto é, as espécies migratórias tropicais não encontram bons territórios na região de invernada e suas condições físicas diminuem em razão da ausência de recursos alimentares de boa qualidade (Norris et al. 2004; Studds \& Marra 2007). Logo, os indivíduos se encontram pouco preparados para enfrentar a viagem do território de invernada para o território de reprodução e com pouca energia para a produção de descendentes durante o período reprodutivo (Norris et al. 2004). Além desse fator, o atraso da chegada dos indivíduos ao território reprodutivo e da data de postura e a assincronia com o pico de abundância alimentar acarretam em menores tamanhos de ninhada (Norris et al. 2004; Laaksonen et al. 2006; Studds \& Marra 2007).

A subespécie $P$. rubinus rubinus diminuiu o tamanho de ninhada em resposta às variações climáticas anuais, em especial ao aumento da precipitação no mês da reprodução. $\mathrm{O}$ aumento da precipitação influi para a maior produtividade do ambiente (Cao et al. 2004), havendo maior disponibilidade de recursos e energia para produção de maiores ninhadas (Stearns 1992; Hoi et al. 2004). Contudo, essa diminuição do tamanho de ninhada pode ser explicada pelo fato de que a precipitação dificulta o forrageamento, diminuindo a quantidade de alimento à disposição dos pais e, enfim, energia para produção e incubação dos ovos (Foster 1974; Domingues 2012). Adicionalmente, o risco de perda de ninhegos e ninhos 
é grande após a produção e eclosão dos ovos (Senapathi et al. 2011; Öberg et al. 2015). Sendo assim, nos trópicos e na região temperada sul, a frequência e a intensidade da precipitação pode ser um fator ambiental preponderante para a determinação de alguns parâmetros reprodutivos como resposta das aves às mudanças climáticas (Senapathi et al. 2011).

\subsection{Conclusões}

$\mathrm{O}$ aumento de temperatura no último século não excedeu $1^{\circ} \mathrm{C}$ entre 1880 e 2012 (Hartmann et al. 2013) e o tamanho de ninhada de Pyrocephalus rubinus variou pouco em resposta à variação climática durante o período estudado. Apesar da pequena variação do tamanho de ninhada, a espécie apresentou variação geográfica desse parâmetro reprodutivo associada à temperatura e à isotermalidade. Adicionalmente, a espécie muda o tamanho de ninhada entre os anos em decorrência do aumento da precipitação.

Considerando apenas a sua resposta às mudanças climáticas, $P$. rubinus pode não responder de maneira a acompanhar o rápido aumento de temperatura $\left(2\right.$ a $\left.4^{\circ} \mathrm{C}\right)$ e de precipitação ( 1 a $3 \%$ por $1^{\circ} \mathrm{C}$ ) previstos para os próximos 100 anos (Collins et al. 2013). Embora, analisando as respostas da espécie à variação geográfica de temperatura e anual de precipitação, os indivíduos podem diminuir o tamanho de ninhada em decorrência dessas variações climáticas preditas o que pode afetar a reprodução da espécie. A partir dos resultados desse trabalho, torna-se possível avaliar a resposta dessa espécie às mudanças previstas pelo Intergovernmental Panel Climate Change (IPCC) para o próximo século. 


\section{CONCLUSÕES GERAIS}

O primeiro capítulo demonstra a importância da história natural para a promoção de estudos derivados dessa área de conhecimento. As subespécies de Pyrocephalus rubinus presentes na região central de sua distribuição possuem poucos registros de ocorrência e pouco ou nenhum registro reprodutivo quando comparadas ao contingente de dados das regiões norte e sul de sua distribuição. Consequentemente, pouco se sabe sobre os períodos reprodutivos e as precisas distribuições geográficas das subespécies, como também se existe comportamento migratório ou residente nas populações presentes na região tropical. Sendo assim, esse trabalho demonstrou que a espécie $P$. rubinus ainda não foi descrita de maneira a detalhar as diferenças existentes entre suas subespécies quanto à distribuição geográfica e à biologia reprodutiva. Adicionalmente, esse estudo foi capaz de melhor detalhar algumas características das subespécies (tamanho de ninhada, período reprodutivo e distribuição geográfica). Evidenciou também as lacunas a serem preenchidas por mais pesquisas e pelo compartilhamento de dados oriundos de instituições de ensino e museus.

No segundo capítulo, a inviabilidade da análise do efeito das mudanças climáticas exerce sobre as populações presentes na região central da distribuição geográfica dessa espécie foi consequência de pouca informação quantitativa e qualitativa das populações presentes nessa região. Apesar dessa limitação, foi possível analisar as variações espaciais e temporais ao longo do último século do tamanho de ninhada de $P$. rubinus para as regiões temperadas norte e sul. Adicionalmente à pequena variação do tamanho de ninhada associada ao aumento de temperatura e à isotermalidade na região de clima temperado norte e sul, respectivamente, e variação temporal do tamanho de ninhada em ambas as regiões em resposta à variação anual da precipitação.

Em decorrência dos resultados, a sugestão é um maior investimento em pesquisa e estudos na região dos trópicos e na biologia reprodutiva das espécies e de suas respectivas subespécies para auxiliar futuros trabalhos em outras áreas de conhecimento, além da história natural. E, a partir dos resultados encontrados, prever a resposta dessa espécie às mudanças previstas pelo Intergovernmental Panel Climate Change (IPCC) para o próximo século. 


\section{REFERÊNCIAS}

Alestram T, Lindström Â. 1990. Optimal bird migration: The relative importance of time, energy, and safety. In: Gwinner E., editor. Capítulo 5: Bird Migration. Berlim (Alemanha): Springer.

Anderson DR. 2007. Model Based Inference in the Life Sciences: A Primer on Evidence. Nova Iorque (EUA): Springer Press.

Ashmole NP. 1963. The regulation on numbers of tropical oceanic birds. The Ibis. 103:458473.

Bancroft G. 1930 The breeding birds of Central Lower California. The Condor. 32:20-49.

Barros VR, Silvestri GE. 2002. The relation between sea surface temperature at the Subtropical South Central Pacific and precipitation in Southeastern South America. Journal of Climate. 15:251-267.

Bartholomew GA. 1986. The role of natural history in contemporary biology. Bioscience. 36:324-329.

Barton K. 2015. Package “MuMIn”: Multi-Model Inference. - Version 1.15.1.

Begon M, Townsend CR, John LH. 2007. Ecologia de Indivíduos a Ecossistemas. Quarta edição. Porto Alegre (Brasil): Artmed.

Bell CP. 2000. Process in evolution of bird migration and pattern in avian ecogeography. Journal Avian Biology. 31:258-265.

Bent AC. 1942. Life histories of North American flycatchers, larks, swallows, and their allies. Washington (EUA): National Museum.

Birkhead TR, Charmantier I. 2009. History of Ornithology. Encyclopedia of Life Science. 18.

Bivand R, Keitt T, Rowlingson B. 2015. Package "rgdal": Bindings for the geospatial data abstraction library. - Version 1.1-3.

Blumstein DT. 2006. Developing an evolutionary ecology of fear: how life history and natural history tratis affect disturbance tolerance in birds. Animal Behavior. 71:389-399.

Bond J. 1947. Notes on Peruvian Tyrannidae. Proceedings of the Academy of Natural Sciences of Philadelphia. 99:127-154.

Borrero JIH. 1972. Historia natural del Titiribí, Pyrocephalus rubinus (Aves, Tyrannidae), en Colombia, con notas sobre su distribución. Mitt. Inst. Colombo-Alemán Invest. Cient. 6:113-133. 
Both C, Tinbergen JM, Visser ME. 2000. Adaptive density dependence of avian clutch size. Ecology. 81:3391-3403.

Both C, Visser ME. 2005. The effect of climate change on the correlation between avian lifehistory traits. Global Change Biology. 11:106-113.

Box TW, Powell J, Drawe DL. 1967. Influence of fire on Chaparral Communities. Ecology. 48:955-961.

Bradley NL, Leopold CA, Ross J, Huffaker W. 1999. Phenological changes reflect climate change in Wisconsin. Proceedings of the National Academy of Science of the United States of America. 96: 9701- 9704.

Breheny P, Burchett W. 2015. Package “visreg”: Visualization of regression models. Version 2.2-0.

Bryant DM. 1975. Breeding biology of House Martins Delichon urbica in relation to aerial insect abundance. The Ibis. 117: 180-216

Bullis RHJr, Lincoln FC. 1952. A Trans-Gulf migration. The Auk. 69:34-39.

Burnham KP, Anderson DR. 2002. Model selection and multimodel inference: a pratical information-theoretic approach. Segunda Edição. Nova Iorque (EUA): Springer Press.

Cao, M, Prince SD, Small J, Goetz SJ. 2004. Remotly sensed interannual variations and trends in terrestrial net primary productivity 1981-2000. Ecosystems. 7:233-242.

Charmantier A, Gienapp P. 2014. Climate change and timing of avian breeding and migration: evolutionary versus plastic changes. Evolutionary Applications. 7:15-28.

Chou C, Tu J-Y, Tan P-H. 2007. Asymmetry of tropical precipitation change under global warming. Geophysical Research Letters. 34:1-5.

Cody ML. 1966. A general theory of clutch size. Evolution. 20:174-184.

Collins M, Knutti R, Arblaster J, Dufresne J.-L, Fichefet T, Friedlingsten P, Gao X, Gutowski WJ, Johns T, Krinner G, Shongwe M, Tebaldi C, Weaver AJ, Wehner M. 2013. Longterm Climate Change: Projections, Commitments and Irreversibility. In: Stocker TF, Qin D, Plattner G-K, Tignor M, Allen SK, Boschung J, Nauels A, Xia Y, Bex V, Midgley PM, editores. Capítuloo 12: Climate Change 2013: The Physical Science Basis. Contribution of Working Group I to the Fifth Assessment Report of the Intergovernmental Panel on Climate Change. Cambridge: Cambridge University Press. Cowpertwait PSP, Metcalfe AV. 2009. Introductory time series with R. Nova Iorque (EUA): Springer.

Domingues LAL. 2012. Variações climáticas que afetam os parâmetros reprodutivos de Neothraupis fasciata (Thraupidae) e previsões para o contexto das mudanças climáticas. 
62 páginas. Dissertação - Institudo de Ciências Biológicas, Universidade de Brasília, Brasília.

Dunn P. 2004. Breeding dates and reproductive performance. In: Møller AP, Wolfgang F, Berthold P, editores. Capítulo 4: Birds and climate change. San Diego (EUA): Academic Press.

Ellison KS. 2008. Nest reuse by Vermilion Flycatchers in Texas. The Wilson Journal of Ornithology. 120:339-344.

Emori S, Brown SJ. 2005. Dynamic and thermodynamic changes in mean and extreme precipitation under changed climate. Geophysical Research Letters. 32:1-5.

Epstein HE, Lauenroth WK, Burke IC. 1997. Effects of temperature and soil texture on ANPP in US Great Plains. Ecology. 78:2628-2631.

Farnsworth A, Lebbin D. 2004. Vermilion Flycatcher (Pyrocephalus rubinus). In: Del Hoyo J, Elliott A, Sargatal J, Christie DA, De Juana E, editores. Handbook of the Birds of the World Alive. Barcelona: Lyns Edicions; [Acessado 09 Outubro 2015]. Disponível em: http://www.hbw.com/node/57383.

Fitzpatrick JW. 1980. Foraging behavior of Neotropical tyrant flycatchers. The Condor. $82: 43-57$.

Fitzpatrick JW. 2004. Family Tyrannidae. In: Del Hoyo J, Elliott A, Sargatal J, Christie DA, editores. Handbook of the Birds of the World. Barcelona: Lynx Edicions. v. 9: Cotingas to Pipits and Wagtails.

Fletcher K, Howarth D, Kirby A, Dunn R, Smith A. 2013. Effect of climate change on breeding phenology, clutch size and chick survival of an upland bird. Ibis. 155:456-463.

Foster MS. 1974. Rain, feeding behavior and clutch size in Tropical bird. The Auk. 91:722726.

Fraga RM. 1977. Notas sobre la reproducción del Churrinche (Pyrocephalus rubinus). El Honero. 11:380-383.

Freckleton RP. 2002. On the misuse of residuals in ecology: regression of residuals vs. multiple regression. Journal of Animal Ecology. 71:542-545.

Fristoe TS. 2015. Energy use by migrants and residents in North American breeding bird. Global Ecology and Biogeography. 24:406-415.

Futuyma DJ. 1998. Wherefore and whither the naturalist? The American Naturalist. 151:1-6.

Garza NEJr, Blackburn WH. 1985. The effect of early winter or spring burning runoff, sediment, and vegetation in Post Oak Savannah of Texas. Journal of Range Management. $38: 283-287$. 
Gibbs HM, Chamber LE, Bennett AF. 2011. Temporal and spatial variability of breeding in Australian birds and potencial implications of climate change. Emu. 111:283-291.

Greene WH. 1986. Capítulo 7: Natural history and evolutionary biology. In: Feder ME, Lander GV, editores. Predator-prey relationships: Perspectives and approaches from the study of lower vertebrates. Illinois (EUA): University of Chicago Press.

Greene WH. 2012. The generalized regression model and heteroscedasticity. In: Greene WH., editor. Econometric Analysis. Sétima Edição. Nova Iorque (EUA): Pearson, 2012.

Griebeler EM, Gaese-Böhning K. 2004. Evolution of clutch size along latitudinal gradients: revisiting Ashmole's hypothesis. Evolutionary Ecology Research. 6:679-694.

Hanes TL. 1971. Succession after fire in the Chaparral of Southern California. Ecological Monographs. 41:27-52.

Hansen JE, Lacis AA. 1990. Sun and dust versus greenhouse gases: an assessment of their relative roles in global climate change. Nature. 346:713-718.

Harmel RD, King KW, Richardson CW, Williams JR. 2003. Long-term precipitation analyses for the central Texas Blackland Prairie. Transactions of the ASAE. 46:1381-1388.

Harris MP. 1973. The Galápagos Avifauna. The Condor. 75:265-278.

Hartmann DL, Tank AMGK, Rusticucci M, Alexander LV, Brönnimann S, Charabi YA-R, Dentener FJ, Dlugokencky EJ, Earsterling DR, Kaplan A, Soden BJ, Thorne PW, Wild M, Zhai P. 2013. Observations: Atmosphere and Surface. In: Stocker TF, Qin D, Plattner G-K, Tignor M, Allen SK, Boschung J, Nauels A, Xia Y, Bex V, Midgley PM, editores. Capítulo 2: Climate Change 2013: The Physical Science Basis. Contribution of Working Group I to the Fifth Assessment Report of the Intergovernmental Panel on Climate Change. Cambridge: Cambridge University Press.

Herman SG. 2002. Wildlife biology and natural history: Time for a reunion. The Journal of Wildlife Management. 66:933-946.

Hijmans RJ, Cameron SE, Parra JL, Jones PG, Jarvis A. 2005. Very high resolution interpolated climate surfaces for global land areas. International Journal of Climatology. 25:1965-1978.

Hijmans RJ. 2015. Package "raster": Geographic data analysis and modeling. - Version 2.5-2. Heming NM. 2012. Estado de conhecimento e padrões de história de vida de Fluvicolinae (Tyrannidae) no Novo Mundo. 114 páginas. Tese - Instituto de Ciências Biológicas, Universidade de Brasília, Brasília.

Heming NM, Greeney HF, Marini MÂ. 2013. Breeding biology research and data availability for New Word flycatchers. Natureza \& Conservação. 11: 54-58. 
Heming NM, Marini MÂ. 2015. Ecological and environmental factors related to variation in egg size of New World flycatchers. Journal of Avian Biology. 46:1-9.

Hoi H, Kristin A, Valera F, Hoi C. 2004. Clutch enlargement in Lesser Gray Shrikes (Lanius minor) in Slovakia when food is superabundant: a maladaptive response? The Auk. 121:557-564, 2004.

Howell TR. 1965. New subspecies of birds from the lowland Pine Savanna of Northeastern Nicaragua. The Auk. 82:438-464.

James PC. 1987. Ornithology in Central and South America. The Auk. 104:348-349.

Jetz W, Sekercioglu CH, Gaese-Böhning K. 2008. The worldwide variation in avian clutch size across species and space. Plos Biology. 6:2650-2657.

Johnson TH, Stattersfield AJ. 1990. A global review of island endemic birds. Ibis. 132:167180.

Jones PD, Mann ME. 2004. Climate over the past millenia. Reviews of Geophysics. 42:1-42.

Joseph L. 1997. Towards a broader view of neotropical migrants: consequences of a reexamination of austral migration. Ornitologia Neotropical. 8:31-36.

Ketterson ED, Nolan VJr. 1983. The evolution of differential bird migration. In: Johnston RF, editor. Current Ornithology. USA: Springer. Volume 1.

Kuan C-M. 2004. Statistics: Concepts and Methods. Segunda Edição. Taipei: Hua-Tai.

Laaksonen T, Ahola M, Eeva T, Väisänen RA, Lehikoinen E. 2006. Climate change, migratory connectivity and changes in laying date and clutch size of Pied Flycatcher. Oikos. 114:277-290.

Lack D. 1967. The Natural Regulation of Animal Numbers. Londres (Inglaterra): Oxford University Press.

Lack D. 1968. Population studies of birds. Londres (Inglaterra): Oxford University Press.

Maden RA, Williams J. 1978. The correlation between temperature and precipitation in the United States and Europe. Monthly Weather Review. 106:142-147

Marchant S. 1960. The breeding of some S.W. Ecuadorian birds. The Ibis. 102:349-382.

Marchant S. 1959. The breeding season in S.W. Ecuador. The Ibis. 101:137-152.

Martin TE. 1992. Interaction of nest predation and food limitation in reproductive strategies. In: Power DM (Ed.) Current Ornithology. EUA: Springer Publisher. Volume 9.

Martin TE. 1996. Life history evolution in Tropical and South Temperate birds: What do we really know? Journal of Avian Biology. 27:263-272.

Martin TE, Martin PR, Olson CR, Heidinger BJ, Fontaine JJ. 2000. Parental care and clutch sizes in North and South American birds. Science. 287:1482-1485. 
Martin TE. 2015. Age-related mortality explains life history strategies of tropical and temperate songbirds. Science. 349:966-970.

Mayr E. 1982. Of what use are subspecies? The Auk. 99: 593-595

Mazerolle MJ. 2015. Package "AICcmodavg”: Model selection and multimodel inference based on (Q)AIC(c). - Version 2.0-3.

Mezquida ET. 2002. Nidificación de ocho especies de Tyrannidae en la Reserva de Nacuñán, Mendonza, Argentina. El Honero. 17:31-40.

Morrison JL, McMillian M, Cohen JB, Catlin DH. 2007. Environmental correlates of nesting success in Red-Shouldered Hawks. The Condor. 109:648:657.

Morrison JL, Pias KE, Cohen JB, Catlin DH. 2009. Environmental correlates of breeding in the Crested Caracara (Caracara cheriway). The Auk. 123:755-764.

Møler, AP. 2002. North Atlantic Oscillation (NAO) effects of climate on the relative importance of first and second clutches in a migratory passerine bird. Journal of Animal Ecology. 71:201-210.

Munhoz MR. 2014. Biologia reprodutiva de Pyrocephalus rubinus (Aves: Tyrannidae) no sul do Brasil. 70 páginas. Dissertação (Mestrado em Zoologia) -Faculdade de Biociências, Pontifícia Universidade Católica do Rio Grande do Sul. Porto Alegre.

Negret A.1988. Fluxos migratórios na avifauna da Reserva Ecológica de IBGE, Brasília, D.F., Brasil. Revista Brasileira de Zoologia. 5:209-214.

Newton I. 1998. Population Limitations in Birds. San Diego (EUA): Academic Press.

Norris DR, Marra PP, Kyser TK, Sherry TW, Ratcliffe LM. 2004. Tropical winter habitat limits reproductive success on the temperate breeding grounds in a migratory bird. Proceedings of Royal Society of London B: Biology Science. 271:59-64.

Öberg M, Arlt D, Pärt T, Laugen AT, Egger S, Low M. 2015. Rainfall during parental care reduces reproductive and survival components of fitness in a passerine bird. Ecology and Evolution. 5:354-356.

Ordano M, Bosisio A, Boscarol B, Beltzer A, Amsler GP. 1999. Stomach contentes of thirty six bird species from northern Argentina. Revista Ceres. 46:555-563.

Parmesan C, Yohe G. 2003. A globally coherent fingerprint of climate change impacts across natural systems. Nature. 421:37-42.

Paynter RA. 1982. Ornithological gazetteer of Venezuela. Cambridge: Bird Department, Museum of Comparative Zoology, Harvard University.

Paynter RA. 1988. Ornithological gazetteer of Chile. Cambridge: Bird Department, Museum of Comparative Zoology, Harvard University. 
Paynter RA. 1993. Ornithological gazetteer of Ecuador. Segunda Edição. Cambridge: Bird Department, Museum of Comparative Zoology, Harvard University.

Paynter RA. 1994. Ornithological gazetteer of Uruguay. Segunda Edição. Cambridge: Bird

Department, Museum of Comparative Zoology, Harvard University.

Paynter RA. 1995. Ornithological gazetteer of Argentina. Segunda Edição. Cambridge: Bird

Department, Museum of Comparative Zoology, Harvard University.

Paynter RA. 1997. Ornithological gazetteer of Colombia. Segunda Edição. Cambridge: Bird

Department, Museum of Comparative Zoology, Harvard University.

Paynter RA, Traylor MA. 1991a. Ornithological gazetteer of Brazil. Cambridge: Bird

Department, Museum of Comparative Zoology, Harvard University. v. 1.

Paynter RA, Traylor MA. 1991b. Ornithological gazetteer of Brazil. Cambridge: Bird

Department, Museum of Comparative Zoology, Harvard University. v. 2.

Pinheiro J, Bates D, DebRoy S, Sarkar D. 2015. Package "nlme": Linear and nonlinear mixed effect models. - Version 3.1-122.

Pivato MAC, Donatelli RJ, Manço DDG. 2008. Aves da Fazenda Santa Emília, Aquidauana, Mato Grosso do Sul. Atividades Ornitológicas. 143:33-37.

Pounds JA, Fogden MPL, Campbell JH. 1999. Biological response to climate change on a tropical mountain. Nature. 398:611-615.

Ramo C.; Busto B. 1984. Nidificacion de los passeriformes en los Llanos de Apure (Venezuela). Biotropica. 16:59-68, 1984.

Ricklefs RE.1980. Geographical variation in clutch size among passerine birds: Ashmole's hypothesis. The Auk. 95:38-49.

Ricklefs RE. 2000a. Lack, Skutch and Moreau: The early development of life history thinking. The Condor. 102:3-8.

Ricklefs RE. 2000b. Density dependence, evolutionary optimization, and the diversification of avian life histories. The Condor. 102:9-22.

Ridgely R, Tudor G. 1946. The birds of South America. Singapore: University of Texas Press. v. 2: The suboscines passerines.

Ripley, B. 2015. Package “ncdf”: Interface to unidata netCDF data files. - Version 3.1-122.

Roof DA. 1992. The evolution of life history: Theory and analysis. Nova Iorque (EUA): Chapman \& Hall.

Root TL, Price JT, Hall KR, Schneider SH, Rosenzweig C, Pounds AJ. 2003. Fingerprints of global warming on wild animals and plants. Nature. 421:57-60. 
Salewski V, Bruderer B. 2007. The evolution of bird migration - a synthesis. Naturwissenschaften. 94:268-279.

Seager R, Ting M, Held I, Kushnir Y, Lu J, Vecchi G, Huang H-P, Harnik N, Leetmaa A, Lau N-C, Li C, Velez J, Naik N. 2007. Model projections of an imminent transition to a more arid climate in Southwestern North America. Science. 316:1881-1884.

Senapathi D, Nicoll MAC, Teplitsky C, Jones CG, Norris K. 2011. Climate change and the risks associated with delayed breeding in a tropical wild bird population. Philosophical Transitions of the Royal Society London B: Biology Science. 278:3184-3190.

Skutch AF. 1949. Do Tropical birds rear as many young as they can nourish? The Ibis. 91:430-455.

Skutch AF. 1950. Outline for an ecological life history of a bird, based upon the Song Tanager Ramphocelus passerinni costariscensis. Ecology. 31:464-469.

Skutch AF. 1985 Clutch size, nesting success and predation on nests of Neotropial birds, reviewed.

Sowers T, Bender M. 1995. Climate records covering the last deglaciation. Science. 269:209214.

Stearns SC. 1992. The Evolution of Life Histories. Nova Iorque (EUA): Oxford Universtiy Press.

Stenseth NC, Mysterud A. 2002. Climate, changing phenology, and other life history traits: Nonlinearity and match-mismatch to the environment. Proceedings of the National Academy of Sciences. 99:13379-13381.

Stephens L, Traylor MA. 1983. Ornithological gazetteer of Peru. Cambridge: Bird Department, Museum of Comparative Zoology, Harvard University.

Studds C, Marra PP. 2007. Linking fluctuacions in rainfall to nonbreeding season performance in a long-distance migratory bird, Setophaga ruticilla. Climate Reaserch. 35:115-122.

Stutchbury BJM, Morton ES. 2011. Behavioral Ecology of Tropical Birds. San Diego (EUA): Academic Press.

Taylor WK, Hanson H. 1970. Observations on the breeding biology of the Vermilion Flycatcher in Arizona. The Wilson Bulletin. 82:315-319.

Turner AK. 1982. Timing of laying by Swallows (Hirundo rustica) and Sand Martins (Riparia riparia). Journal of Animal Ecology. 51: 29-46. 
Visser ME, Both C, Lambrechts MM. 2004. Global climate change leads to mistimed avian reproduction In: Møller AP, Wolfagang F, Berthold P, editores. Capítulo 5: Birds and climate change. San Diego: Academic Press.

Vuilleumier F. 2003. Neotropical Ornithology: Then and now. The Auk. 120:577-590.

Wallmo OC. 1955. Vegetation of the Huachuca Mountains, Arizona. The American Midland Naturalist. 54:466-480.

Walther G-R, Post E, Convey P, Menzel A, Parmesan C, Beebee TJC, Frometin J-M, HoeghGuldberg O, Bairlein F. 2002. Ecological responses to recent climate change. Nature. 416:389-395.

Walther, G.-R. 2010. Community and Ecossistem responses to recent climate change. Philosophical Transitions of the Royal Society London B, Biology Sciences. 365:20192024.

Whittaker RH, Niering, WA. 1965. Vegetation of the Santa Catalina Mountains, Arizona: A gradient analysis of the South Slope. Ecology. 46:429-452.

Winkler DW, Dunn PO, McCulloch CE. 2002. Predicting the effects of climate change on avian life-history traits. Proceedings of the National Academy of Sciences. 99:1359513599.

Winkler DW. 2004. Nests, eggs, and Young: breeding biology of birds. In: Podulka S, Rohrbaugh RJr, Bonney R, editores. Capítulo 8: Handbook of Bird Biology. Nova Iorque (EUA): The Cornell Lab of Ornithology.

Wolda H. Seasonal fluctuations in rainfall, food and abundance of tropical insects. Jouranl of Animal Ecology. 47: 369-381.

Wormworth J, Şekercioğlu HÇ. 2011. Winged Sentinels Birds and Climate Change. Cambridge: Cambridge University Press.

Yom-Tov Y, Christie MI, Iglesias GJ. 1994. Clutch size in passerines of South America. The Condor. 96:170-177.

Zimmer, J.T. 1941. The genera Oreotriccus, Tyrannulus, Acrochordopus, Ornithion, Leptopogon, Mionectes, Pipromorpha, and Pyrocephalus. Amer. Mus. Novit. 1126:1-25.

Zuria I, Rendón-Hernández G. 2010. Notes on the breeding biology of common resident birds in an urbanized area of Hidalgo, Mexico. Huitzil. 11:35-41. 


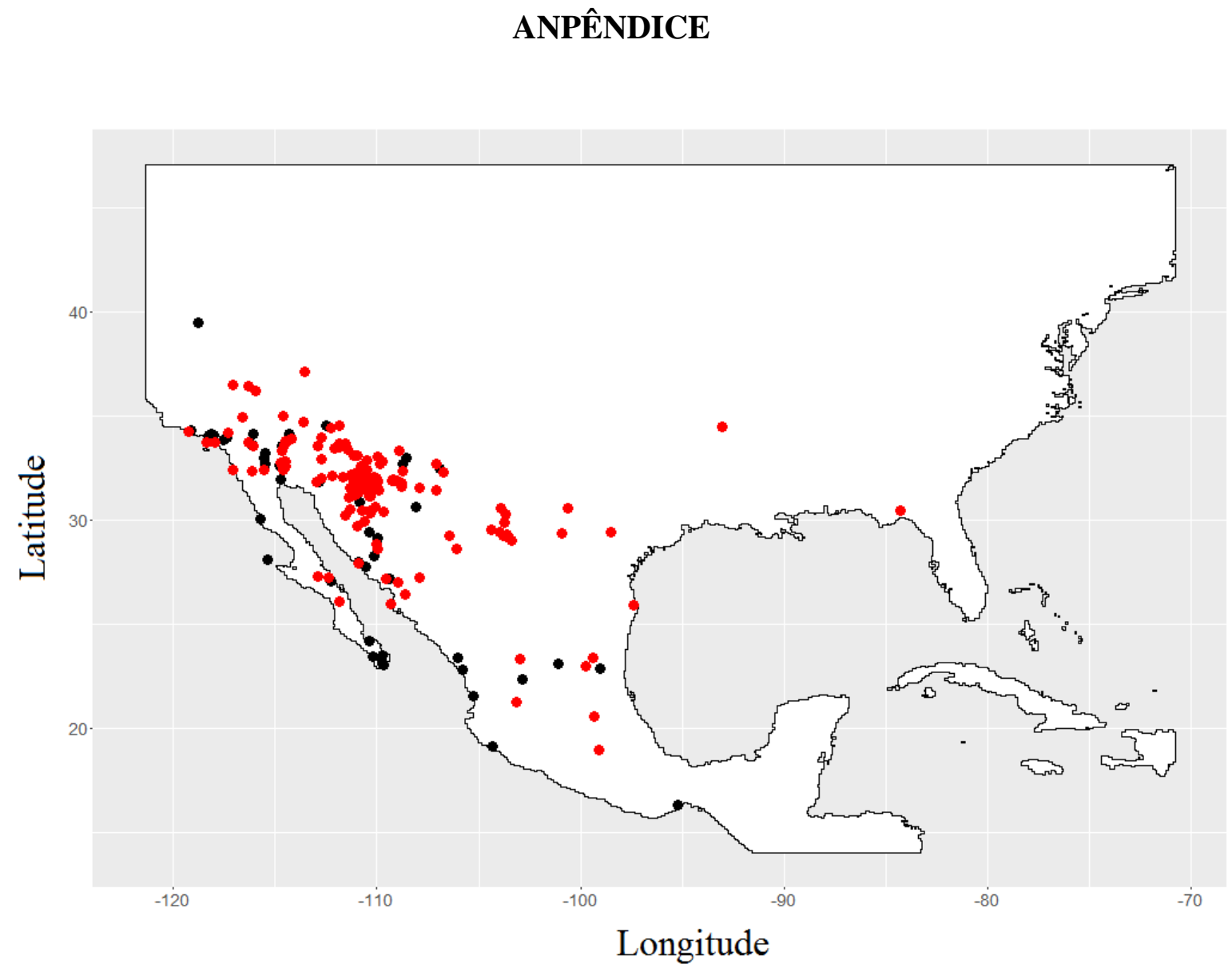

Figura 1. Mapa de distribuição geográfica de Pyrocephalus rubinus flammeus no sul dos EUA e no norte e no centro do México. Os pontos em vermelho são referentes aos registros reprodutivos (ninhos, ninhadas, registro visual de cuidado parental). Registros não reprodutivos como peles, tecidos, fluídos, ossos, vídeos, mudas e registros sonoros e de ocorrência que estivessem datados dentro do período reprodutivo da subespécie foram utilzados como fonte de dados para a construção de mapas de distribuição geográfica da região reprodutiva da subespécie. Os pontos pretos são referentes aos registros não reprodutivos (peles, tecidos, fluídos, ossos, vídeos, mudas e registros sonoros e de ocorrência) fora do período reprodutivo. 


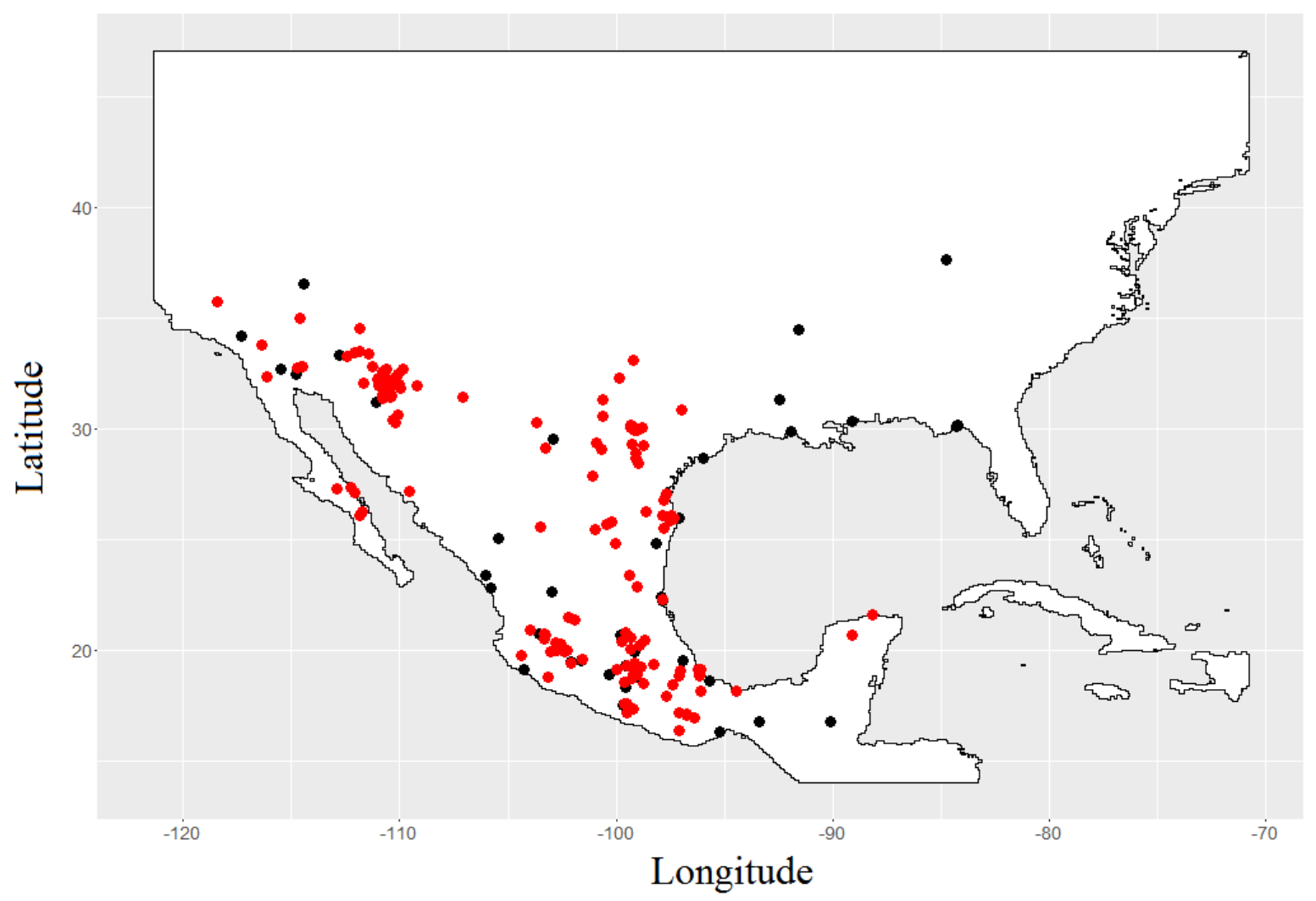

Figura 2. Mapa de distribuição geográfica de Pyrocephalus rubinus mexicanus no sul dos EUA e no México. Os pontos em vermelho são referentes aos registros reprodutivos (ninhos, ninhadas, registro visual de cuidado parental). Registros não reprodutivos como peles, tecidos, fluídos, ossos, vídeos, mudas e registros sonoros e de ocorrência que estivessem datados dentro do período reprodutivo da subespécie foram utilzados como fonte de dados para a construção de mapas de distribuição geográfica da região reprodutiva da subespécie. Os pontos pretos são referentes aos registros não reprodutivos (peles, tecidos, fluídos, ossos, vídeos, mudas e registros sonoros e de ocorrência) fora do período reprodutivo. 


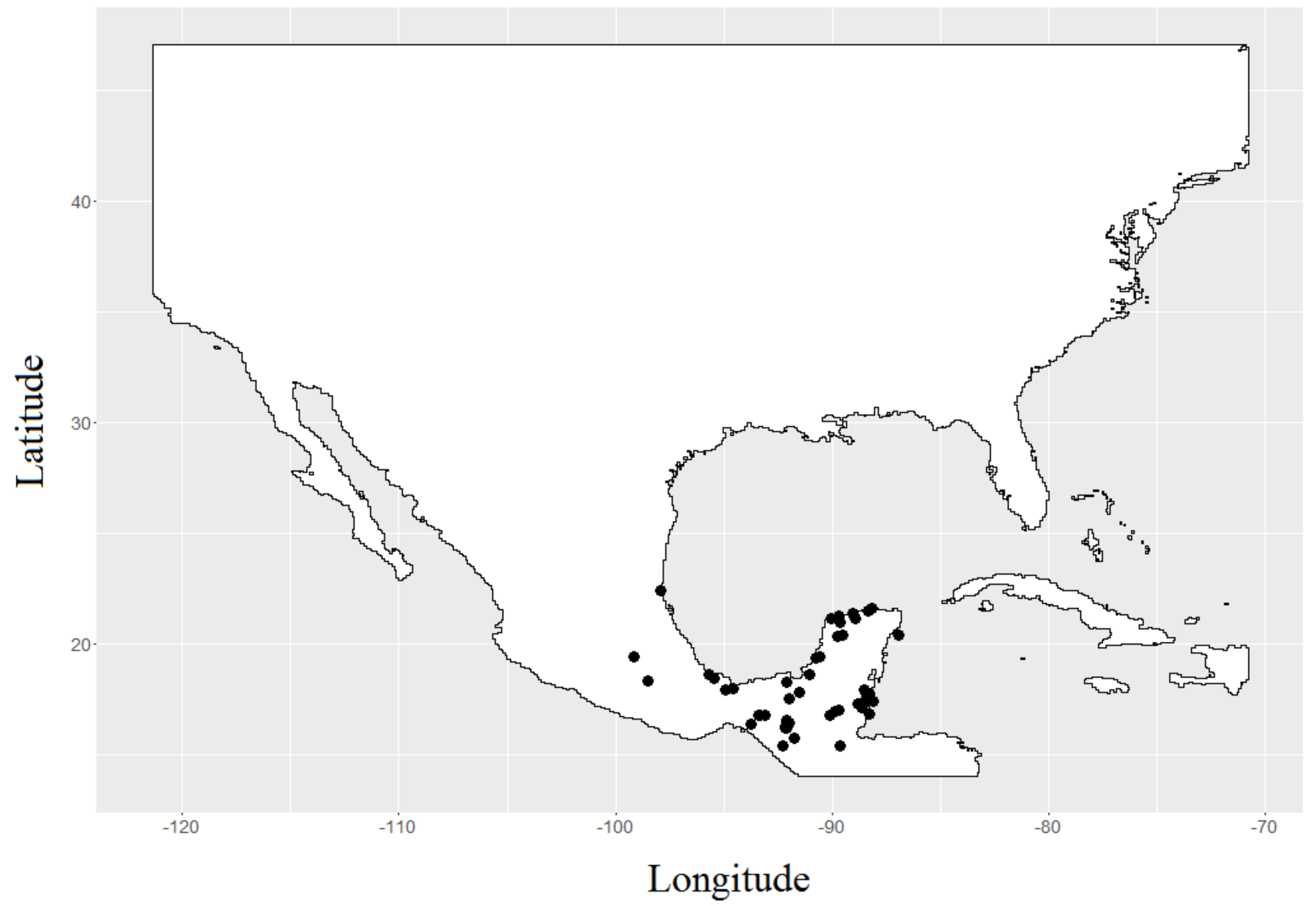

Figura 3. Mapa de distribuição geográfica de Pyrocephalus rubinus blatteus no sul e no centro do México. Os pontos pretos são referentes a registros como peles, tecidos, fluídos, ossos, vídeos, mudas e registros sonoros e de ocorrência.

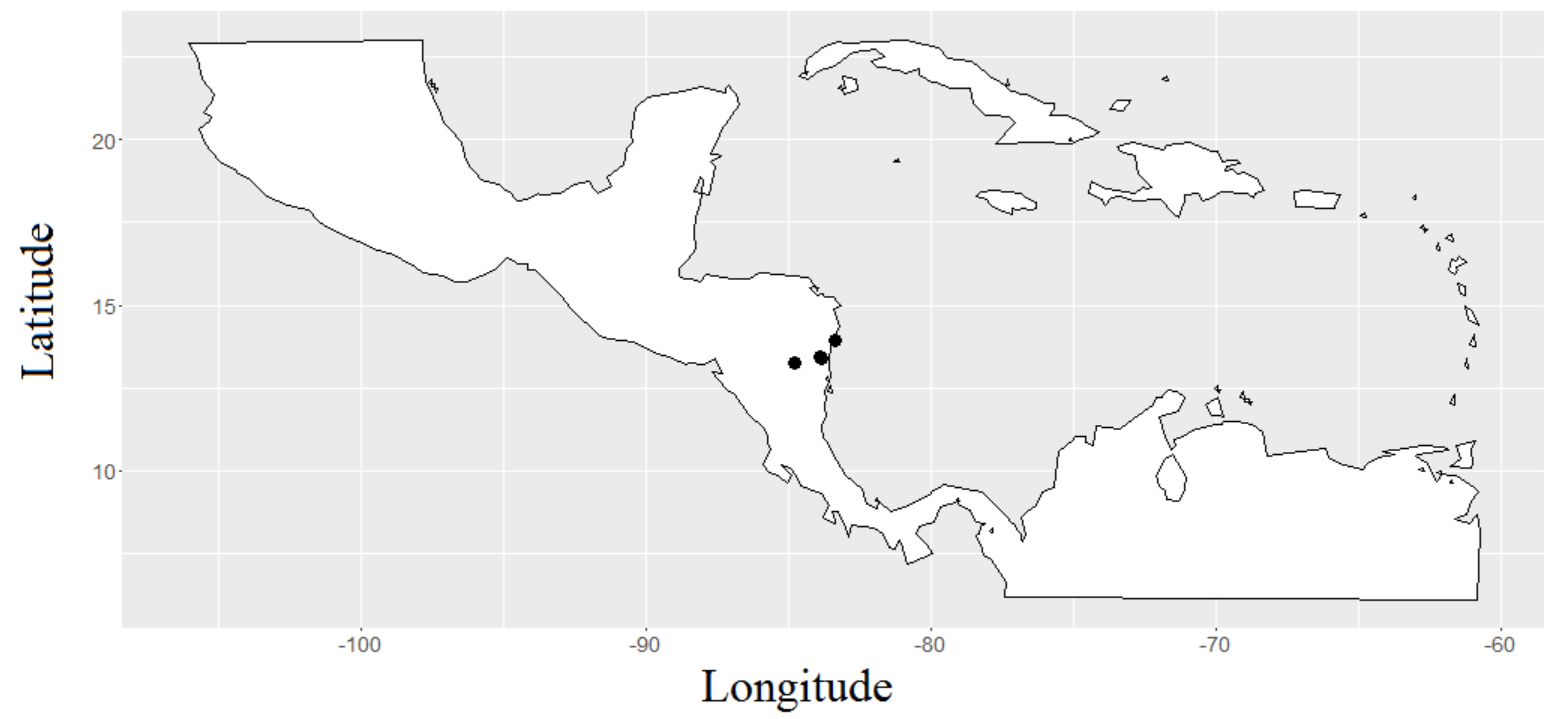

Figura 4. Mapa de distribuição geográfica de Pyrocephalus rubinus pinicola na Nicarágua, América Central. Os pontos pretos são referentes a registros como peles, tecidos, fluídos, ossos, vídeos, mudas e registros sonoros e de ocorrência. 


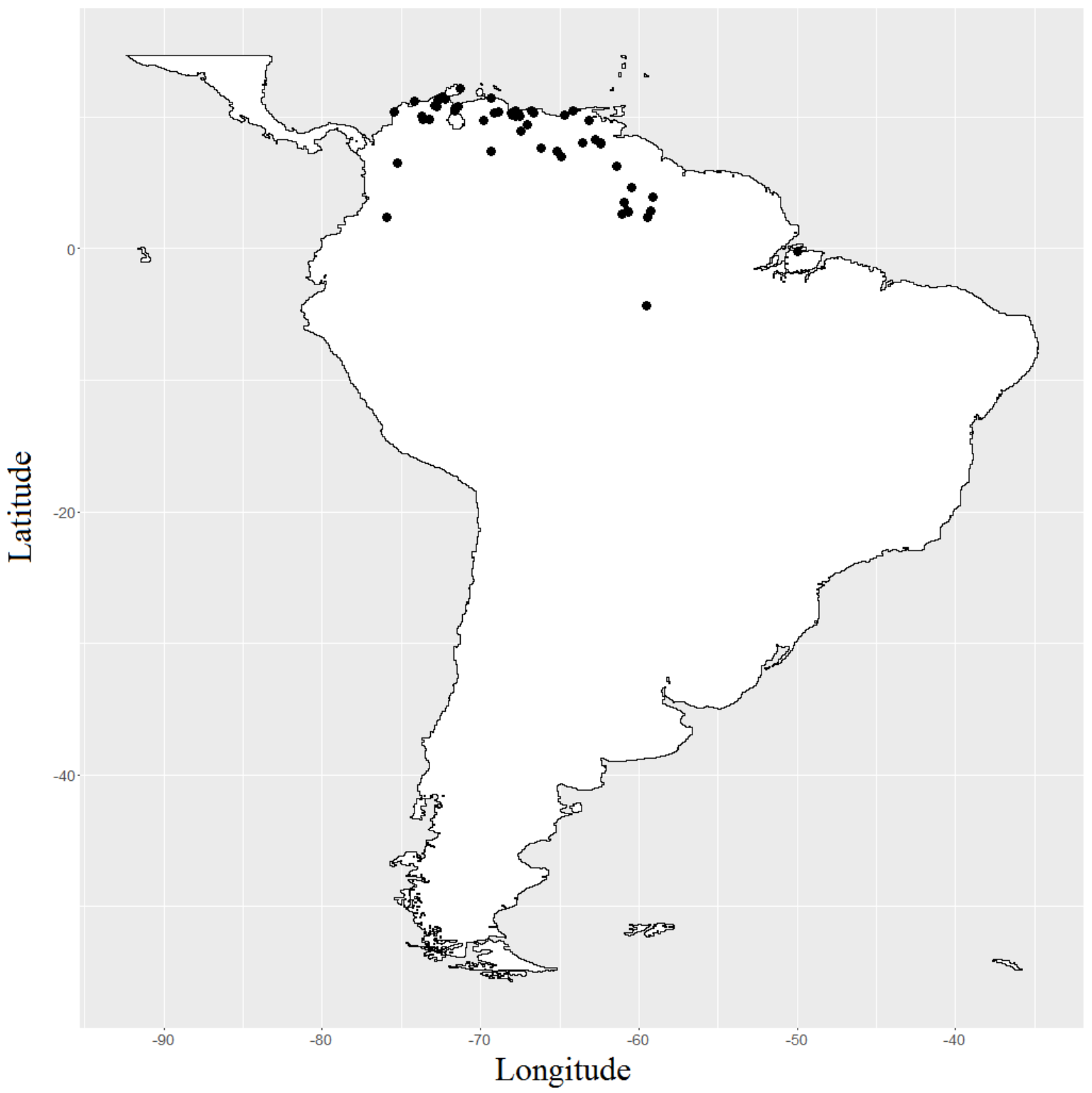

Figura 5. Mapa de distribuição goegráfica de Pyrocephalus rubinus saturatus no oeste da Colômbia, no norte da Venezuela e do Brasil. Os pontos pretos são referentes a registros como peles, tecidos, fluídos, ossos, vídeos, mudas e registros sonoros e de ocorrência. 


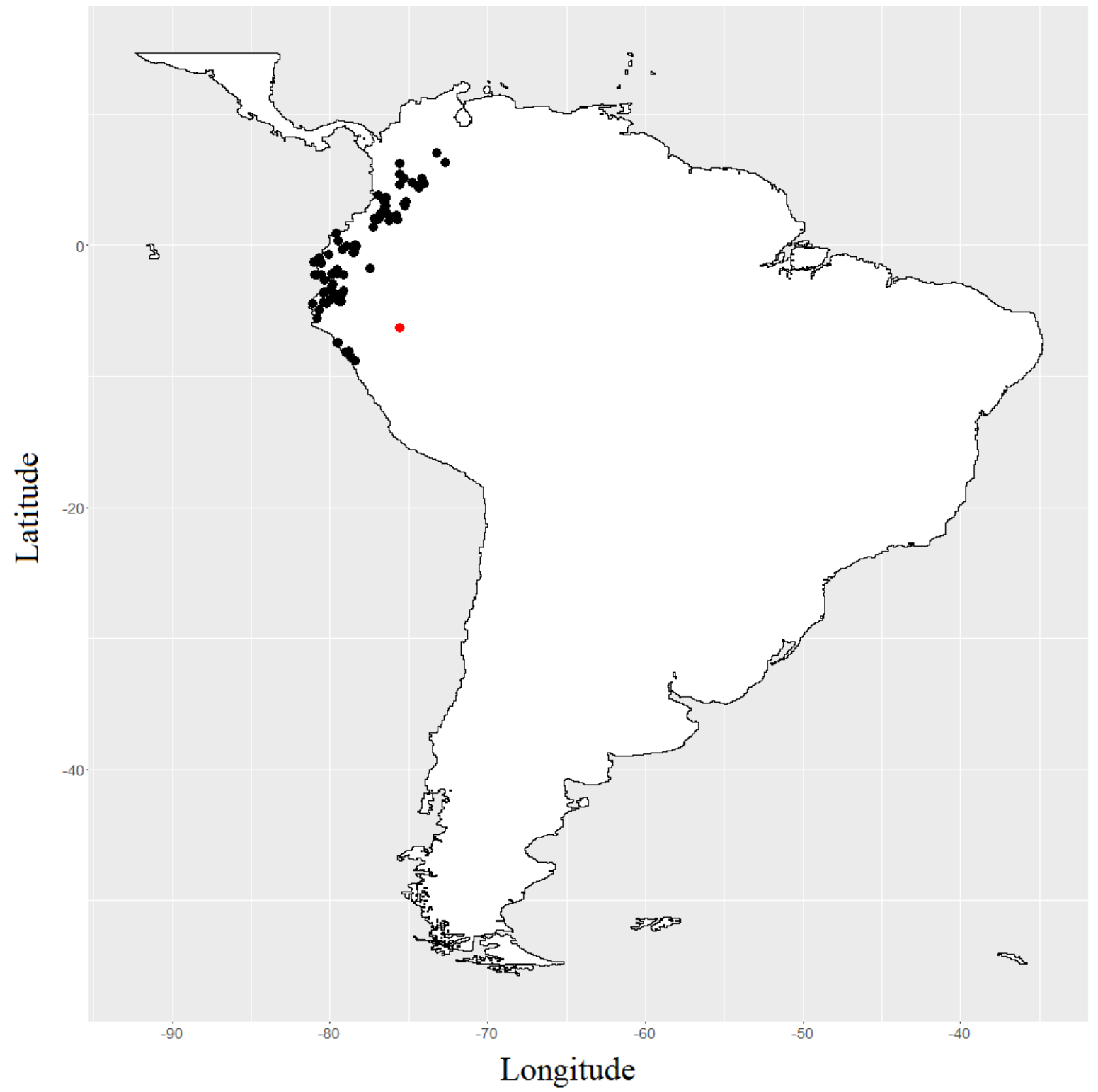

Figura 6. Mapa de distribuição geográfica de Pyrocephalus rubinus piurae no centro e no sul da Colômbia, no oeste e no centro do Equador e noroeste do Peru. Os pontos em vermelho são referentes aos registros reprodutivos (ninhos, ninhadas, registro visual de cuidado parental). Os pontos pretos são referentes aos registros não reprodutivos (peles, tecidos, fluídos, ossos, vídeos, mudas e registros sonoros e de ocorrência) fora do período reprodutivo. 


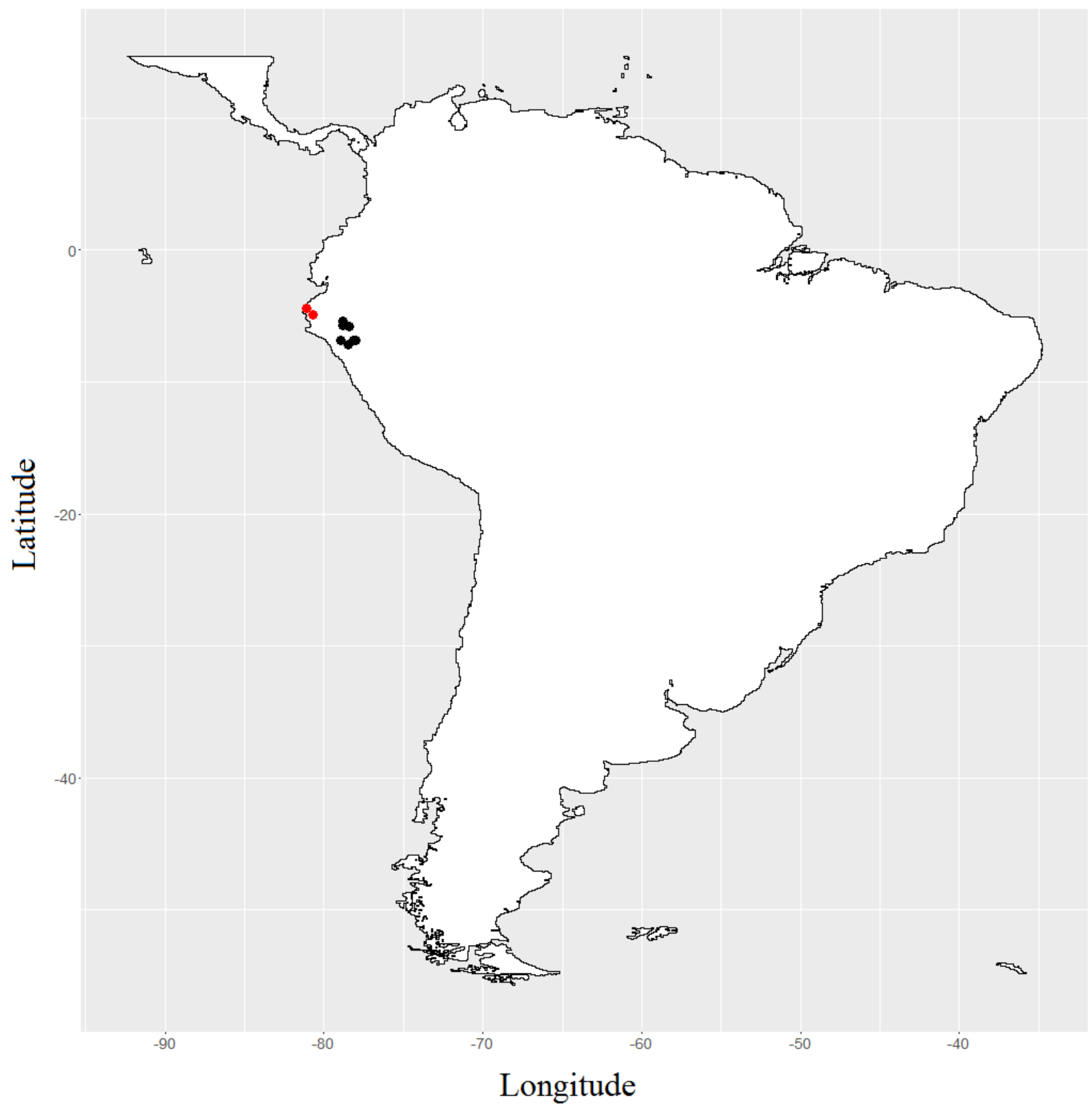

Figura 7. Mapa de distribuição geográfica de Pyrocephalus rubinus ardens no noroeste do Peru. Os pontos em vermelho são referentes aos registros reprodutivos (ninhos, ninhadas, registro visual de cuidado parental). Os pontos pretos são referentes aos registros não reprodutivos (peles, tecidos, fluídos, ossos, vídeos, mudas e registros sonoros e de ocorrência) fora do período reprodutivo. 


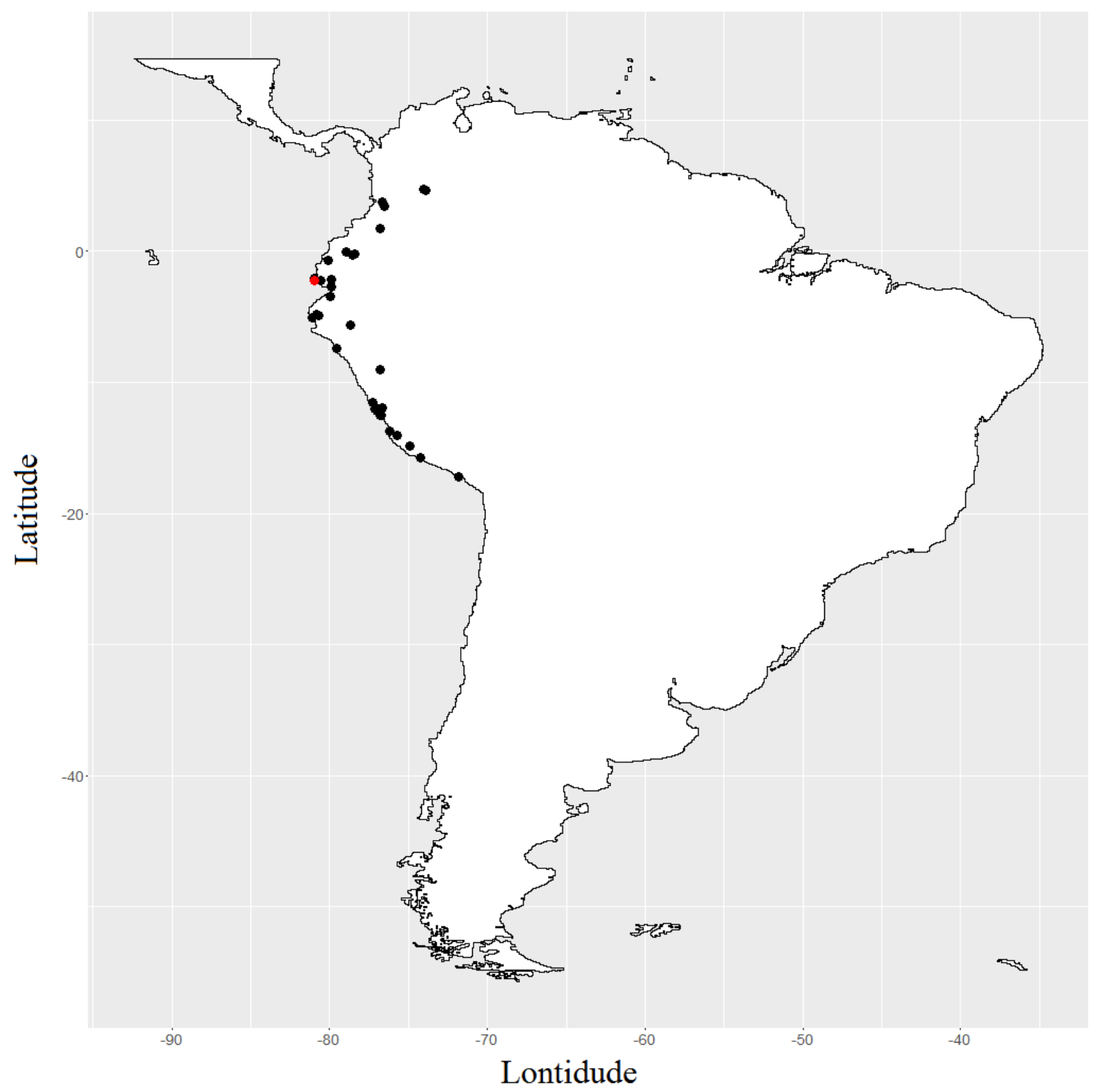

Figura 8. Mapa de distribuição geográfica de Pyrocephalus rubinus obscurus no oeste da Colômbia, do Equador e do Peru. Os pontos em vermelho são referentes aos registros reprodutivos (ninhos, ninhadas, registro visual de cuidado parental). Os pontos pretos são referentes aos registros não reprodutivos (peles, tecidos, fluídos, ossos, vídeos, mudas e registros sonoros e de ocorrência) fora do período reprodutivo. 


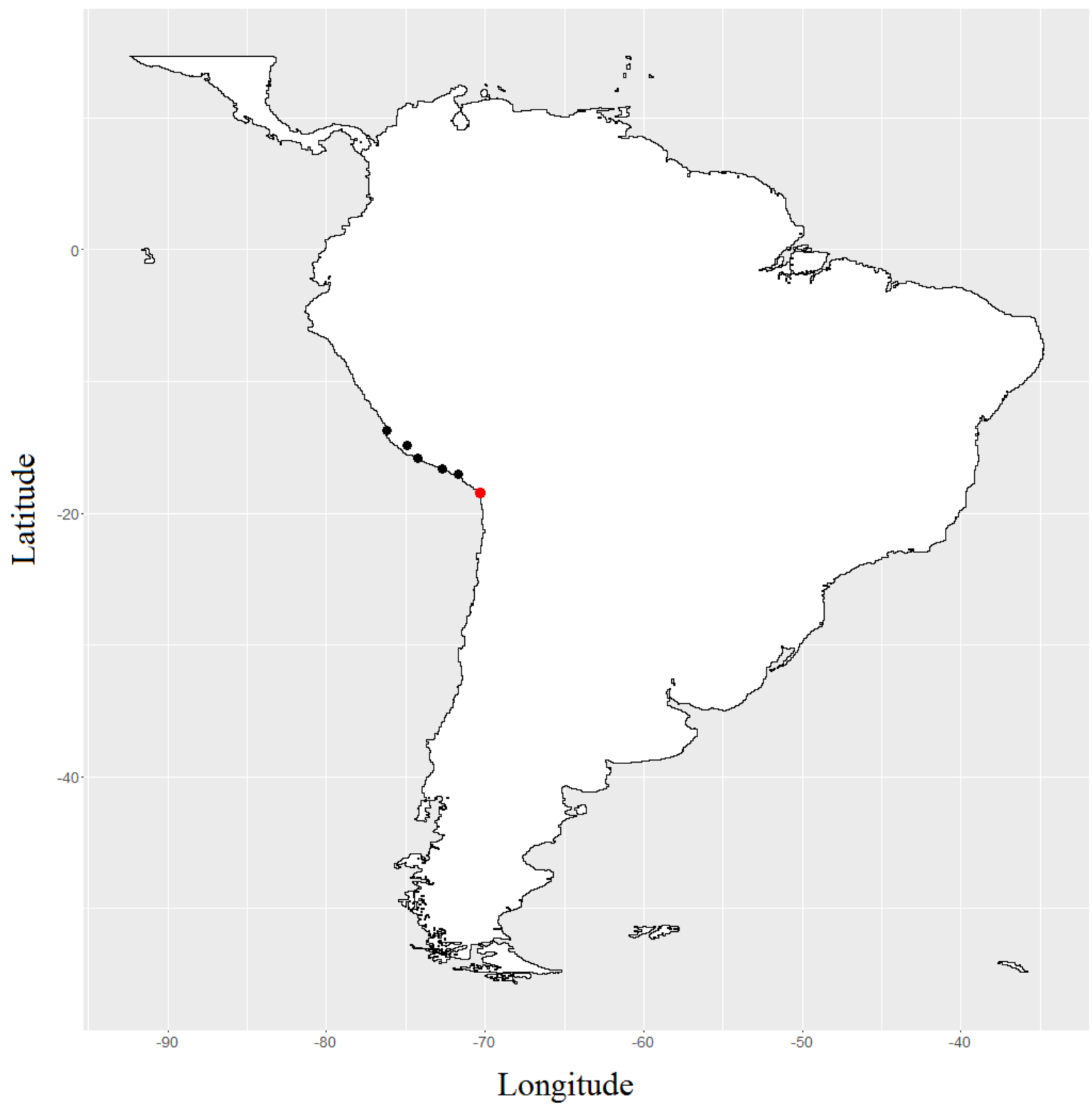

Figura 9. Mapa de distribuição geográfica de Pyrocephalus rubinus cocachacrae no sudoeste do Peru. Os pontos em vermelho são referentes aos registros reprodutivos (ninhos, ninhadas, registro visual de cuidado parental). Os pontos pretos são referentes aos registros não reprodutivos (peles, tecidos, fluídos, ossos, vídeos, mudas e registros sonoros e de ocorrência) fora do período reprodutivo. 


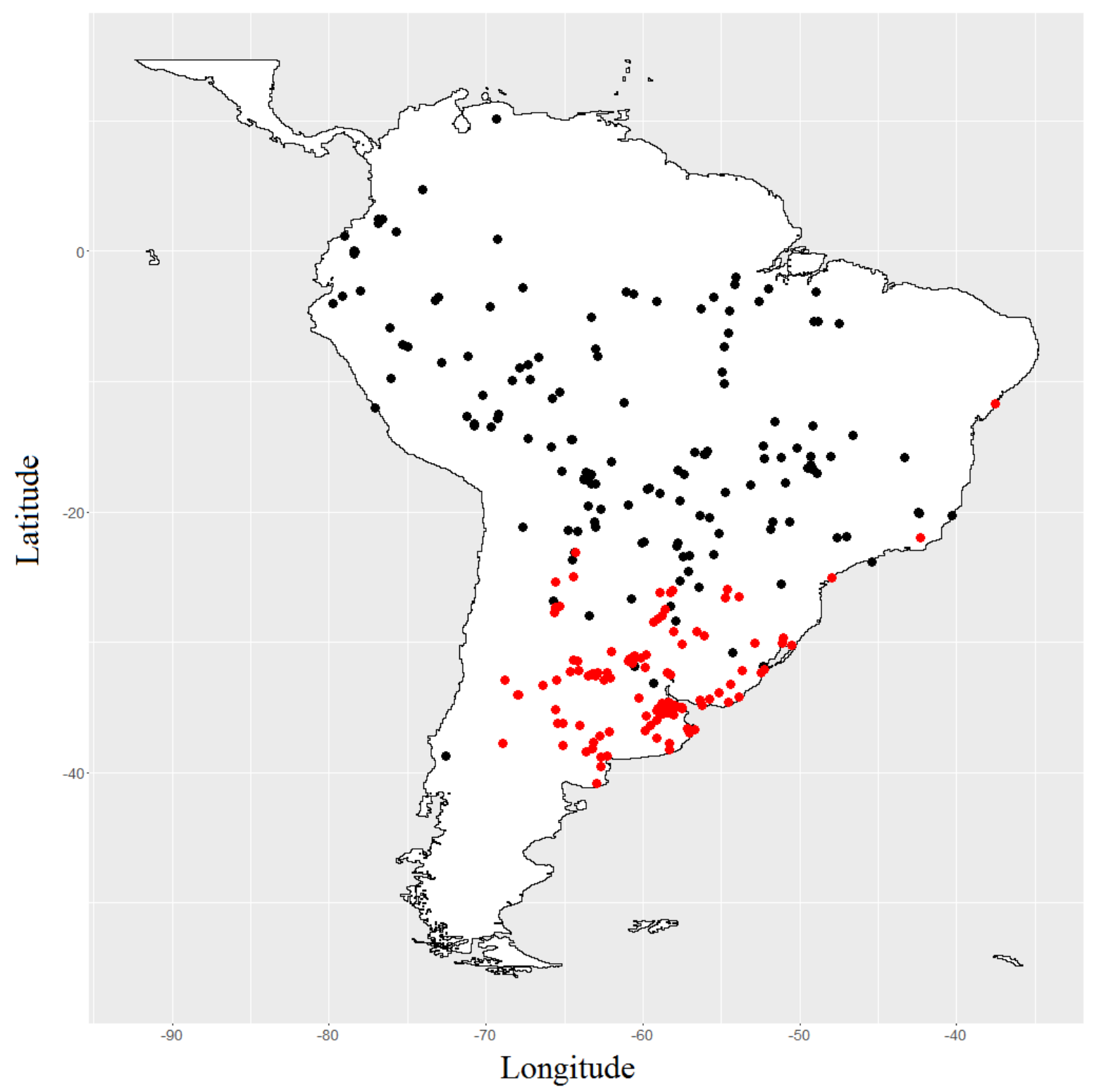

Figura 10. Mapa de distribuição geográfica de Pyrocephalus rubinus rubinus. Os pontos em vermelho são referentes aos registros reprodutivos (ninhos, ninhadas, registro visual de cuidado parental). Registros não reprodutivos como peles, tecidos, fluídos, ossos, vídeos, mudas e registros sonoros e de ocorrência que estivessem datados dentro do período reprodutivo da subespécie foram utilzados como fonte de dados para a construção de mapas de distribuição geográfica da região reprodutiva da subespécie. Os pontos pretos são referentes aos registros não reprodutivos (peles, tecidos, fluídos, ossos, vídeos, mudas e registros sonoros e de ocorrência) fora do período reprodutivo. 


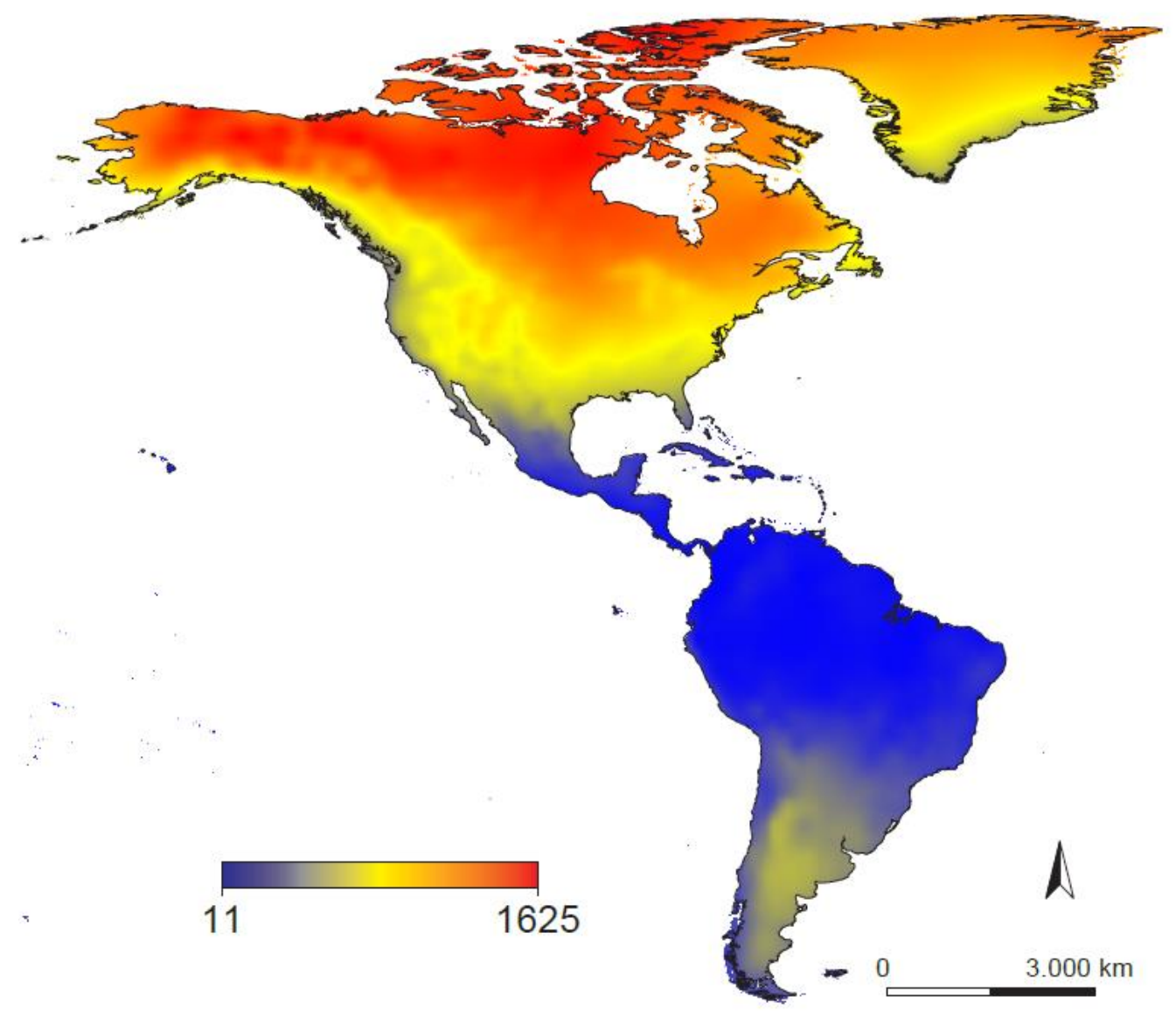

Figura 11. Sazonalidade de temperatura para as Américas do Norte, Central e do Sul. Mapa construído a partir do raster extraído da base de dados WorldClim Bioclimatic Database. 


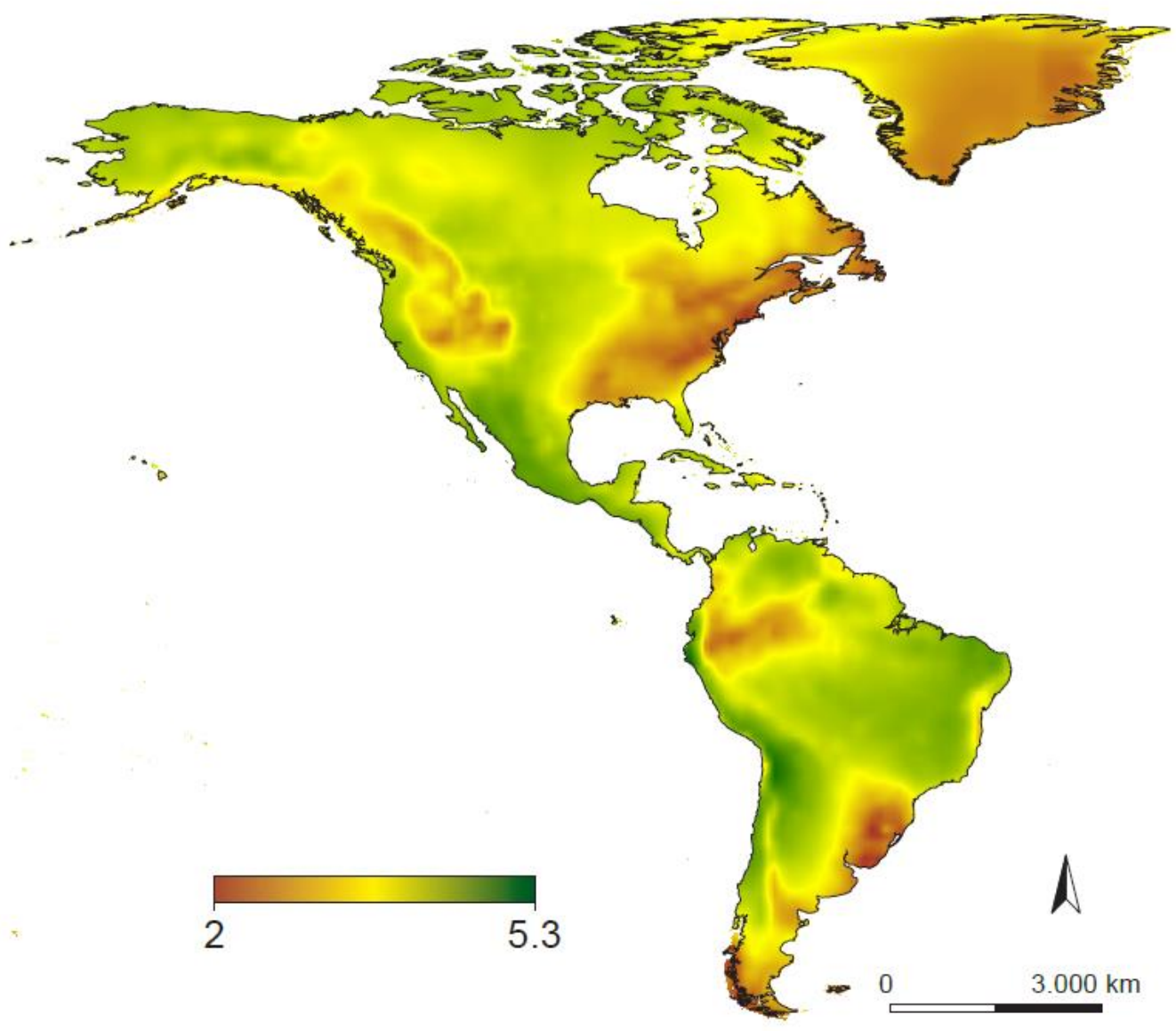

Figura 12. Log da sazonalidade da precipitação nas Américas do Norte, Central e do Sul. Mapa construído a partir do raster extraído da base de dados WorldClim Bioclimatic Database. 
Tabela 1. Número de registros reprodutivos coletados por meio de revisão da literatura e coleções de museus.

\begin{tabular}{|c|c|c|}
\hline Fonte & Acrônimo do Museu & Número de registros \\
\hline Revisão bibliográfica & - & 287 \\
\hline $\begin{array}{l}\text { American Museum of } \\
\text { Natural History }\end{array}$ & AMNH & 09 \\
\hline $\begin{array}{c}\text { Borror Laboratory of } \\
\text { Bioacustics }\end{array}$ & BLB & 01 \\
\hline $\begin{array}{c}\text { California Academy of } \\
\text { Siencies }\end{array}$ & CAS & 06 \\
\hline $\begin{array}{c}\text { Carnegie Museum of Natural } \\
\text { History }\end{array}$ & $\mathrm{CM}$ & 06 \\
\hline $\begin{array}{l}\text { Chicago Academy of } \\
\text { Sciences }\end{array}$ & CHAS & 01 \\
\hline $\begin{array}{c}\text { Cornell University Museum } \\
\text { of Vertebrates }\end{array}$ & CUMV & 03 \\
\hline $\begin{array}{l}\text { Delaware Museum of } \\
\text { Natural History }\end{array}$ & DMNH & 01 \\
\hline $\begin{array}{l}\text { Denver Museum of Nature \& } \\
\text { Science }\end{array}$ & DMNS & 05 \\
\hline $\begin{array}{c}\text { Florida Museum of Natural } \\
\text { History }\end{array}$ & FLMNH & 13 \\
\hline $\begin{array}{l}\text { Field Museum of Natural } \\
\text { History }\end{array}$ & FMNH & 21 \\
\hline $\begin{array}{l}\text { Museo Argentino de } \\
\text { Ciencias Naturales }\end{array}$ & MACN & 06 \\
\hline $\begin{array}{l}\text { Museum of Comparative } \\
\text { Zoology, Harvard University }\end{array}$ & $\mathrm{MCZ}$ & 17 \\
\hline $\begin{array}{c}\text { Museo Provincial de } \\
\text { Ciencias Naturales } \\
\text { "Florentino Ameghino" }\end{array}$ & MFA & 03 \\
\hline Museo de La Plata & MLP & 05 \\
\hline Museu Nacional & $\mathrm{MN}$ & 01 \\
\hline $\begin{array}{l}\text { Museum of Vertebrate } \\
\text { Zoology, UC Berkeley }\end{array}$ & MVZ & 10 \\
\hline $\begin{array}{l}\text { Museu de Zoologia da } \\
\text { Universidade de São Paulo }\end{array}$ & MZUSP & 04 \\
\hline
\end{tabular}


Tabela 1. Continuação

\begin{tabular}{ccc}
\hline Fonte & Acrônimo do Museu & Número de registros \\
\hline $\begin{array}{c}\text { Natural History Museum, } \\
\text { Tring UK }\end{array}$ & NHM & 46 \\
$\begin{array}{c}\text { Sam Noble Oklahoma } \\
\text { Museum of Natural History } \\
\text { Slater Museum of Natural } \\
\text { History }\end{array}$ & OMNH & 06 \\
Royal Ontario Museum & PSM & 03 \\
University of Michigan \\
$\begin{array}{c}\text { Museum of Zoology } \\
\text { University of Oklahoma }\end{array}$ & ROM & 07 \\
National Museum of Natural \\
History, Smithsonian \\
Institution \\
$\begin{array}{c}\text { Western Foundation of } \\
\text { Vertebrate Zoology, } \\
\text { California }\end{array}$ & UMMZ & 09 \\
Naturhistorisches Museum \\
Wien
\end{tabular}

